\title{
THE ROLE OF CAPILLARITY IN THE VAPEX PROCESS
}

\author{
A Thesis \\ Submitted to the Faculty of Graduate Studies and Research \\ In Partial Fulfillment of the Requirements for the \\ Degree of Master of Applied Science \\ in \\ Petroleum Systems Engineering \\ University of Regina
}

by

Mohammad Tuhinuzzaman

Regina, Saskatchewan

July, 2006

Copyright $\subset$ 2006: Mohammad Tuhinuzzaman 


$\begin{array}{ll}\begin{array}{l}\text { Library and } \\ \text { Archives Canada }\end{array} & \begin{array}{l}\text { Bibliothèque et } \\ \text { Archives Canada }\end{array} \\ \begin{array}{l}\text { Published Heritage } \\ \text { Branch }\end{array} & \begin{array}{l}\text { Direction du } \\ \text { Patrimoine de l'édition }\end{array} \\ \begin{array}{l}\text { 395 Wellington Street } \\ \text { Ottawa ON K1A ON4 }\end{array} & \begin{array}{l}\text { 395, rue Wellington } \\ \text { Ottawa ON K1A ON4 } \\ \text { Canada }\end{array}\end{array}$

Your file Votre référence ISBN: 978-0-494-20240-1 Our file Notre référence ISBN: 978-0-494-20240-1

NOTICE:

The author has granted a nonexclusive license allowing Library and Archives Canada to reproduce, publish, archive, preserve, conserve, communicate to the public by telecommunication or on the Internet, loan, distribute and sell theses worldwide, for commercial or noncommercial purposes, in microform, paper, electronic and/or any other formats.

The author retains copyright ownership and moral rights in this thesis. Neither the thesis nor substantial extracts from it may be printed or otherwise reproduced without the author's permission.
AVIS:

L'auteur a accordé une licence non exclusive permettant à la Bibliothèque et Archives Canada de reproduire, publier, archiver, sauvegarder, conserver, transmettre au public par télécommunication ou par l'Internet, prêter, distribuer et vendre des thèses partout dans le monde, à des fins commerciales ou autres, sur support microforme, papier, électronique et/ou autres formats.

L'auteur conserve la propriété du droit d'auteur et des droits moraux qui protège cette thèse. $\mathrm{Ni}$ la thèse ni des extraits substantiels de celle-ci ne doivent être imprimés ou autrement reproduits sans son autorisation.
In compliance with the Canadian

Privacy Act some supporting forms may have been removed from this thesis.

While these forms may be included in the document page count, their removal does not represent any loss of content from the thesis.
Conformément à la loi canadienne sur la protection de la vie privée, quelques formulaires secondaires ont été enlevés de cette thèse.

Bien que ces formulaires aient inclus dans la pagination, il n'y aura aucun contenu manquant.

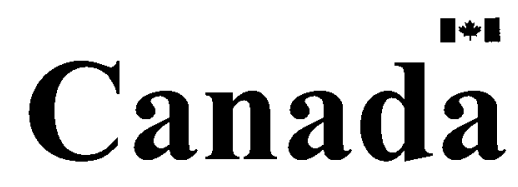




\section{UNIVERSITY OF REGINA}

\section{FACULTY OF GRADUATE STUDIES AND RESEARCH}

\section{SUPERVISORY AND EXAMINING COMMITTEE}

Mohammad Tuhinuzzaman, candidate for the degree of Master of Applied Science, has presented a thesis titled, The Role of Capillarity in the VAPEX Process, in an oral examination held on July 13,2006 . The following committee members have found the thesis acceptable in form and content, and that the candidate demonstrated satisfactory knowledge of the subject material.

External Examiner: $\quad$ Dr. Mohamed El-Darieby, Faculty of Engineering

Supervisor: $\quad$ Dr. Muhammad Ayub, Faculty of Engineering

Committee Member: $\quad$ Dr. Mingzhe Dong, Faculty of Engineering

Committee Member: $\quad$ Dr. Gary Zhao, Faculty of Engineering

Chair of Defense: $\quad$ Dr. Malek Mouhoub, Department of Computer Science 


\begin{abstract}
The process using hydrocarbon vapours to extract bitumen or heavy oil, known as VAPEX (Vapour Extraction), has been studied in the last decade. The original concept of this non-thermal process is similar to that of the steam-assisted gravity drainage (SAGD) process. In the VAPEX process, gas and/or solvent is injected at or near the dew point so that the solvents can remain vapourized in the chamber around the horizontal injector.
\end{abstract}

Dilution of heavy oil and thus lowering the viscosity, density, IFT and capillary pressure is regarded as the basic mechanism of the VAPEX process. Although, in VAPEX, researchers have studied many influencing factors on oil recovery, the effect of capillary pressure has never been studied or understood completely. This research addresses the issue related to this important parameter on a preliminary basis.

The research commences with diluting the original heavy oil with kerosene at different weight percentages to generate 4 different oil samples. Experiments are conducted to construct capillary pressure curves for the lighter oil samples. Heavier oil samples were utilized to construct corresponding relative permeability curves by un-steady state displacement technique. Thereafter, the main phase of the experimental studies commences with lab scale applications of the VAPEX process using the heavier oil samples. While the dynamic process continues, efforts are put forward to calculate oil drainage rate, gas rate, gas-to-oil ratio (GOR) and cumulative recovery with respect to time. 
The final stage of this research work is composed entirely of simulation studies. At the initial stage, two different oil compositions are generated in WINPROP to represent the heavier oil samples prepared earlier in the lab. Care has been taken to match the simulated and original oil sample physical properties by utilizing the Regression feature in WINPROP. Henceforth, all the available data are plugged into the CMG GEM simulator to predict the performance of VAPEX in lab scale. For each oil sample, results were generated with or without tuning in the capillary pressure curves.

By comparing the experimental and simulation results, it can be deduced that capillary pressure's major contribution on the VAPEX process is its influence in shaping up the vapour chamber. In the absence of capillary pressure data in simulation, the vapour chamber tends to grow vertically with a minimal sideways leaching. Fitting capillary data results in a mushroom-shaped vapour chamber, which is more prevalent for the heavier oil sample. Secondly, capillarity prolongs the solvent breakthrough, occurrence of which initiates the VAPEX process. However, after solvent breakthrough, capillary pressure causes drainage rate to increase by extending the effective diffusion area. Simulation studies show that fitting in capillary pressures anticipates higher rates and productions. 


\section{ACKNOWLEDGEMENTS}

Correlating pieces of information and compiling a masters' thesis is a great deal of work. People who influenced me with their views, extended their helping hands in times of need are many, some of whom are mentioned in this section, while many others still remain anonymous. First of all, I would like to thank the Almighty for His endless shower of blessings. I acknowledge my indebtedness and express my great appreciation to Dr. Muhammad Ayub, who, with a unique blend of wisdom, peerless expertise and friendly attitude, guided me throughout my graduate studies towards the successful completion of the project.

I would like to extend my gratitude to Petroleum Technology Research Center (PTRC) for its financial contribution. Faculty of Graduate and Studies and Research is gratefully acknowledged for its financial contribution in the form of Graduate Scholarships. I express my thankfulness to my co-workers Weihong Xu and Muhammad Jawad Ahmad for their moral support, helping attitude and group discussion to overcome problems associated with laboratory works. Whole-hearted appreciation is extended to Dyna Industry for manufacturing the lab-scale replicas used in this research. 


\section{DEDICATION}

I am dedicating this work to my beautiful wife, Farheen Akbar, my loving mother, Mrs.

Meher Zaman, and my caring mother-in-law, Mrs. Monoara Begum. 


\section{TABLE OF CONTENTS}

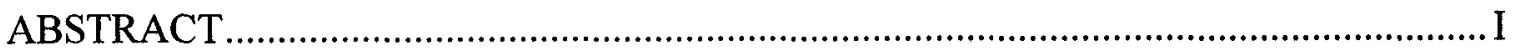

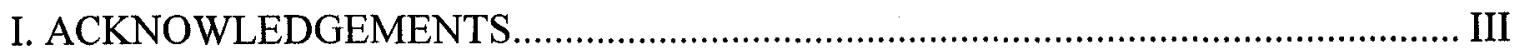

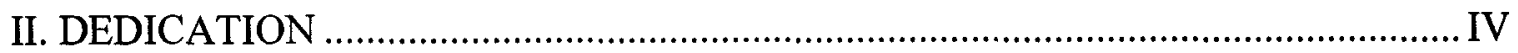

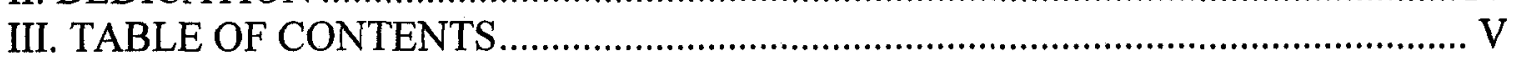

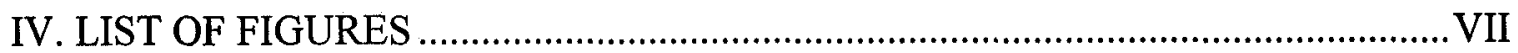

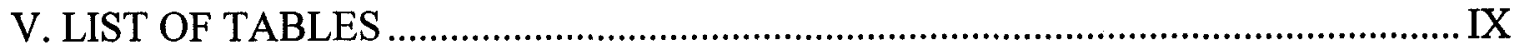

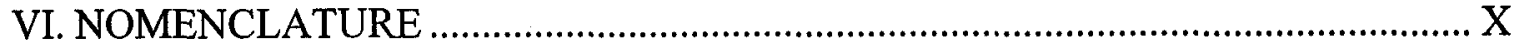

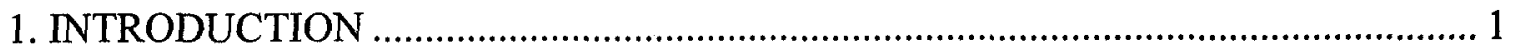

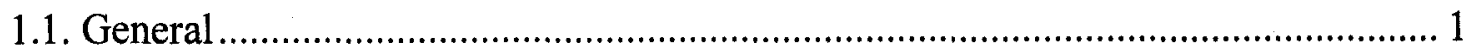

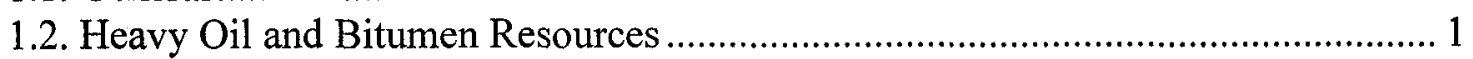

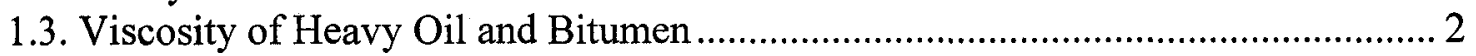

1.4. Thermal Processes ......................................................................................... 2

1.5. Vapour Extraction and Effect(s) of Capillarity ................................................... 3

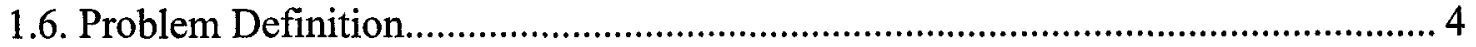

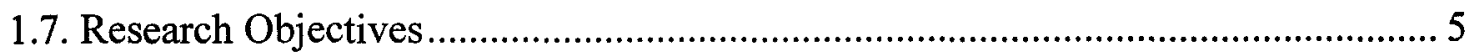

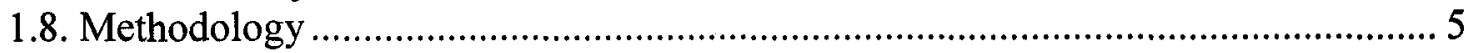

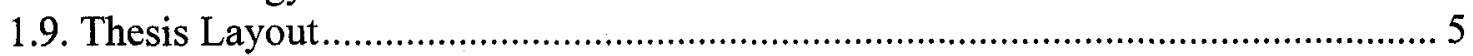

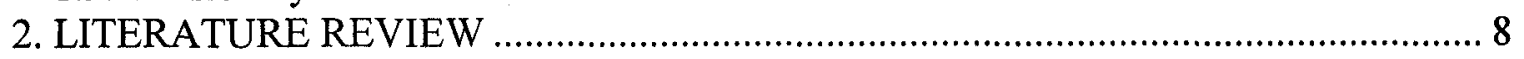

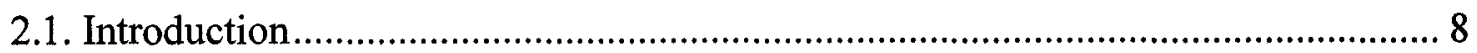

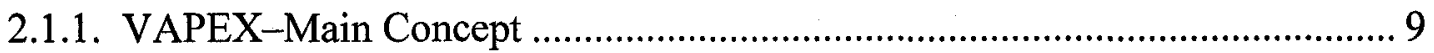

2.1.2. Early Development by Butler ................................................................ 13

2.1.3. Further Development by Butler .............................................................. 17

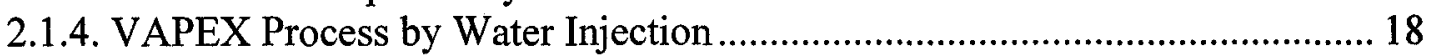

2.1.5. Counter Current Extraction....................................................................... 20

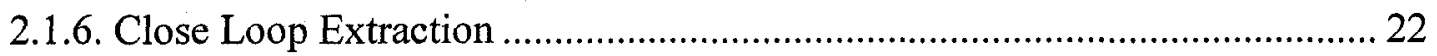

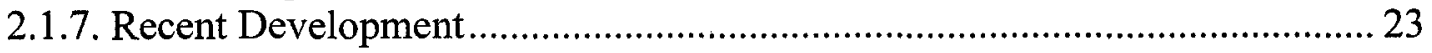

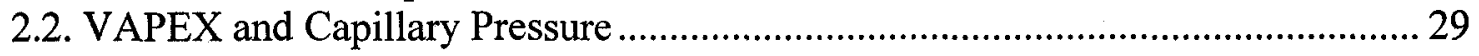

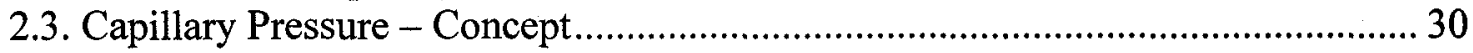

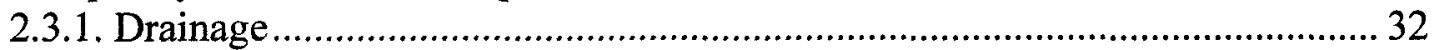

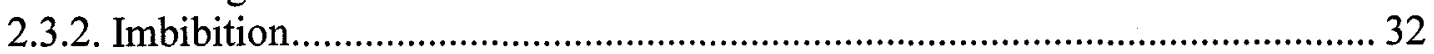

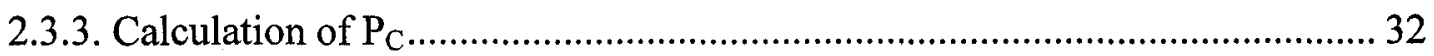

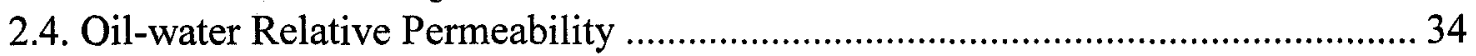

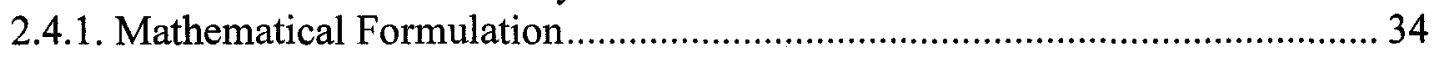

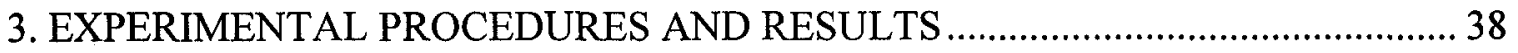

3.1. Capillary Pressure - Experimental Set-up....................................................... 38

3.1.1. Major Components of the Experimental Set-up ......................................... 38

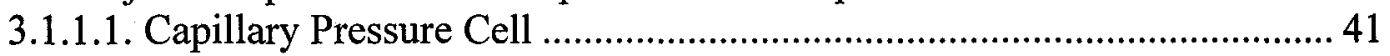

3.1.1.2. CoreTest Control Panel........................................................................ 41

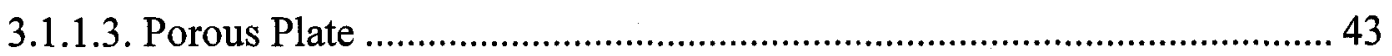

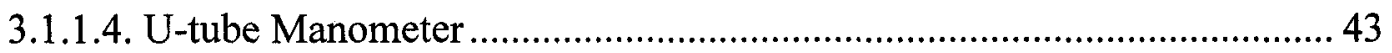

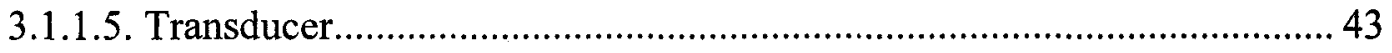

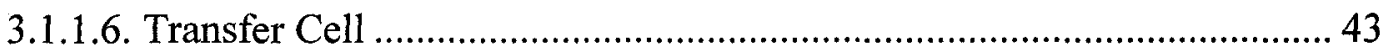

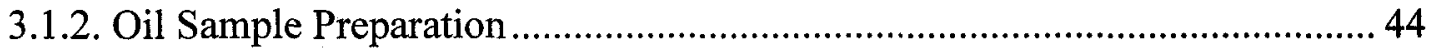


3.1.3. Sieve Analysis......................................................................................... 44

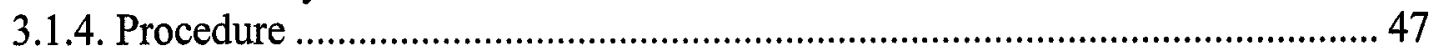

3.1.4.1. Displacing water from top chamber..................................................... 47

3.1.4.2. Capillary pressure underway................................................................. 48

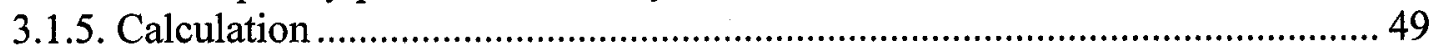

3.1.5.1. Initial Saturation Level .......................................................................... 49

3.1.5.2. Capillary Pressure from the Experimental Data ........................................ 50

3.1.6. Results and Discussion ............................................................................. 50

3.1.7. Capillary Pressure Utilized for Simulation ..................................................... 55

3.2. Vapour Extraction Process (VAPEX) ................................................................... 57

3.2.1. Experimental Set - up............................................................................ 57

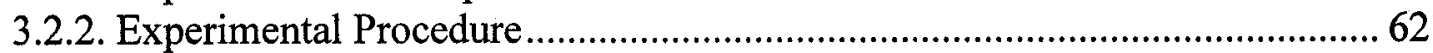

3.2.3. Results of the Visual Cell Experiments ............................................................ 64

3.3. Relative Permeability ………………............................................................... 73

3.3.1. Experimental Set - up ................................................................................ 73

3.3.3. Experimental Procedure.................................................................................... 73

3.3.4. Experimental Results .................................................................................. 76

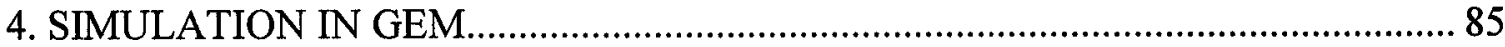

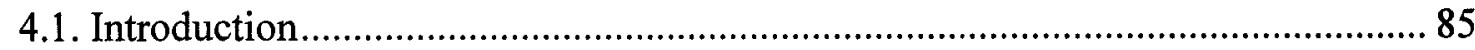

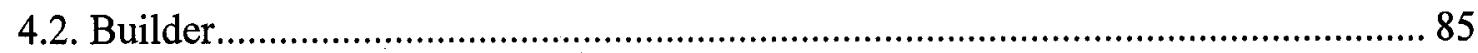

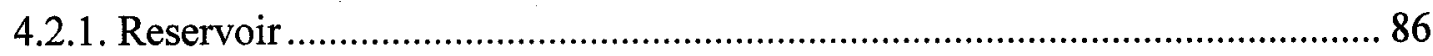

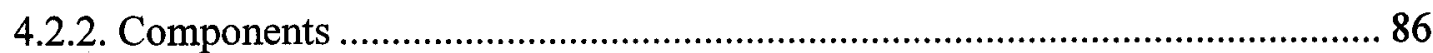

4.2.2.1. Oil Sample Generation in Winprop …………………………………..... 88

4.1.3. Rock fluid properties.................................................................................. 91

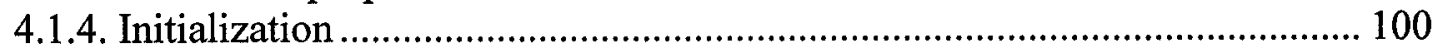

4.1.5. Wells and Recurrent Data ........................................................................ 103

4.1.6. Executing the Simulator................................................................................. 103

5. RESULTS AND DISCUSSION ………………................................................. 105

5.1. Growth of the Vapour Chamber .......................................................................... 105

5.2. Effects on Drainage Rate and Gas Production....................................................... 109

6. CONCLUSIONS AND RECOMMENDATIONS ………..................................... 116

7. REFERENCES …....................................................................................... 118

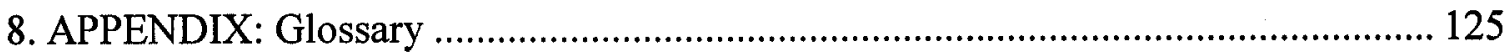




\section{LIST OF FIGURES}

Figure 1.1. Research methodology ..................................................................... 6

Figure 2.1. Vapour Extraction Process ................................................................. $\quad 10$

Figure 2.2. VAPEX Process - cross sectional view 11

Figure 2.3. Capillary pressure as a difference between non-wetting and wetting phase pressure

Figure 2.4. Oil/water interface in a capillary tube

Figure 3.1. Fittings connected to the capillary pressure cell

Figure 3.2. Capillary pressure measurement-schematic

Figure 3.3. Components of the capillary pressure cell

Figure 3.4. Viscosity of the Swimming Field heavy oil against temperature

Figure 3.5. Capillary pressure calculation - equation development

Figure 3.6. Capillary pressure Vs. Saturation (Sample 1)

Figure 3.7. Capillary pressure curve for oil sample 2

Figure 3.8. Components of the experimental model

Figure 3.9. Locations of the wells on the glass plates

Figure 3.10. Visual cell with the wells and external components installed

Figure 3.11. Growth of the vapour chamber 66

Figure 3.12. GOR and oil flow rate in VAPEX I (Sample 3)

Figure 3.13. GOR and oil flow rate in VAPEX II (Sample 4) 68

Figure 3.14. Cumulative oil production in VAPEX I and II 72

Figure 3.15. Schematic of the relative permeability experiment 74 


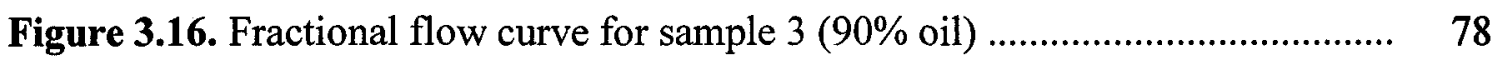

Figure 3.17. Fractional flow curve for sample 4 (95\% oil) ................................ 79

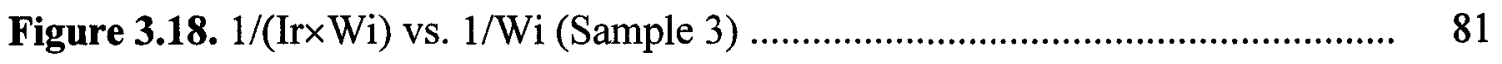

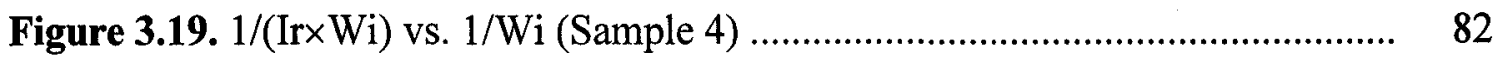

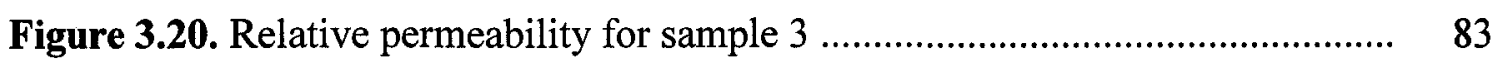

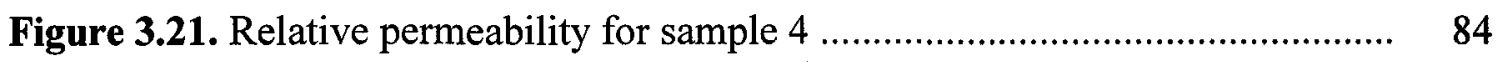

Figure 4.1. Isotropic compression tests on different sands .............................. 87

Figure 4.2. Original and extrapolated capillary pressure curve 1 for sample $3 \ldots \ldots . . \quad 101$

Figure 4.3. Original and extrapolated capillary pressure curve 2 for sample $3 \ldots \ldots . . \quad 102$

Figure 5.1. Growth of the vapour chamber with/without capillary effect $\ldots \ldots \ldots \ldots \ldots \ldots . \ldots 108$

Figure 5.2. Oil drainage rates with or without capillary pressure (Sample 3) ......... 110

Figure 5.3. Gas rates with or without capillary pressure (Sample 3) .................... 111

Figure 5.4. Oil drainage rates with or without capillary pressure (Sample 3) ......... 112

Figure 5.5. Gas rates with or without capillary pressure (Sample 3) ..................... 113

Figure 5.6. Enhanced diffusion area because of capillary pressure ........................ 114 


\section{LIST OF TABLES}

Table 3.1. Physical properties of the Swimming Field heavy oil at $21^{\circ} \mathrm{C}$...................... 45

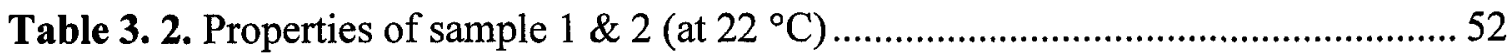

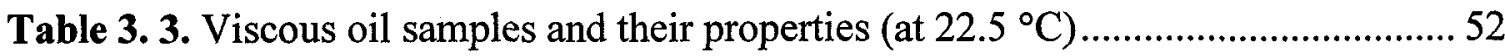

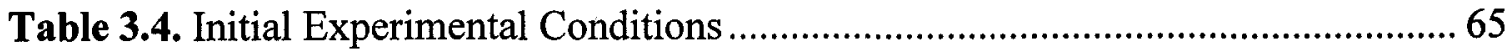

Table 3.5. Injection - production scheme for the Experiments .................................. 71

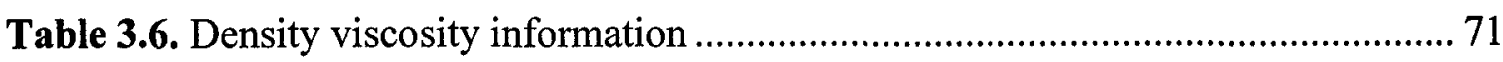

Table 3.7. Dimension of the Core - holder .............................................................. 75

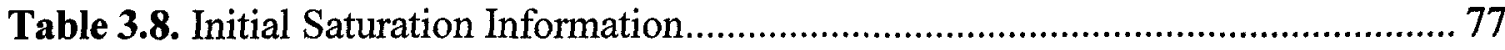

Table 4.1. Composition of the sample extracted from literature..................................89

Table 4.2. Densities and viscosities of the standard and simulated sample at 1 atmosphere

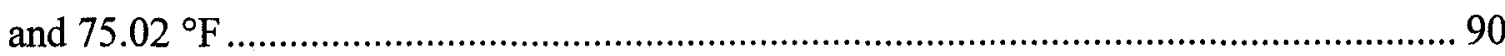

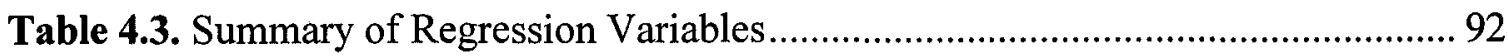

Table 4.4. Composition model of the Sample 3 …..................................................... 93

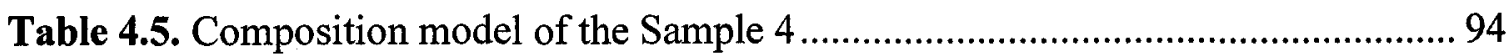

Table 4.6. Compositional analysis and properties of the lumped components for Sample

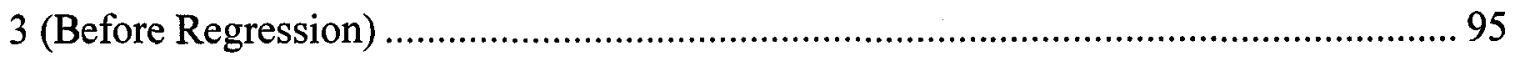

Table 4.7. Compositional analysis and properties of the lumped components for Sample

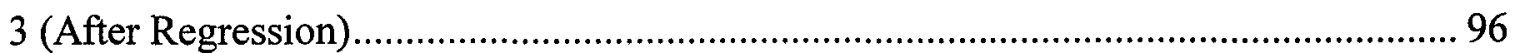

Table 4.8. Compositional analysis and properties of the lumped components for Sample

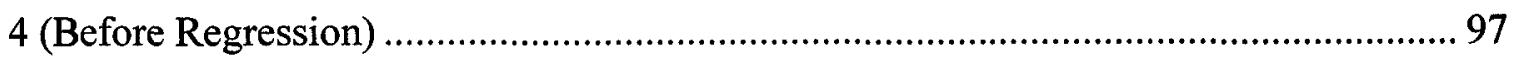

Table 4. 9. Compositional analysis and properties of the lumped components for Sample

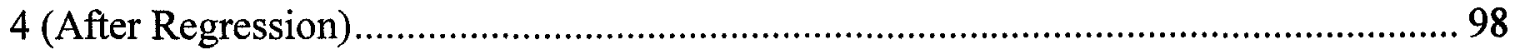

Table 4.10. Matched viscosity and density of Sample 3 and 4 after lumping and regression 99

Table 4.11. Locations and properties of the wells................................................... 104

Table 4.12. Constraints for Sample 3 and Sample 4 ............................................... 104

Table 5.1. Cumulative oil production and time to gas breakthrough .......................... 107 


\section{NOMENCLATURE}

$Q=$ Stabilized drainage rate

$k=$ Absolute permeability of the porous medium

$g=$ Gravitational force

$\phi=$ Porosity of the porous medium

$\Delta S_{o}=$ Change in oil saturation before and after steam flood

$h=$ Drainage height

$N=$ A Dimensionless number defined by Butler and Mokrys as a function of system temperature, mixture viscosity, density difference, thermal diffusivity and solvent concentration

$\alpha=$ Thermal diffusivity

$\mu=$ Bitumen viscosity at a given temperature

$T=$ Temperature

$T_{R}=$ Reservoir temperature

$T_{s}=$ Steam temperature

$T_{\min }=\mathrm{A}$ temperature slightly above the reservoir temperature

$\Delta \rho=$ Density difference

$c_{s}=$ Solvent concentration

$c_{s_{\min }}=\mathrm{A}$ very small solvent concentration

$D_{s}=$ Diffusivity coefficient

$N_{s}=$ A Dimensionless number defined by Butler and Mokrys as a function of system 
temperature, mixture viscosity, density difference and diffusivity coefficient and solvent concentration

$\Omega=$ Cementation factor of the porous medium

$L=$ Length of the horizontal well

$t_{F}=$ Field (reservoir) time

$t_{M}=$ Model time

$H_{M}=$ Model drainage height

$H_{F}=$ Reservoir drainage height

$k_{F}=$ Reservoir absolute permeability

$k_{M}=$ Model absolute permeability

$L_{F}=$ Actual length of the horizontal well

$L_{M}=$ Length of the horizontal well in the model

$q_{F}=$ Field drainage rate

$q_{M}=$ Model drainage rate

$\gamma=$ Interfacial Tension (IFT)

$P_{c}=$ Capillary Pressure

$P_{o}=$ Pressure in the oil

$P_{w}=$ Pressure in the water

$r_{I}, r_{2}=$ Radii of curvature of the interfaces measured perpendicular to each other

$P_{n w}=$ Pressure in the non-wetting phase

$P_{w}=$ Pressure in the wetting phase

$\theta=$ Contact angle 
$W_{i}=$ Total pore volume injected

$f^{\prime}=$ Slope of the fractional flow curve at different saturation level

$f_{o}=$ Fractional flow of oil

$f=$ Fractional flow of water

$k_{r o}=$ Relative permeability of oil to water

$k_{r w}=$ Relative permeability of water to oil

$\mu_{o}=$ Oil viscosity

$\mu_{0}=$ Water viscosity

$\left(f_{o}\right)_{2}=$ Fractional Flow of oil at the outlet

$S_{a v}=$ Average saturation behind the front

$S_{2}=$ Saturation of water at the outlet

$f_{2}^{\prime}=$ Fractional flow with respect to saturation at the outlet

$I_{r}=$ Relative injectivity

$u=$ Rate of injection per unit area

$\rho_{H g}=$ Density of mercury

$\Delta h_{H g}=$ Difference between the mercury heights in the manometer

$P_{w}=$ Density of water

$h_{l}=$ Height of water column above the reference point on the right manometer leg

$h_{w}=$ Dead water head in the left manometer leg

$P_{\text {Threshold }}=$ Pressure at which non-wetting phase enters the porous medium

$S_{w c}=$ Connate water saturation

$1 / a_{w}=$ Pore size distribution index 


\section{INTRODUCTION}

\subsection{General}

Ever since the dawn of the Industrial Revolution during the eighteenth century, civilization, with time, has replaced coal with mineral fuels as a source of energy to operate machines. Although people had been known to harvest oil for medical purposes and, as a source of lamp fuel and machine lubrication as far back as $1410 \mathrm{AD}$, the first commercial well drilled solely for oil production was completed in Titusville, Pennsylvania, USA in 1859. Known as the 'Drake Well', after "Colonel" Edwin Drake, the man responsible for the well, initiated an international search for petroleum, and in many ways eventually changed the way we live.

\subsection{Heavy Oil and Bitumen Resources}

With the decline in conventional oil reserves, a major thrust of oil industries throughout the world is in the exploitation of heavy oil and bitumen reservoirs. The magnitude of these resources is about six trillion barrels of oil, which is approximately six times the total conventional oil reserves (Butler and Das, 1998). A major part of these resources are located in Venezuela, Canada, and the United States. The estimated original oil in place (OOIP) of heavy oil and bitumen in Canada is about 2.7 trillion barrels, which is twice the total conventional oil reserves in the Middle East. Total estimated resources in only the province of Alberta is 1.6 trillion barrels, buried at a depth of $0-800 m$ (Das, 1995). 


\subsection{Viscosity of Heavy Oil and Bitumen}

Natural bitumen (often called tar sands or oil sands) and heavy oil differ from light oils by their high viscosity and high density (low API gravity) at reservoir temperatures. Most heavy oil is found at the margins of geologic basins and is thought to be the residue of formerly light oil that has lost its light-molecular-weight components through degradation by bacteria, water-washing, and evaporation. Oil with viscosity beyond $1000 \mathrm{mPa} . \mathrm{s}$ and API below $20^{\circ}$ is called heavy oil, whereas oil with a viscosity above $10000 \mathrm{mPa} . \mathrm{s}$ and API less than $10^{\circ}$ is known as bitumen (Speight, 1991). In some reservoirs, such as Athabasca, the oil viscosity is in millions of $\mathrm{mPa} . \mathrm{s}$ at reservoir conditions. Primary recovery, which depends on natural reservoir pressure and mechanical pumping, cannot be implemented. Secondary recovery techniques (waterflooding, gas injection etc.) also lack efficiency due to high oil viscosity.

\subsection{Thermal Processes}

The viscosities of heavy oil and bitumen are strong functions of temperature and decrease drastically with an increase in temperature. Thus, thermal recovery processes such as, Cyclic Steam Stimulation (CSS), In Situ Combustion, and Steam Assisted Gravity Drainage (SAGD) are applied to produce these crudes. Maximum recovery with CSS is relatively low and only $15-20 \%$ of OOIP can be recovered economically, beyond which the Steam Oil Ratio (SOR) becomes prohibitively high. The In Situ combustion technique requires sufficient mobility of the oil and is difficult to control. Currently, SAGD has become a popular technique for the recovery of heavy oil and bitumen. In SAGD, steam is injected into the reservoir through a horizontal well. Steam condenses at the oil 
interface, heats the oil, and, thus, reduces its viscosity. Because of lower viscosity, hot oil drains to another horizontal well placed right underneath the injection well.

Despite the apparent successes of the steam processes for the recovery of heavy oil and bitumen, there are inherent disadvantages. While heating up the reservoir oil, the major fraction of the thermal energy is used up in heating the bulk reservoir rock, overburden and underburden. Steam processes are not economically viable for reservoirs with thin pay zones, bottom water zones and/or overlying gas zones, low thermal conductivity of the rock matrix, high water saturation, low porosity, and vertical fractures and/or fissures (Karmaker and Maini, 2003).

\subsection{Vapour Extraction and Effect(s) of Capillarity}

Vapour Extraction (VAPEX) is a relatively new process that involves reduction of viscosity by diluting the oil with vapourized hydrocarbon solvents. The concept is analogous to that of SAGD and is discussed in detail in Chapter 2. In VAPEX, production rates are directly related to the viscosity reduction, which in turn depends on the amount of solvent dissolved in the crude. Unlike SAGD, the main mechanism of vapour extraction is mass transfer between vapour and oil. The rate of mass transfer is proportional to the area of contact. In actual reservoirs, and also in the physical model used in this study, co-existence of oil and water in the porous medium creates a curvature at the interface due to capillary pressure and thus enhances the total available area for mass transfer. Theoretical knowledge suggests that this particular effect of capillary pressure works in favour of VAPEX process. However, the other characteristic 
of capillary pressure, which strongly retains oil and water within the porous medium, works against the vapour extraction process. This research addresses the resultant effect(s) of capillary pressure on the VAPEX process by coupling experimental results with simulation studies.

\subsection{Problem Definition}

In VAPEX, the growth of vapour chamber, diffusion of molecules, and dilution and draining of oil is a dynamic process. In the study of such process, it is difficult to incorporate every phenomenon that is taking place. Existence of three phases (oil, water, gas) aggravates the situation by initiating three sets of capillarity for three combinations of fluid-fluid systems: oil-water, oil-solvent, and water-solvent. However, diffusion of solvent into oil gives evidence of a very weak capillary force between them, and, hence, its effects can be readily neglected. In addition to that, if water is assumed to be left behind the swept zone, existence of water-solvent capillary pressure is overshadowed by that of the oil-water system existing within and beyond the transition zone. Moreover, capillary pressure is a function of porous medium and density of the non-wetting fluid (as water is always the wetting phase). Addressing the changes in capillary pressure with varying porous medium and its overall effects on VAPEX is beyond the scope of this study. The main focus of this research is - to determine the effect(s) of oil-water capillary pressure on VAPEX for different viscosities of reservoir oils within a fixed porous medium. 


\subsection{Research Objectives}

This research is a part of the project for extending the concept of the VAPEX process further by pinpointing the effects of interfacial phenomena on the leaching process. The aim of this research is to study the effect(s) of capillary pressure on VAPEX with the following objectives:

i. To study the mechanism of the VAPEX process

ii. To observe the capillarity effect on VAPEX with the help of a simulator

\subsection{Methodology}

This research is a compilation of experimental and simulation studies. Three tasks were accomplished in the experimental studies, they are: capillary pressure curve generation, oil-water relative permeability estimation, and lab-scale VAPEX emulation. Capillary pressure and relative permeability obtained from experiments were the inputs for simulation studies. Production data obtained from experiments and simulation were compared and conclusions were drawn. Figure 1.1 presents the methodology in a diagram.

\subsection{Thesis Layout}

There are six chapters that constitute this thesis. Chapter 1 is the introduction of the research. A brief presentation of, objectives, scope, and goals are given. Chapter 2 includes discussion of the previous studies on the VAPEX process and describes the basic concepts of capillary pressure and relative permeability measurement. 


\section{Methodology}

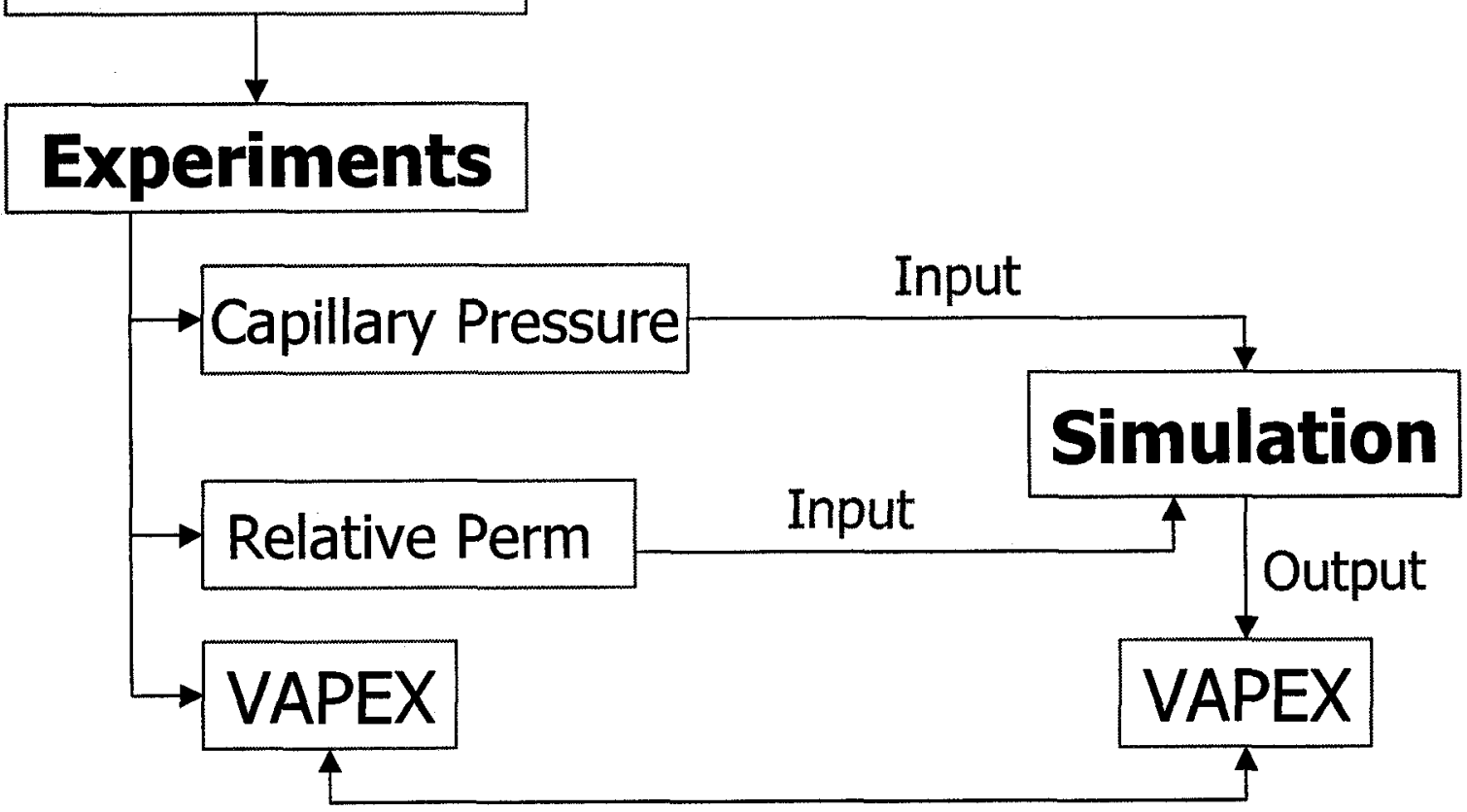

History matching

Figure 1.1. Research methodology 
Chapter 3 describes the experimental procedure on VAPEX, capillary pressure derivation, and oil-water relative permeability curves generation in three separate sections. Observations, results, and brief data analysis are also presented. Chapter 4 describes the assumptions and steps to simulate the lab-scale replica in CMG GEM. Simulation results are compared with experimental data in Chapter 5. Finally, conclusions drawn from the current research and recommendation for future work are presented in Chapter 6 . 


\section{LITERATURE REVIEW}

\subsection{Introduction}

Injection of solvent vapour into bitumen and heavy oil reservoirs is a process evolved gradually from other types of recovery techniques. Initially, solvent, in small amounts, was introduced together with steam into the reservoir to improve the sweep (Harman and Shu, 1988). Vapourized solvent was found to be a supporting force able to condense in the cooler region of the reservoir, and thus creating a lower viscosity transition zone between the steam and heavy oil. Solvent with the right volatility at reservoir pressure and temperature was proved vital to creating adequate transition zones. Farouq Ali and Snyder in 1973 studied naphtha injection prior to steam injection in a 2-D vertical model filled with tar sand. Naphtha was found to be highly effective in opening a steam flow path in a homogeneous sand pack. Alikhan and Farouq Ali, in 1974, further studied the steam-drive solvent-slug process in a linear cell model packed with glass beads. It was found that the light hydrocarbon slug injected before the steam slug improved the oil recovery through improvement in the mobility ratio. Redford and McKay, in 1980, presented results of a physical model experiment. A range of hydrocarbons (methane, ethane, propane, butane, pentane, natural gasoline, naphtha and, syncrude) were coinjected with steam in displacement and drawdown modes. It was demonstrated that for a given set of conditions of pressure and temperature, and with the proper choice of solvent, the use of hydrocarbon additives with steam can markedly increase recovery.

VAPEX as a non-thermal recovery process has been in use with vertical well systems 
since 1974, mostly in 'huff and puff' process models (Butler, 1994). Use of this process in conjunction with horizontal wells was first proposed and investigated by Butler and Mokrys in 1991.

\subsubsection{VAPEX-Main Concept}

The viscosity of heavy oils can be reduced by diluting them with solvent. This is the basic principle behind VAPEX, which is schematically shown in Figure 2.1 and Figure 2.2. With this process, vapourized hydrocarbon solvents are injected into the reservoir through a horizontal injector. Solvent vapour rises slowly to form a vapour chamber after breakthrough of the diluted oil occurs in the production well placed under the horizontal injector on the same vertical plane. Diffusion of the light solvent vapour into the heavy oil occurs along the edge of the vapour chamber, diluted oil drains toward the production well due to gravity, and new interface is created to continue the dynamic production process. Since the hydrocarbon vapours are highly absorbed and soluble in oil phase (Das, 1995), they will only affect the mobilization of oil. Theoretically, there will be no interaction of these vapours with fresh water and reservoir clays (Chatzis et al, 2001). When the vapour chamber reaches the caprock, it extends sideways to reach the pattern boundary. In essence, the concept is similar to SAGD, except solvent, instead of steam, is used in VAPEX (Das, 1997).

Apart from horizontal injector-producer configurations, several other configurations of injection and production wells are also possible. In a relatively mobile heavy oil reservoir, the injector can be placed at the top of the reservoir, whereas, in a bitumen 


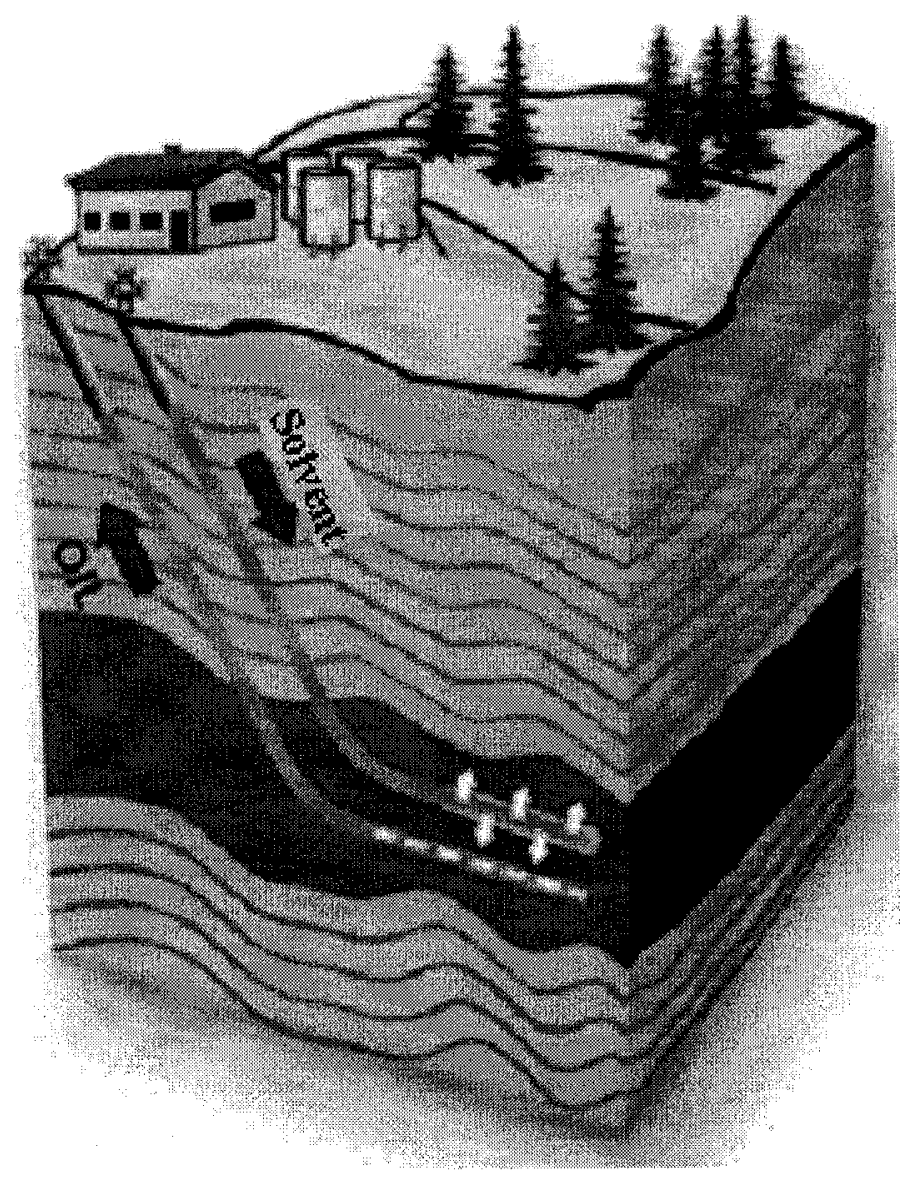

Figure 2.1. Vapour extraction process

(Source: http://www.petro-canada.ca/eng/images) 


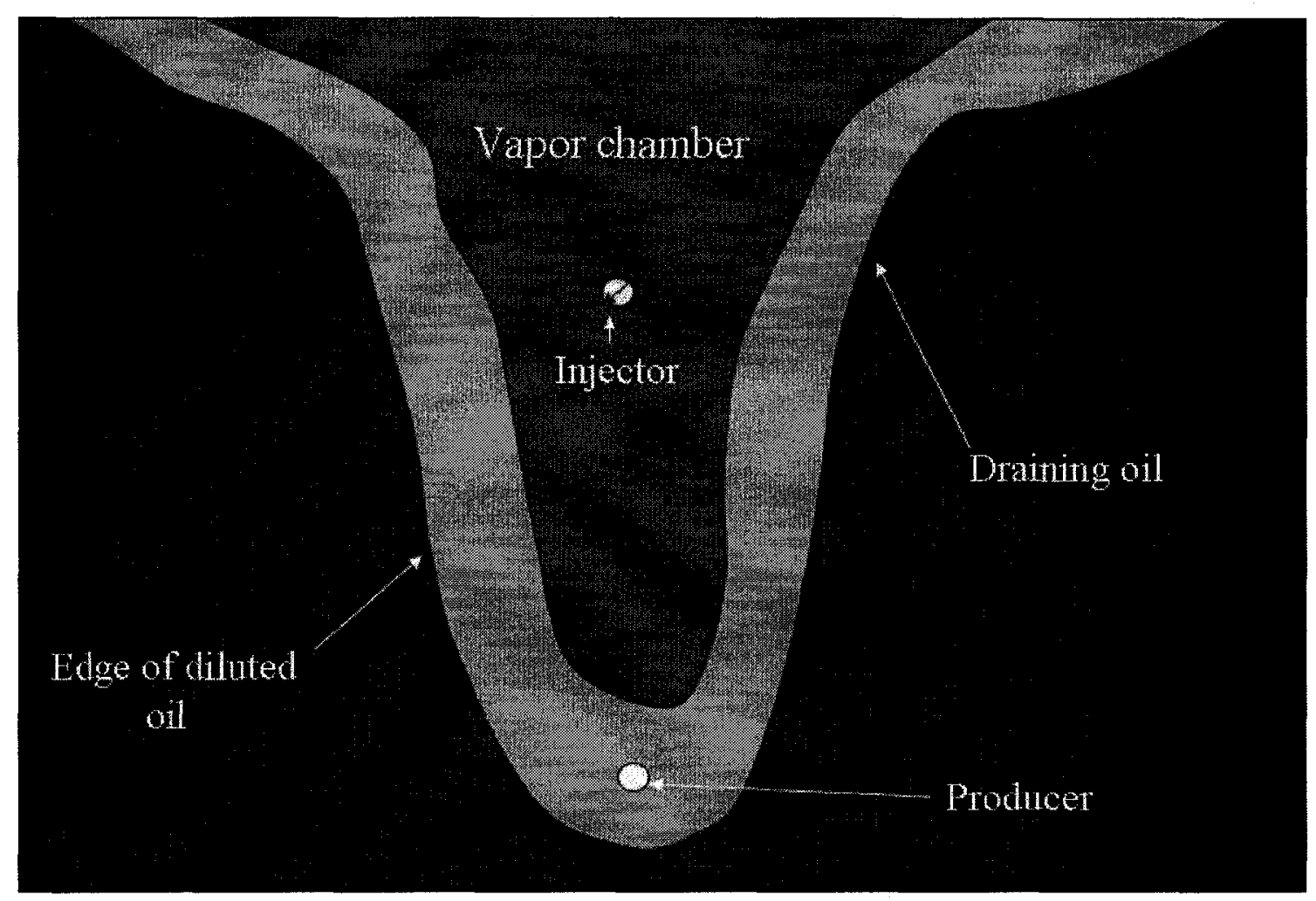

Figure 2.2. VAPEX process - cross sectional view 
reservoir, for low mobility, the horizontal well pair should be placed close to the bottom edge of the reservoir and also close enough to each other to achieve early communication between them (Das, 1997).

The VAPEX process involves the diffusion of solvent into bitumen. Production rates are directly related to the viscosity reduction, which, in turn, depends on the increase of solvent concentration through diffusion. Since the molecular diffusivity of solvent in bitumen is much lower than thermal diffusivity, it is generally expected that production rates will be much lower in this solvent process than those in a steam process. An extensive investigation of this process has shown that due to the enhanced interfacial contact, extraction rates are an order of magnitude higher than the prediction. Moreover, it is possible to use longer horizontal wells, thereby further increasing the reservoir contact and bringing the production levels close to that of SAGD (Butler and Jiang, 1997; Das et al., 1996).

In VAPEX, it is assumed that a volume of produced oil is equal to that of the volume of the liquid solvent. Since the densities of the liquid solvents employed are much less than that of the oil, considerably more than one unit mass of oil is displaced by one unit mass of solvent. Butler and Mokrys $(199,1995)$ stated the two extreme points in solvent injection scheme to determine Net Cumulative Solvent to Oil Ratio (NCSOR). At one extreme, the NCSOR is the weight of the solvent vapour that has the same volume as the produced oil. This is usually very small (e.g., 0.02 tonnes of propane per tonne of produced oil). At the other extreme, the NCSOR is the weight of the corresponding 
volume of liquid solvent and this is much larger (e.g. about 0.5 tonnes or propane per tonne of oil).

\subsubsection{Early Development by Butler}

Butler and Mokrys, in 1991, somewhat formed the basis of the VAPEX process. They pointed out the energy and economical inefficiencies of SAGD in thin reservoirs, and recommended injection of hydrocarbon vapour close to its dew point pressure in the reservoir for non-thermal molecular diffusivity-guided recovery process. Later they further extended this idea by comparing the recovery of heavy oil at and above the reservoir temperature. Experiments were conducted in a thin line source Hele-Shaw Cell and later in point source Hele-Shaw Cell. For both cases, Lloydminster heavy oil was the reservoir fluid and propane vapour was the primary injection fluid. In the latter experiment, hot water was injected to increase the reservoir temperature. Results comparison revealed that although injection of propane vapour caused the oil production rate to increase further than that with liquid solvents, injection of hot water simultaneously with propane vapour caused the process to proceed at a faster rate than the previous two cases. This idea was corroborated in a model packed with $1 \mathrm{~mm}$ diameter glass beads. Firstly, hot water was injected at a controlled rate, and later, vapourized

propane was introduced within the packed model when oil production rate caused by hot water injection virtually decreased to zero. A solvent vapour chamber was formed and spread laterally from the vertical plane of the injector and producer. As the diluted bitumen drained by gravity towards the producer, it interacted with hot water and a part of the dissolved propane was boiled off into the solvent chamber where it propagated 
further lateral growth of the chamber. The solvent vapour thus acted as a heat carrier and caused warming at the boundary of the chamber. Butler and Mokrys, in 1991 showed that the recovery mechanism using solvents is very similar to that found with steam. Whereas with steam, it is necessary for heat to diffuse into the reservoir by thermal conduction, the process with solvents involves molecular diffusion. The rates at which the process occurs can be described by analogous equations:

$$
Q=\sqrt{2 k g \phi \Delta S_{o} h N}
$$

where $\mathrm{N}$ is a dimensionless number defined for the steam process as

$$
N=\int_{T_{\min }}^{T_{S}} \frac{\alpha \Delta \rho}{\mu} \times \frac{d T}{T-T_{R}}
$$

Whereas for the solvent process, $\mathrm{N}$ is defined as

$$
N=\int_{C_{S_{\min }}}^{1} \frac{D_{S}\left(1-C_{S}\right) \Delta \rho}{\mu} \frac{d C_{S}}{C_{S}}
$$

Experimental evidence again proved that injection of propane vapour with hot water results in high recovery, which is far higher than what could be obtained with hot water or propane vapour alone. In 1991, Butler and Mokrys described vapourized propane injection process (without hot water injection) as uneconomic, with which many future studies did not agree.

Butler and Mokrys, in 1993, justified the idea of injecting solvent close to its dew point pressure by conducting five experiments at room temperature $\left(20^{\circ} \mathrm{C}\right)$ covering the pressure range 708-984 $\mathrm{kPa}$ (i.e., from below the propane dew point to the pressures beyond it). Propane was injected from the top, and oil was produced from the diagonal 
bottom end. The authors termed it as 'Dry VAPEX' due to the absence of steam. The experiments were designed to show the effect of propane equilibrium pressure on the oil drainage rate, percent recovery, asphaltene precipitation, and produced oil viscosity. The highest extraction rate of oil in VAPEX with propane injection was achieved at 846-915 $\mathrm{kPa}$ under steady-state conditions for an initial reservoir temperature of $20^{\circ} \mathrm{C}$. At higher operating pressure, too much asphaltene precipitation caused pore plugging and, thus, drastically reduced the permeability to cause impairment in drainage flow. The authors observed that propane injection close to its dew point pressure resulted somewhat close to the overall recovery achieved at higher operating pressure, with fairly less asphaltene precipitation. Simultaneous steam-propane injection, which was termed by the authors as 'Wet VAPEX', resulted in heavy oil production comparable to that of SAGD. Moreover, the steam-propane process was found more energy efficient than SAGD. Steam was employed to create a limited hot region in which propane was stripped from the draining oil, accumulated heat energy in the vapour chamber, and, with upward motion, not only heated up the oil but also by molecular diffusion decreased its viscosity.

Butler and Mokrys, in 1993, further extended the idea previously proposed (Butler and Mokrys, 1991). They not only confirmed the previously developed theory by designing a large-scale physical model equipped with 62 thermocouples, but also investigated the idea of conducting VAPEX without the injection of hot water. The physical model was vibro-packed with glass beads and filled with the same heavy oil (Lloydminster) used by the researchers before (Butler and Mokrys, 1991). Target conditions were 1.536 MPa and $45^{\circ} \mathrm{C}$. Hot water and propane injection protocol was the same as former studies. 
The result of adding saturated vapour was a sharp increase in oil production accompanied by a similarly sharp decrease in the gas-to-oil and water-to-oil ratios. The same physical model was used to conduct VAPEX with propane as the sole injection fluid, which the authors termed as Dry VAPEX. Diagonal positioning of the injector and producer was the main area of deviation from the previous experiment. Absence of hot water to boil off propane back to the vapour chamber when connection between the injector and producer was made was the main reason behind placing the wells the furthest apart achievable in order to avoid high gas-to-oil ratio (GOR) once the connection was established. Recovery data indicated continuing steadily declining oil production rate accompanied by steadily increasing GOR. Recovery reached $55 \%$ within the first 8 hours of experimental run compared to the $60 \%$ recovery of oil within the first 7 hours using hot water in the previous case.

In VAPEX, the proper selection of well configurations is desirable to control the initial displacement, and, more importantly, the profiles of the vapour chamber in the formation. De-asphalting and its effect on flow of diluted oil could also be related to the determination of well configurations, which control the shape, and direction of interface movement. Butler and Jiang in 1996 conducted experiments in a scaled packed physical model in which Tangleflags heavy oil was extracted by co-injection of solvent (nbutane) and a non-condensable gas (nitrogen) at a pressure just above the vapour pressure of the injected solvent under different scenarios associated with the relative positioning of horizontal injector and producer. It was determined that for conventional heavy oil, top injection is better than bottom injection for homogeneous, and particularly for 
heterogeneous reservoirs when an injector is placed horizontally apart from a producer.

\subsubsection{Further Development by Butler}

Butler and Mokrys, in 1989, carried out experiments in a Hele-Shaw cell and a scaled packed cell to evaluate the performance of VAPEX and study its mechanism. They derived mathematical formulas based on moving interface and also by assuming that oil flows along the interface in a thin diffusion boundary layer. They assumed a pseudosteady state process, the advancement of the interface at a constant unspecified velocity at any position, and solvent concentration dependent properties like viscosity, density, diffusivity, to be uniform across the cell thickness. The flow rate out of the cell thickness was derived as (Butler and Mokrys, 1989, 1998)

$$
Q=\sqrt{2 k g \phi \Delta S_{o} N_{s} h}
$$

It is worth mentioning that in a Hele-Shaw cell, $\phi$ and $\Delta S_{o}$ are unity. The above analysis does not include the effects of de-asphalting on the process. Das and Butler, in 1997, modified the Butler-Mokrys mathematical formulation based on Hele-Shaw cell by introducing apparent diffusion coefficient of the solvent in bitumen in porous medium and a cementation factor term. The final form of the flow rate out of cell becomes

$$
Q=2 L \sqrt{2 k g \phi^{\Omega} \Delta S_{o} N_{s} h} .
$$

Based on the above analysis, they also pointed out the relation between production rates and permeability. The investigators stated that for identical conditions of temperature and pressure for the same bitumen-solvent system, the values of $\mathrm{N}_{\mathrm{s}}$ are equal. The production rates and the VAPEX parameters of two different media under such conditions can be 
related as:

$$
\frac{q_{1}}{q_{2}}=\frac{L_{1}}{L_{2}} \sqrt{\frac{k_{1} \phi_{1}^{\Omega_{1}} \Delta S_{o_{1}}}{k_{2} \phi_{2}^{\Omega_{2}} \Delta S_{o_{2}}}},
$$

i.e. if all conditions other than permeability remain the same, the production rate and the VAPEX parameter should be proportional to the square root of permeability. To validate the idea developed in the above formulation, the researchers conducted experiments in a model with observation facility of the process in real time. The model was packed with Ottawa sand/glass beads saturated with crude, which was extracted by injecting butane vapour at a constant pressure. To avoid liquefaction of butane in the porous bed, the operating pressure was maintained lower than the vapour pressure of butane at the operating temperature. In this way, two sets of VAPEX experiments were conducted using two different permeabilities of the medium and with the same solvent-bitumen system, keeping the pressure and temperature constant. The linear nature of the stabilized production rate vs. square root of corresponding permeability plot was in perfect agreement with the theory developed in this study. They observed higher production rate associated with porous media, compared to Hele-Shaw cell, and assigned the credit to capillary pressure, which enhances the interfacial area for diffusion in porous media. This idea was developed based on the literature and the established theory describing flow through porous medium. No specific experimental study was conducted to reach such a conclusion.

\subsubsection{VAPEX Process by Water Injection}

A considerable fraction of heavy oil resources of Alberta and Saskatchewan is 
present in thin reservoir underlain by active aquifers. Primary production from these reservoirs is plagued with large quantities of water production even before $5 \%$ of the oil in place is recovered. VAPEX can work better than SAGD in this condition. Butler and Das, in 1996, studied the effect of water injection together with solvent and noncondensable gas injection on VAPEX extraction rate. The injection schemes followed by the investigators were: injection of non-condensable gas and solvent one after another, followed by injection of water; co-injection of carrier gas and solvent vapour, followed by water injection; controlled injections of the fluids towards the enhancement of oil production rate. The investigators stated the necessity of an optimum solvent and carrier gas injection strategy for a successful field application, because of higher injection rate of solvent and carrier gas leading to accumulation of liquid solvent in the chamber affecting the production rates and, unnecessary recycling of the solvent vapour respectively. Also, it was shown that water injection and time of injection is very important. The authors hinted that a higher rate of production due to controlled water injection is caused by the wettability scenario, which places the thin water film in between the flowing oil film and the wall of the capillaries and, thus, reducing the viscous forces acting on the oil film. The best injection scheme they found was injection of carrier gas, which may lead to small amounts of initial production, followed by injection of solvent vapour along with the carrier gas, and finally controlled injection of water, yielding considerable increase in production.

Using the dynamic and geometric similarities for the VAPEX process discussed elsewhere (Butler and Das, 1995), the equivalent model time $\left(t_{M}\right)$ and reservoir 
time $\left(t_{F}\right)$ were related to the model and reservoir thickness $H_{M}$ and $H_{F}$ by

$t_{F}=t_{M}\left(\frac{H_{F}}{H_{M}}\right)^{2}$.

For the same oil-solvent system in a physical model and field conditions, the relation between the field and model permeabilities was derived as follows:

$k_{F} H_{F}=k_{M} H_{M}$.

It was also shown by Das and Butler, in 1995, that

$\frac{q_{F}}{L_{F}}=\frac{q_{M}}{L_{M}}$

stating that the production rate per unit length of the horizontal well in the model and in the field would be equal.

\subsubsection{Counter Current Extraction}

Butler and Das in 1996, and Butler and Mokrys, in 1998, investigated another VAPEX approach by injecting solvent vapour and producing diluted oil both at the water-oil contact. They defined the mechanism behind this type of VAPEX as countercurrent extraction. Experimental results and an analytical model to analyze experimental data was presented in this work. With this approach, solvent vapour was injected right at the oil-water contact, where solvent spread and extended the solvent-oil contact underneath the entire pattern, which resembled a planar well. Initially, butane vapour pushed water to the production well to accommodate itself underneath the oil zone. The second phase began with solvent vapour contacting the oil zone at the oil-water contact plane, moving upward, and dissolving while diluted oil moved downward counter-currently. 
Diluted oil first filled up the originally water saturated sand at the bottom and developed an oil bank. Production rate during this period was relatively low. Once the oil bank was developed, drainage rate increased. Finally, when the solvent vapour reached top of the reservoir, the production mechanism was mainly guided by gravity drainage, which also slowed down as the height of the oil bank decreased. Laboratory experiments proved 410 times higher extraction rates compared to conventional VAPEX processes with sideways spreading chambers.

Das, in 1997, extended the ideas previously discovered by Butler (Butler, 1996) to a broader extent by comparing the data gathered by conducting VAPEX in a Hele-Shaw cell and sand pack model. Theoretical analysis coupled with experimental results and the feasibility of the process for implementation in heavy oil and Bitumen reservoirs were presented.

In some previous experiments (Butler and Das, 1995), VAPEX has been carried out at pressure much greater than the vapour pressure of the pure solvent. The pressurehandling characteristic of non-condensable gas was utilized to manage this problem. This was achieved by mixing solvent vapour with the non-condensable gas; the solvent dilutes the oil, and non-condensable gas maintains the operating pressure. Because gas phase diffusion is the main mechanism of VAPEX, non-condensable gas build-up in the extracted chamber would reduce the solvent concentration and may slow down the diffusion process. This can be eliminated by using a near miscible vapour mixture (e. g., ethane and propane or, propane and butane) in some cases, or allowing a controlled 
volume of gas production to reduce the buildup of the non-condensable gas inside the extracted chamber. If the solvent vapour is injected at a pressure close to its saturated vapour pressure at the operating temperature, deasphalting takes place. The amount of asphaltene is less with butane than with propane.

\subsubsection{Close Loop Extraction}

Butler and Mokrys, in 1998, discussed the scaled physical model results for Peace River and Lloydminster using 20-30 mesh and 30-50 mesh Ottawa sand as porous medium and propane as the injection fluid considering two scenarios: with or without aquifer. The essential features of the system were gas recycle loop and propane make-up line to recycle and back inject produced and/or solution gas and 62 thermocouples connected to the physical model to predict the temperature distribution. To establish initial communication between the wells, an electrical coil heater was used. For VAPEX experiments without the recycle loop, produced gas to oil ratio at the end of the run typically reached about 0.5 by weight (i.e., one half of a kilogram of propane was required to recover one half of a kilogram of oil). Addition of propane stripper and gas recycle loop lowered the produced gas to oil ratio from 0.5 to 0.13 by weight. In 1998 , Butler and Mokrys, assuming the same bitumen-solvent system, constant porosity, invariable saturation change, and injector-produced assembly, also derived the following drainage ratio equation for different packing permeabilities from the original VAPEX drainage rate equation: 


$$
\left(\frac{Q_{1}}{Q_{2}}\right)=\sqrt{\frac{k_{1}}{k_{2}}} .
$$

\subsubsection{Recent Development}

Previous researchers (Butler and Mokrys, (1989,1993); Butler and Das, 1998; Butler and Jiang, 1997) predicted the production rate in VAPEX to be very low for field application. Their predictions were based on the results from physical model experiments and the scaling-up theory that hypothesizes that the oil recovery rate in VAPEX should be proportional to the square root of the reservoir transmissibility. This approach ignored the role of dispersional mixing between solvent vapours and In Situ oil during the gravity drainage process. Karmaker and Maini, in 2003, reinvestigated the production rate to reexamine the scale-up method followed by the previous researchers. They carried out an extensive experimental study using physical models of varying sizes with sand grains of three different size distributions. They pointed out that with the increase in grain size, permeability of the packing increases and so does the oil drainage rates. Variation in grain size also causes the capillary pressure to change; however, how this change affected the oil drainage rate could not be fathomed from their work.

Effects of model height were also studied by plotting $Q / \sqrt{h}$ against $\sqrt{h}$ for the same grain size distribution. As was predicated from the mathematical formulation relating the drainage rate and transmissibility, $Q / \sqrt{h}$ did not remain constant and increased with the increase in $\sqrt{h}$. This result indicated that increase in model height had a significant impact on the magnitude of convective dispersion in the VAPEX flow situation. To 
investigate the scaling-up theory followed by the previous researchers to predict VAPEX drainage rate in the field, Karmaker and Maini, in 2003, compared the ratio of $\left(\sqrt{k h \phi^{\Omega}}\right)_{\text {medium }} /\left(\sqrt{k h \phi^{\Omega}}\right)_{\text {small }}$ between physical models with two different heights, but $\left(\sqrt{k h \phi^{2}}\right)_{\text {medium }} /(\sqrt{k h \phi}$

packeu willl llle salle grain size distribution and proved the discrepancies associated with the scaled-up method described by the following mathematical formulation:

$$
\frac{Q_{\text {model }}}{Q_{\text {field }}}=\frac{\left(\sqrt{k h \phi^{\Omega}}\right)_{\text {model }}}{\left(\sqrt{k h \phi^{\Omega}}\right)_{\text {field }}} .
$$

This led to the conclusion that the scale-up method was not valid for the VAPEX process. It also confirmed that much higher oil rates in the field are possible compared to those predicted by previous investigators (Butler and Mokrys, $(1989,1993)$; Butler and Das, 1998; Butler and Jiang, 1997).

Karmaker and Maini, in 2003, studied the effects of temperature, operating pressure, oil viscosity, overlying/underlying aquifer, and overlying gas cap on the VAPEX process. They designed an experimental model, which was somewhat close to the primary model, considering the design specifications used by Butler (Butler, 1991). The physical model constituted a cavity to hold the sand pack in an aluminum body, the open side of which was confined with a glass plate for visual inspection. Six sets of experiments were designed to simulate different scenarios using the same 16-20 US mesh grain size distribution. Conducting VAPEX experiments at $10^{\circ}$ and $19^{\circ} \mathrm{C}$ and comparing the results revealed that average oil rate increased by $2 \%$ for every $1^{\circ} \mathrm{C}$ increase in the process temperature. This was due to the facts that viscosity reduced and solvent diffusivity 
increased with increase in temperature. The researchers adopted a similar approach to investigate the effects of pressure by conducting experiments at 152 and 135 psig operating pressure and pointed out that with increase in pressure, the solubility of the vapourized solvent in the oil increases and so does the oil recovery. Effect of oil viscosity was also studied by the investigators. In VAPEX, oil recovery rate is governed by the diffusion of solvent molecules into the heavy oil. They stated that as molecular diffusivity of propane increases with decrease in oil viscosity, this in turn enhances the oil recovery. The fourth step of this experimental study investigated the significance of an overlying gas cap on the VAPEX process. In the reservoir containing a gas cap, the injected solvent can rapidly spread over the gas-oil contact area and make the diffusion process fast from the beginning if the injection well is completed in the gas zone. Two sets of experiments were designed, one with a gas cap and the other without any overlying gas cap. Production in the gas-cap case started earlier and non-condensable gas injection was half of that in the case without a gas cap. Comparing the final oil recoveries, it was proved that presence of a small gas cap was fully compatible with the application of VAPEX for oil recovery.

The economic viability of the VAPEX process is dependent on the cost of the injected gases per barrel of produced oil. With predicted increase of gas price, this situation is sure to deteriorate. To reduce the solvent cost, commercially available non-condensable gas (methane, natural gas, $\mathrm{CO}_{2}$ ) is mixed with vapourized solvent (propane and/or butane) and is injected into the reservoir. The non-condensable gas works here as a carrier gas and helps increasing the bubble point pressure close to the reservoir 
pressure. Maini et al. (2003, 2004) studied the cost effectiveness and environmental friendliness of a $\mathrm{CO}_{2}$-based VAPEX process by extensive experimental study. Performance of $\mathrm{CO}_{2}$ as a carrier gas was compared to methane at two different pressures. Both at 250 psig and 600 psig, volumetric injections of $\mathrm{CO}_{2}$ were higher than methane, because solubility of $\mathrm{CO}_{2}$ in heavy oil is significantly higher than that of methane. At lower operating pressure (250 psig), both $\mathrm{CO}_{2}$-propane and methane-propane mixtures produced oil at the same average drainage rate, whereas, final oil recovery for the methane-propane system was slightly higher $(2 \%)$ than $\mathrm{CO}_{2}$-propane system. However, the use of $\mathrm{CO}_{2}$ can be justified by its cost effectiveness and environmental benefits. At higher operating pressure ( 600 psig), not only the oil drainage rate, but also the final oil recovery was $11 \%$ higher in $\mathrm{CO}_{2}$ propane system that methane-propane system. This promising result can be explained by the high solubility of $\mathrm{CO}_{2}$ in propane at high pressure, which leads to greater reduction of the crude viscosity.

Butler and Mokrys's (Butler and Mokrys, 1997) analytical model showed that the oil drainage rate is proportional to the square root of reservoir transmissibility. However, the effects of convective dispersion between solvent and virgin heavy oil in porous medium were ignored in developing this model. Maini and Yazdani, in 2004, conducted experiments in a different type of physical model and developed an improved scaled-up method for the VAPEX process. They employed a new design of slice-type physical model, which was able to handle high pressure. The annulus between two co-axial hollow transparent cylinders was used as the housing for the sand-pack. There were two physical models, the smaller of which was almost identical to the largest rectangular model 
used by Karmaker and Maini in 2003. This made it possible to compare and verify which scale-up method best describes the original scenario. Two types of oil samples (Dina and Elk Point) with viscosity in the order of $18000 \mathrm{cp}$ and three different mesh size distributions of glass beads, coupled with different heights of models, were used to study the effects of reservoir height and grain size distribution. Plots of oil drainage rates against time $(h r)$ for different reservoir heights for each of the grain size distribution clearly indicated a positive relationship. Average experimental values of $Q / \sqrt{k \phi^{\Omega}}$ versus $\sqrt{h}$ showed a polynomial relationship between the two terms. Based on observation and, later, further mathematical manipulation following the power-law curve fitting relationship, the following relationships were derived:

Quadratic: $Q=0.0174 h^{1.26} \sqrt{k \phi^{\Omega}}$,

Cubic: $Q=0.0288 h^{1.13} \sqrt{k \phi^{\Omega}}$.

Based on the above analysis, they also proposed to correct the relationship first described by Karmaker and Maini (2003) to predict the field rates obtained from the scale-up experimental rates by the following equation:

$$
\frac{Q_{\text {field }}}{Q_{\text {model }}}=\left(\frac{h_{\text {field }}}{h_{\text {model }}}\right)^{n} \times \frac{\left(\sqrt{k \phi^{\Omega}}\right)_{\text {field }}}{\left(\sqrt{k \phi^{\Omega}}\right)_{\text {model }}}
$$

where, $n \approx 1.10-1.30$.

The above equation was applied to scale up the stabilized rates from the experiments to the typical field rate. For this purpose, the Fort McMurray formation located in Canada was chosen to examine the potential VAPEX process implementation. $10 m$ thickness, $33 \%$ porosity, and 3 Darcy of vertical permeability were the reservoir 
characteristics used for scale up. A pair of $1 \mathrm{~km}$ horizontal wells delivered $350 \mathrm{~m}^{3} / d a y$ as the stabilized oil flow rate. This work proved that the transmissibility-based scaling up method seriously under-predicts the results at larger scales.

Karmaker and Maini, in 2003, investigated the effect of a small gas cap on the VAPEX process and hinted the possible effect of overlying/underlying aquifer as too complex to determine. Frauenfeld et al. (2004) re-visited the idea proposed by Maini (2003) and strove to determine the effect of an active underlying aquifer on VAPEX. A series of experiments were designed in an acrylic visual model. Pujol and Boberg scaling (1972) were used to produce a lab model scaling of a field process by a 1000:1 ratio and by compressing field time by a ratio of 10,000:1. The model represented a slice of a $30 \mathrm{~m}$ thick reservoir with a $10 \mathrm{~m}$ thick underlying aquifer. A pair of horizontal wells, both 500 $m$ long and $25 \mathrm{~m}$ apart, was placed at the oil/water interface. Homogeneous reservoirs, layered reservoirs, and reservoir with low permeability sand lenses in high permeability sand were simulated. The authors stated the reason behind placing both the producer and injector into the oil/water contact as to take advantage of the curvature of interfaces that exist there and, thus, to contact larger surface areas by injected solvent. The singlepermeability sand reservoir produced faster than the layered reservoir. The layers inhibited the rise of the vapour chamber and caused a series of mini-chambers to form. Sand lenses did not significantly inhibit the oil production. Oil was able to flow around the sand lenses, and the continuous vapour chamber thus formed produced oil at nearly the same rate, as did the uniform high permeability reservoir. In each of the scenarios, initially, solvent pushed some water out to make room for itself to come in contact 
with the oil. Due to capillary force, oil was also observed transferring to the water zone. The investigator concluded that, although oil production was modest in the experiments, wider well pair spacing in the field would expose larger gas/oil contact and increase rates proportionately.

\subsection{VAPEX and Capillary Pressure}

Butler and Das (1997) was the first to point out the effect of capillary pressure on VAPEX only after they had observed an increase in production rate in the physical model with porous medium, an extension of previous work by Butler and Mokrys (1989) with a Hele-Shaw model. Recently, Karmaker and Maini (2003) conducted VAPEX experiments in three different sizes of physical model with varying sand grain distributions and observed that production rate increases with increase in grain size. They did not mention any capillary pressure effect, which also varies with varying grain size distribution, on overall production rate and recovery.

Effect of capillary pressure on VAPEX has been postulated based on sound theoretical understanding. No definite experimental or simulation studies can be found to support this apothegm. This research will not only conduct VAPEX in a uniquely designed physical model, but will also make every effort to simulate VAPEX in GEM including and excluding capillary data to compare the end results and, thus, to clearly demonstrate how capillary pressure can affect VAPEX.

The following section provides a brief discussion of the capillary pressure concept. 
Representative relative permeability data is another requirement for accurate VAPEX simulation. The unsteady-state Johnson-Bossler-Naumann (JBN) method is employed to calculate relative permeabilities, which will also be discussed later.

\subsection{Capillary Pressure - Concept}

When two immiscible fluids, such as oil and water, are in contact, a discontinuity in pressure, which depends upon the curvature of the interface separating them, exists between the two fluids. This pressure difference, which is called the capillary pressure and is denoted by $P_{c}$, is given by Laplace's Equation (Adamson, 1982; Dullien, 1979):

$$
P_{c}=P_{o}-P_{w}=\gamma\left(\frac{1}{r_{1}}+\frac{1}{r_{2}}\right)
$$

where,

$\gamma=$ Interfacial Tension (IFT), $P_{c}=$ Capillary Pressure,

$P_{o}=$ Pressure in the oil, $P_{w}=$ Pressure in the water,

$r_{1}, r_{2}=$ Radii of curvature of the interfaces measured perpendicular to each other.

By convention, the capillary pressure is defined as $P_{0}-P_{w}$. Because of this definition, a radius of curvature directed into the oil is positive, while the one directed into the water is negative. Depending on the curvature of surface, the capillary pressure can be positive or negative. When the interface is flat, the capillary pressure is zero. When fluids other than oil and water are used, the capillary pressure is usually defined as

$$
P_{c}=P_{n w}-P_{w} .
$$

Where $P_{n w}$ is the pressure in the non-wetting fluid and $P_{w}$ is the pressure in the wetting fluid (Figure 2.3). 


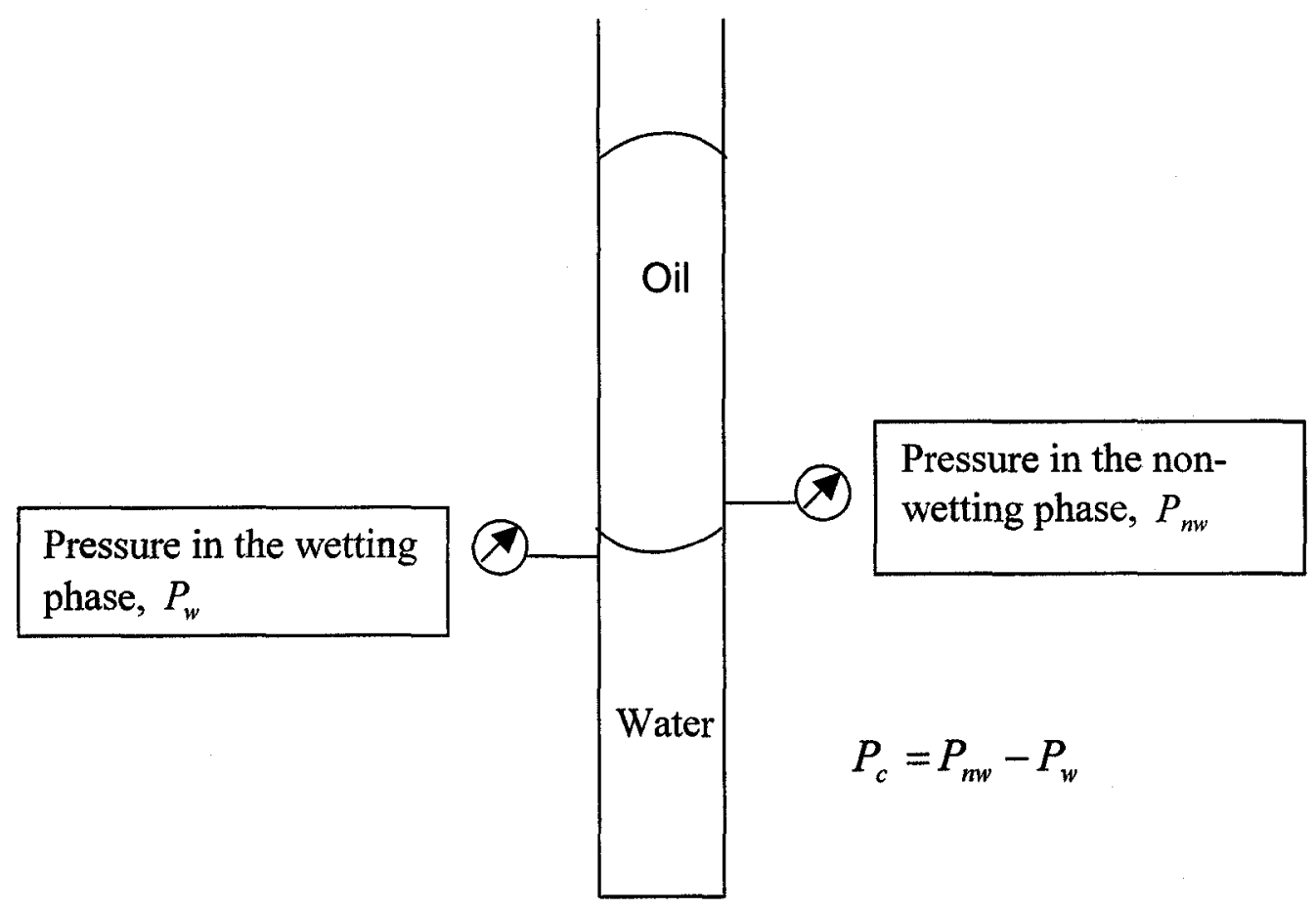

Figure 2.3. Capillary pressure as a difference between non-wetting and wetting phase pressure 


\subsubsection{Drainage}

In drainage, one of the two capillary processes, the non-wetting fluid displaces the wetting fluid. Consider a sample of reservoir rock or a similar porous solid, which is fully saturated with a wetting fluid, such as, for example, water. The quasi-static displacement of this phase by a non-wetting phase (e. g. oil) is then defined by the set of increasing values of the capillary pressure, $P_{c}$ and a corresponding set of decreasing values of the wetting phase saturation. The wetting phase saturation is reduced from its maximum to the irreducible minimum.

\subsubsection{Imbibition}

The capillary pressure versus saturation relationship for the reverse process, where the wetting phase imbibes and displaces the non-wetting phase in quasi-static state is known as the imbibition capillary pressure curve. It is important to note that two distinctly different portions of the imbibition curve can be measured. The first is the spontaneous imbibition curve, which is determined immediumtely after measurement of the drainage capillary pressure curve. The capillary pressure is decreased to zero, allowing the wetting phase to imbibe. The second portion is the forced imbibition, where the capillary pressure is decreased from zero to a large negative value.

\subsubsection{Calculation of $P_{C}$}

Figure 2.4 shows an interface between two fluids, water and oil, having a contact angle of $\theta$ through water in a capillary. One can use this figure and the Laplace's Equation to 


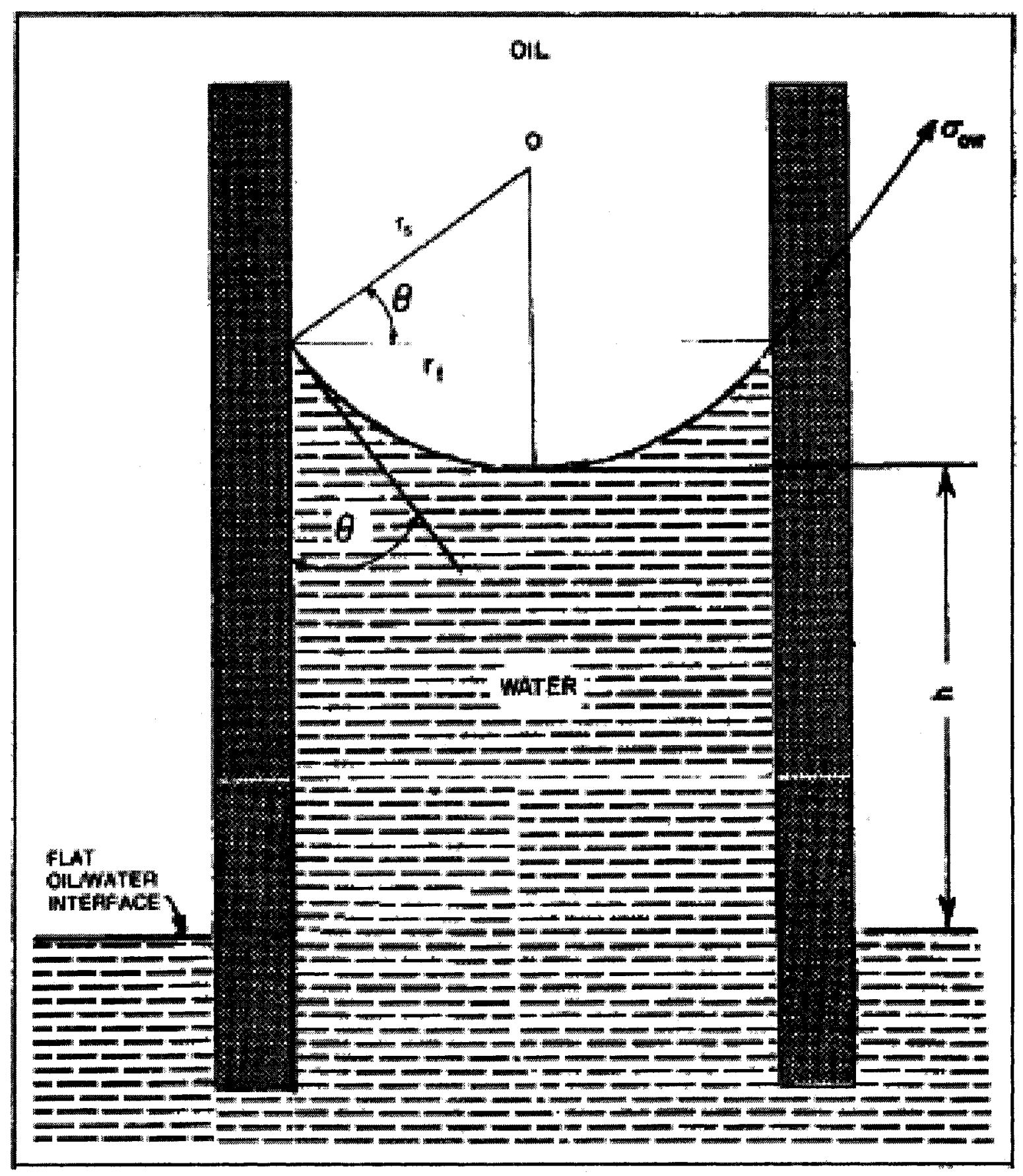

Figure 2.4. Oil/water interface in a capillary tube 
calculate $P_{c}$. Because the surface is spherical, both radii of curvature are equal to $r_{S}$. The relationship between radius of curvature and that of capillary tube is

$$
\frac{r_{t}}{r_{S}}=\cos \theta \quad \text { or } \quad \frac{1}{r_{S}}=\frac{\cos \theta}{r_{t}}
$$

Substituting Eqn (2.17) into Eqn (2.15) and considering $r_{l}=r_{2}=r_{s}$, we get:

$$
\begin{aligned}
& P_{c}=P_{o}-P_{w}=\gamma\left(\frac{\cos \theta}{r_{t}}+\frac{\cos \theta}{r_{t}}\right), \\
& \Rightarrow P_{C}=\frac{2 \gamma \cos \theta}{r_{t}} .
\end{aligned}
$$

For a water-wet medium, the pressure in the oil above the interface is greater than the pressure in the water below just to balance the upward force caused by IFT. On the contrary, when the surface is oil-wet, $\theta>90^{\circ}$, the IFT acts downward, and, thus, creates a concave-up interface within the capillary tube.

\subsection{Oil-water Relative Permeability}

The famous Johnson-Bossler-Naumann (JBN) method is employed to derive representative oil-water relative permeability values for $80-120$ mesh size sand grain. Data collected during a displacement test is manipulated to construct individual relative permeability curves for each of the oil samples. This JBN method is based on sound theoretical considerations.

\subsubsection{Mathematical Formulation}

The theory assumes two conditions that must be achieved before the method is applicable. These are that the flow velocity be high enough to achieve what has been 
termed as stabilized displacement, and that the flow velocity is constant all across the section of the linear porous body. The second assumption requires that the phases behave as immiscible incompressible fluids. Some of the relations presented previously by Welge in 1952 are needed for the calculation of individual relative permeabilities. These are as follows:

$$
\begin{aligned}
& W_{i}=\frac{1}{f^{\prime}}=\frac{1}{d f / d S}, \\
& \frac{1}{1-f}=\frac{f}{f_{o}}=\frac{k_{r w} \mu_{o}}{k_{r o} \mu_{w}}, \\
& \left(f_{o}\right)_{2}=\frac{d S_{a v}}{d W_{i}}, \\
& S_{a v}=S_{2}+W_{i}\left(f_{o}\right)_{2}, \\
& f_{o} u=-\frac{k k_{r o}}{\mu_{o}} \frac{\delta p}{\delta x} .
\end{aligned}
$$

Considering now a particular instant during a displacement experiment, the pressure drop across the system of length $L$ may be expressed as the integral

$$
\Delta p=-\int_{o}^{L} \frac{\delta p}{\delta x} d x
$$

Substituting for $\delta p / \delta x$ from Eqn. (2.23),

$$
\Delta p=\frac{u \mu_{o}}{k} \int_{0}^{L} \frac{f_{o}}{k_{r o}} d x
$$

At a given instant in the displacement, location of the various saturations as they moved along the length of the core is given by 


$$
\begin{aligned}
& \frac{x}{L}=W_{i} \frac{d f}{d S_{w}}, \\
& \Rightarrow \frac{x}{L}=\frac{1}{f^{\prime}} f_{2}^{\prime}, \\
& \Rightarrow x f^{\prime}=L f_{2}^{\prime} .
\end{aligned}
$$

Substitution of Eqn. (2.26) into Eqn. (2.25) gives

$$
\int_{0}^{f_{2}^{\prime}} \frac{f_{0}}{k_{r o}} d f^{\prime}=\frac{\Delta p k f_{2}^{\prime}}{u \mu_{o} L}=f_{2}^{\prime} \frac{u_{s} / \Delta p_{s}}{u / \Delta p}=\frac{f_{2}^{\prime}}{I_{r}} .
$$

The symbol $I_{r}$ is defined by Rapoport (Leas and Rapoport, 1953) in terms of intake capacity, $u / \Delta p . I_{r}$, designated as relative injectivity, and is a dimensionless function of cumulative injection, describing the manner in which the intake capacity varies with cumulative injection. From a physical viewpoint, the relative injectivity may be defined as the ratio of the intake capacity at any given flood stage to the intake capacity of the system at the very initiation of the flood (at which moment, particularly only oil is flowing through the system). This latter definition permits the determination of the relative injectivity function for a given type of reservoir rock from the measurements of flow rate and pressure drop taken at a successive stage of a waterflood susceptibility test.

Practical applications of the derivation outlined so far can be achieved by treating the relationship in Eqn. (2.27) as an equation in terms of variable, $f_{2}^{\prime}$. Differentiating Eqn. (2.27) with respect to $f_{2}^{\prime}$ and noting that ordinary rather than partial differentiation can be used, since $f_{2}^{\prime}$ is the only independent variable at the moment considered, yields 


$$
\frac{d\left(f_{2}^{\prime} / I_{r}\right)}{d f_{2}^{\prime}}=\frac{f_{o}}{k_{r o}}
$$

A more usable form from Eqn. (2.28) can be obtained by making use of the fact that $f_{2}^{\prime}$ is equal to the reciprocal of the cumulative volume injection

$$
\frac{d\left(\frac{1}{W_{i} I_{r}}\right)}{d\left(\frac{1}{W_{i}}\right)}=\frac{f_{o}}{k_{r o}} .
$$

The expression for the relative permeability of the displacing phase at $S_{2}$ is obtained by rearranging Eqn. (2.20) for $k_{r w}$,

$$
k_{r w}=\frac{\left(1-f_{o}\right)}{f_{o}} \frac{\mu_{w}}{\mu_{o}} k_{r o} .
$$




\section{EXPERIMENTAL PROCEDURES AND RESULTS}

This chapter provides a detailed description of the experimental set-ups and procedures followed in deriving capillary pressure data, conducting VAPEX on lab scale, and obtaining relative permeability data for the targeted oil samples. Each section also presents the results obtained from experiments.

\subsection{Capillary Pressure - Experimental Set-up}

The procedure is best aided by referring to Figure 3.1 and 3.2. The capillary pressure cell, which is the prime component of this experimental set-up, is connected to a U-tube manometer and a transfer cell at the bottom and top end, respectively. The CoreTest control panel comes in series in between the pressure source and transfer cell. There are 2-way valves attached at each connection port. Two transducers, one at one of the sideports of the pressure cell and the other at the U-tube manometer, were attached. The capillary pressure cell was the housing for the ceramic plate and porous medium.

\subsubsection{Major Components of the Experimental Set-up}

Major components of the experimental set-up are:

Capillary Pressure Cell

CoreTest Control Panel

Porous Plate

U-tube Manometer

Transducer

Transfer Cell 


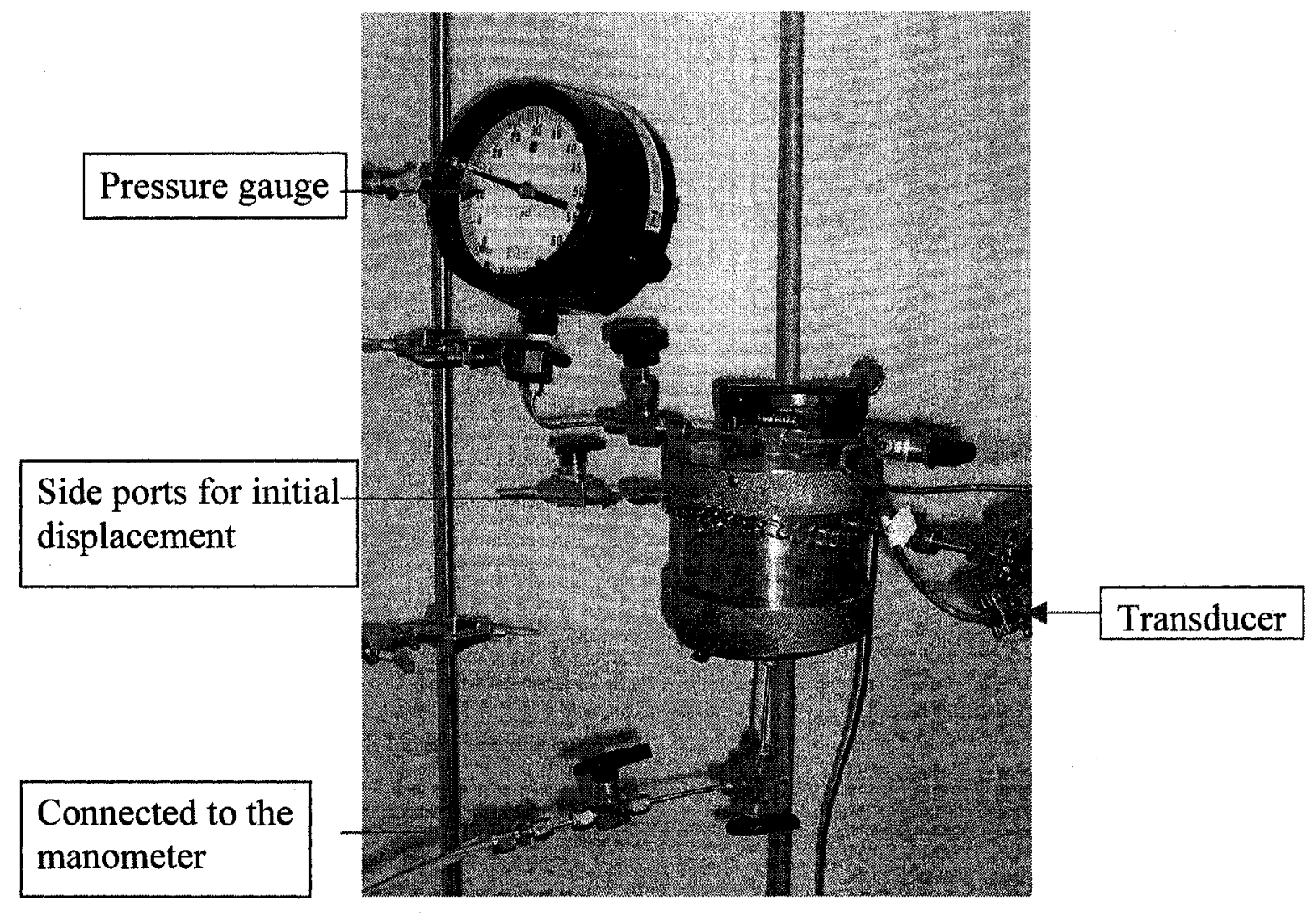

Figure 3.1. Fittings connected to the capillary pressure cell 


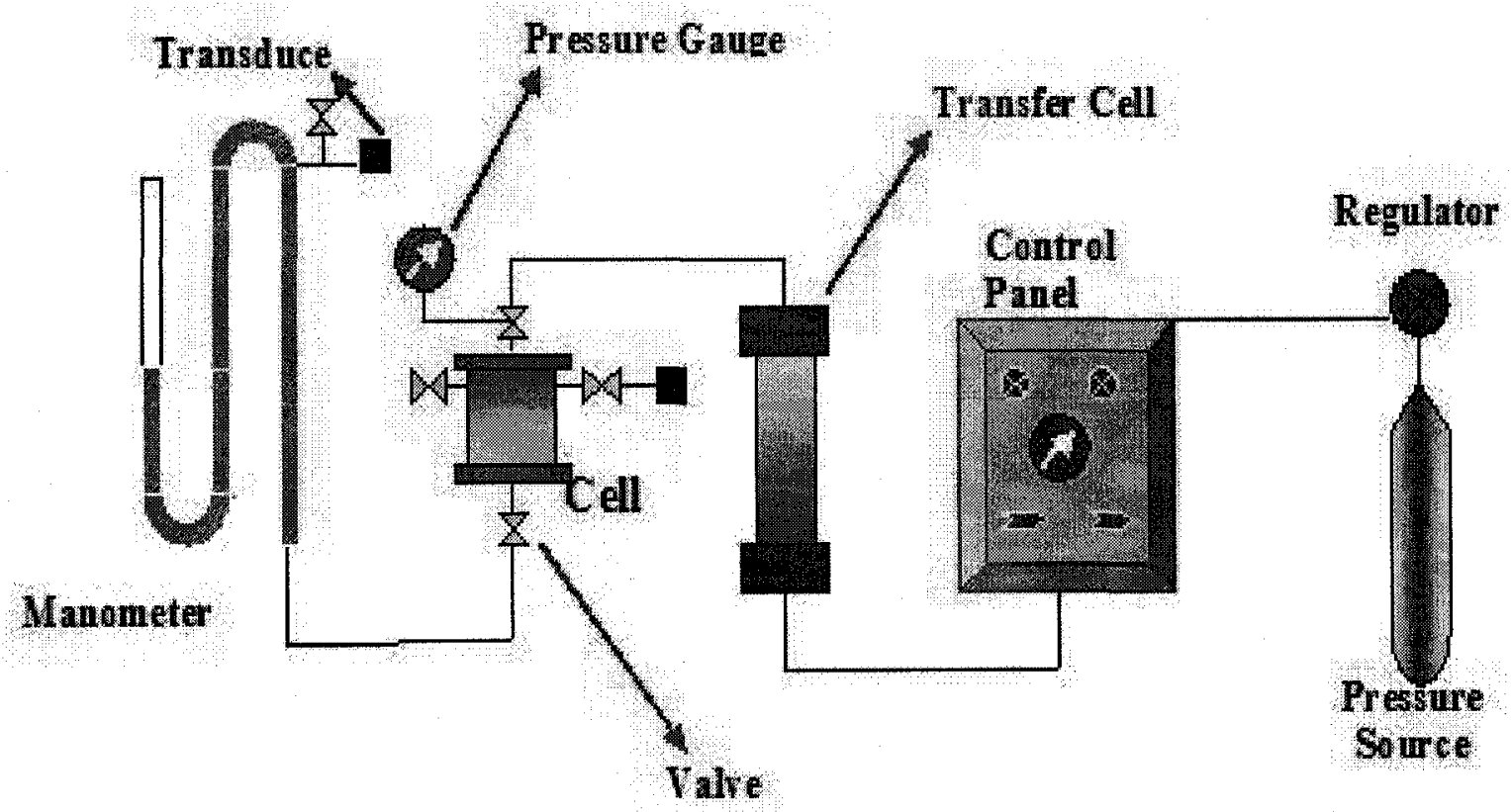

Figure 3.2. Capillary pressure measurement-schematic 


\subsubsection{Capillary Pressure Cell}

To develop the saturation capillary pressure curve, a stainless steel model, able to operate at a maximum pressure of $2000 \mathrm{psi}$, is designed (Figure 3.3.). This cylindrical capillary pressure cell has top and bottom lids, which, with the help of o-rings, make perfect seals when in place. There are two distributor plates adjusted close to the top and bottom edges of the pressure cell. With these two plates held in place, the capillary pressure cell is divided into three separate chambers. The reason for creating the top chamber is to create an oil reservoir at an initial stage to let oil spread all over the porous medium, which lies on the other side of the distributor plate, and, hence, to allow oil to uniformly displace water within the porous medium. Water reservoir in the bottom chamber facilitates the pressure surge to flow to the manometer. There are inter-connected channels carved on one side of the end plates to let oil and water spread uniformly. The top end plate has 180-200 mesh screen attached to it to restrict the movement of the sand particles. The pressure cell has four side-ports, which rest just above the porous medium and are perfectly inline with the axial grooves of the top end plate. Water is displaced out by oil from the top chamber through these side ports.

\subsubsection{CoreTest Control Panel}

The CoreTest control panel is utilized for precise control of the pressure source. With the help of this control panel, pressure can be increased by $1 p s i$ at each step. The top end of the transfer cell is connected to the capillary cell and the bottom end with the control panel. 


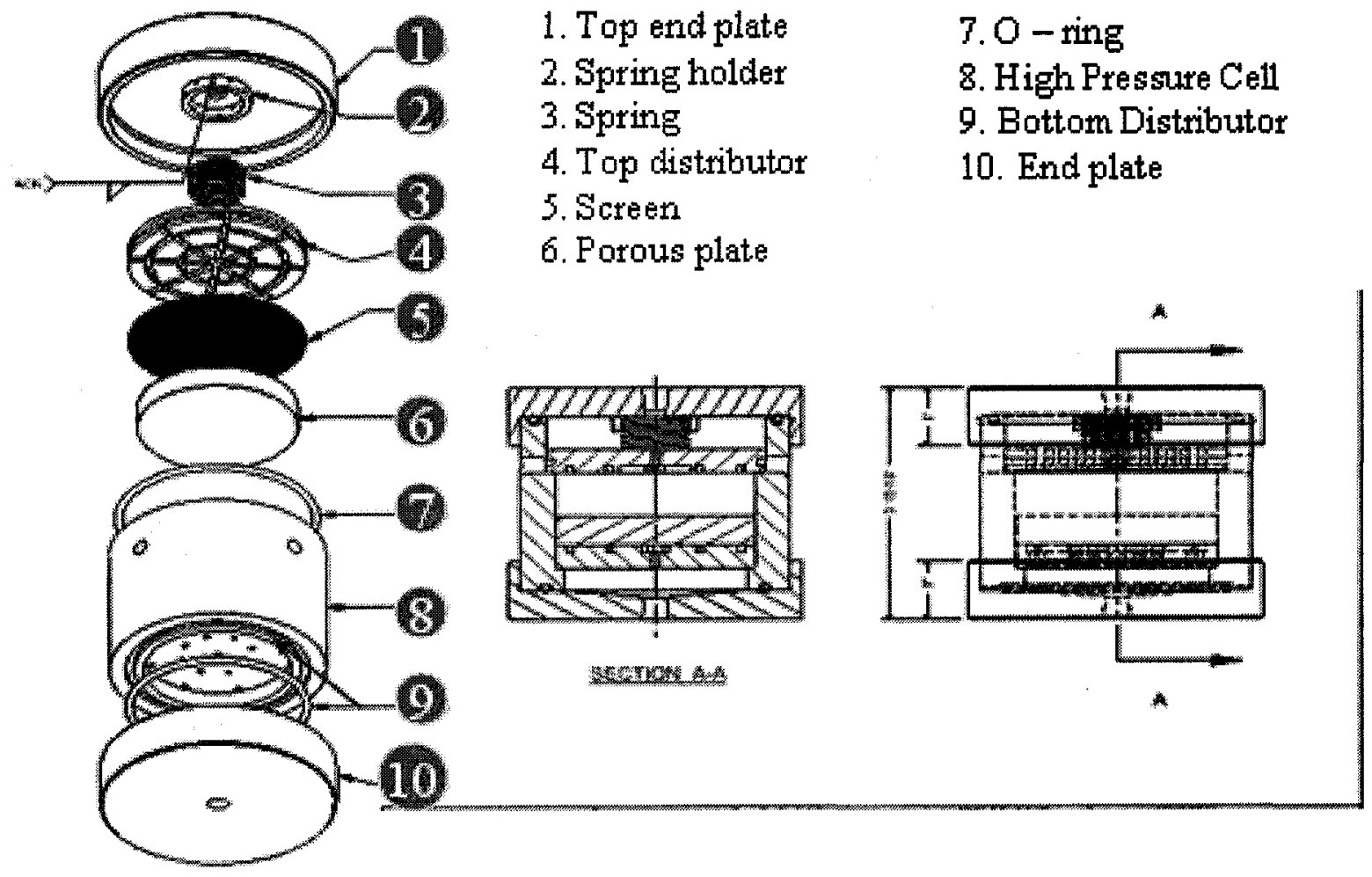

Figure 3.3. Components of the capillary pressure cell 


\subsubsection{Porous Plate}

The most essential part of this assembly is the hydrophilic ceramic plate. Its diameter, thickness, and porosity are $3.04^{\prime \prime}, 0.385^{\prime \prime}$, and $35.4 \%$ respectively. For a maximum pore pressure of $225 \mathrm{psi}$, this porous plate is water-wet and is able to restrict oil flow. To prevent any unwanted flow of oil, rubber cement was used to seal the space between the porous plate and the inner wall of the capillary cell.

\subsubsection{U-tube Manometer}

The manometer is designed to accommodate the maximum amount of displaced fluid within and, thus, indicate actual wetting phase pressure during the drainage capillary pressure experiment. In view of this, one leg of the manometer is stretched up to $10 \mathrm{ft}$ and is filled with mercury having a density of $13.546 \mathrm{~g} / \mathrm{cc}$. Inner diameter of the glass tube is 0.24 in.

\subsubsection{Transducer}

Two Validyne pressure transducers with $0.5 \%$ full-scale accuracy were used to sense the liquid movement in the manometer, as well as to record the wetting phase pressure within the porous medium. Transducers were connected to a data acquisition system.

\subsubsection{Transfer Cell}

The transfer cell contains the oil sample to be injected into the capillary cell once the anticipated saturation level and history are achieved. 


\subsubsection{Oil Sample Preparation}

The heavy oil used in this research is provided by Husky Energy Inc. from the Swimming Field at the Lloydminster in the Alberta-Saskatchewan area. Impurities, such as water and, sand were removed by two-stage separation in a centrifuge revolving at 10, $000 \mathrm{rpm}$ for 2 hours. Properties of the cleaned oil measured in the laboratory are summarized in Table 3.1 and presented in Figure 3.4. Viscosity measurement of the oil was completed on a Brookfield Programmable DV-II+ Viscometer. Density was measured in the Anton Paar density evaluation unit, mPDS $2000 \mathrm{~V}_{3}$. Original oil was diluted by mixing kerosene at different weight percentage. Four different oil samples were created. Samples 1 and 2 were used for capillary pressure measurement; samples 3 and 4 were used in the VAPEX and relative permeability experiment.

\subsubsection{Sieve Analysis}

Grain size distribution plays a vital role in determining the capillary pressure. Depending on the size of sand grains and relative positioning of the grains in accordance with their size, the pore throat diameter will vary and so will the capillary pressure, as it is a function of pore diameter. Poorly sorted and non-uniform grains result in poor packing, which may lead the whole experiment astray. To be consistent with the data, a predefined grain size within the range of $80-120$ mesh size was chosen. The deployed Fisher Rotto Sieve Shaker operates based on circular and vertical motion. Every time, the same volumetric amount of sand is sieved for 30 minutes. This reduces the chances of any inconsistency, which may arise with the sieve analysis technique. 
Table 3.1. Physical properties of the Swimming Field heavy oil at $21^{\circ} \mathrm{C}$

\begin{tabular}{|c|c|}
\hline Density & $0.993 \mathrm{~g} / \mathrm{cm}^{3}$ \\
\hline Viscosity & $100,000 \mathrm{cp}$ \\
\hline
\end{tabular}

NOTE: The viscosity at $21^{\circ} \mathrm{C}$ was extrapolated based on measured viscosities, as is shown in Figure 3.1.4 
$y=7 E+09 x^{-3.6717}$

$\mathrm{R}^{2}=0.9999$

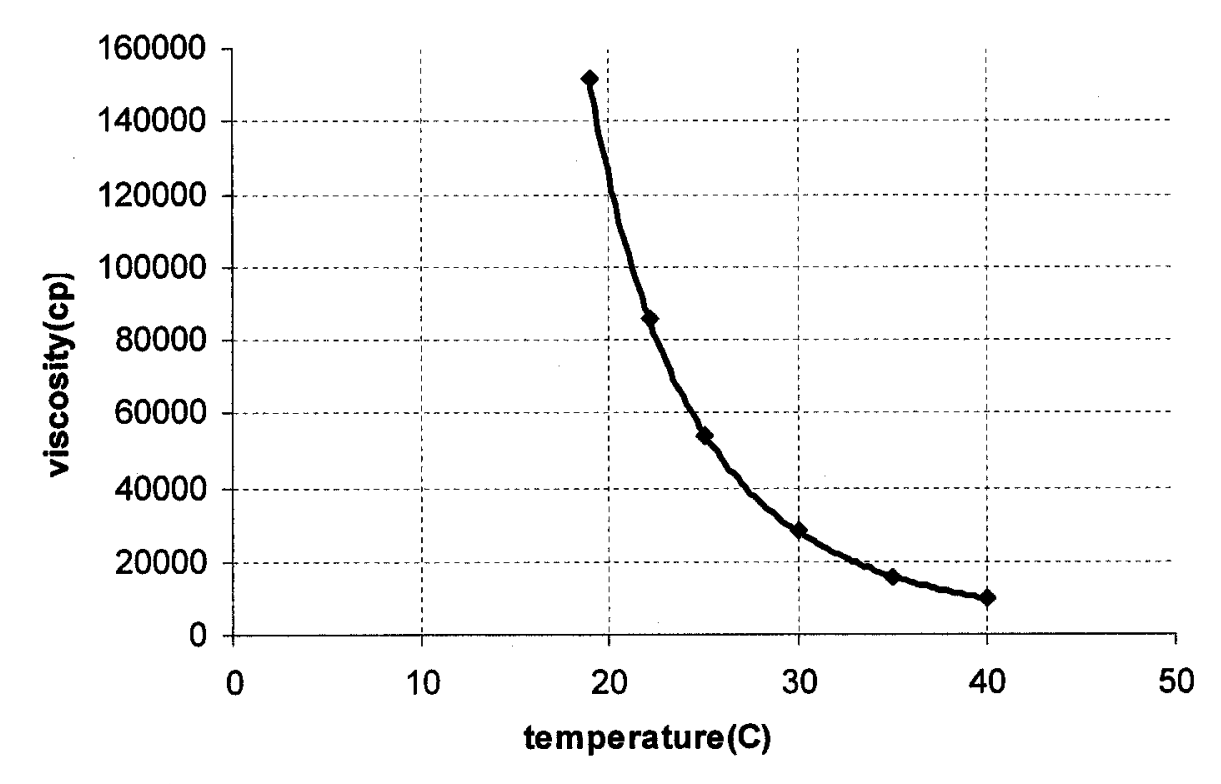

Figure 3.4. Viscosity of the Swimming Field heavy oil against temperature 


\subsubsection{Procedure}

With the bottom plate in place, the porous plate is set on top of it. Rubber cement is applied between the porous plate and inner surface of the capillary cell to restrict any kind of oil channeling. Space in between the porous plate and top distributor plate is filled up with $80-120$ mesh size sand grains. After the apparatus is set-up and sealed, vacuum is applied for one half hour and then the porous medium is saturated by letting distilled water flow at a very low rate into the model at the bottom from a burette. As soon as water is observed emerging through the niddle-valve adjusted at the top of the model, the valve connecting the pressure cell with the burette is turned off. An estimate about the dead end volume, which occupies the tubing and valves used to connect the model with the burette, indicates precisely how much water is injected into the model. Using the porosity value of the ceramic plate and the dimension of the pressure cell, the saturation level of the porous medium within the model is readily calculated. For each run, the saturated porous medium is left for 48 hours to develop the same saturation history.

\subsubsection{Displacing water from top chamber}

Once the experimental set up is ready, only the niddle valve is kept open whilst all the other valves are closed. Pressure at a slight increment (initially as low as $1 \mathrm{psi}$ ) is applied at the bottom of the transfer cell to let oil flow out through the niddle valve. This is done only to make the tubing air-free and, thus, prevent the occurrence of a third phase (air) into the two-phase system (oil and water). When no more air bubbles are observed in the flow line, the pressure is brought back to zero, the niddle vale is closed, the side port 
valves are opened, and again pressure is applied at the bottom of the transfer cell. This is done to displace water at the top chamber with oil. Pressure is decayed to zero, and the whole process was re-run to ensure that almost all the water is displaced by oil. Each time, the external pressure is kept very low to allow oil to spread all over the water phase in the top chamber, and, hence, displacement takes place at a very low flow rate. After a sufficient amount time has been taken for the initial displacement process, the model is ready for the main experiment.

\subsubsection{Capillary pressure underway}

Pressure is decayed to zero, the side port valves are closed, and the bottom end valve, which connects the pressure cell with the manometer, is opened. The niddle valve is opened only after a pressure gauge is connected with it for visual representation. One of the side ports is chosen to adjust a pressure transducer, which is also connected to the computer for automatic pressure data acquisition. A rise in the height of the leg from the reference point is observed in the manometer, when the pressure is increased by a factor of 1 . This is due to the fact that the remaining water, which survived the initial drainage process, is being displaced by the injected oil. When this process diminishes (i.e., when there is no movement in the mercury height), pressure in the non-wetting phase (oil) is recorded with the help of the attached transducer. This is assumed as the first point on the capillary curve when there is $100 \%$ water saturation in the porous medium. Then, pressure is increased to the next level (1 psi increment) and sufficient amount of time (sometimes up to 24 hours) is taken to see if the oil is draining any water out. The whole process is repeated until slight movement in the mercury height is observed. Pressure 
before this point is termed as threshold capillary pressure. The process is continued in this way, and at each step, the mercury height and non-wetting phase pressure is recorded only when the mercury height becomes stagnant. Movement of the mercury height can be easily checked with the help of the transducer attached to it. When further increment in the applied pressure causes no movement in the mercury height, the experiment is terminated.

\subsubsection{Calculation}

\subsubsection{Initial Saturation Level}

The initial saturation level is determined by simple mass balance. The porous medium is saturated with water after adjusting the porous plate in its proper location. The known porosity of the porous plates and inside dimension of the chamber within the Capillary Cell which contains the porous medium are employed to determine the initial saturation level, which is described as follows:

Void + Porous medium grain volume

+ Pore volume + Ceramic grain volume $=\mathbf{A} c c \ldots$ (1)

+ Ceramic pore

Void + Pore Volume + Ceramic Pore $=\mathbf{B} c c \ldots$ (2)

(2) $-(1) \Rightarrow$ Porous medium grain volume + Ceramic Grain $=\mathbf{A}-\mathbf{B}=\mathbf{C} c c .$.

Porous medium grain volume + pore volume $=\mathbf{D} c c \ldots$ (4)

Ceramic plate bulk volume $=\mathbf{E} c c$

Ceramic pore volume $=\mathbf{F} c c \ldots(6)$

(4) $-(5)=>$ Ceramic grain volume $=\mathbf{E}-\mathbf{F}=\mathbf{G} c c \ldots$ (7)

(3) $-($ (7) $\Rightarrow>$ Porous medium grain volume $=\mathbf{C}-\mathbf{G}=\mathbf{H} c c \ldots$ (8) 
$(4)-(8)=>$ Pore volume $=100 \%$ Water saturation $=\mathbf{D}-\mathbf{H}=\mathbf{S}_{\mathbf{W}}$

\subsubsection{Capillary Pressure from the Experimental Data}

Figure 3.5 schematically describes the approach towards capillary pressure calculation from the experimental data. A small water head, which is applied to stop mercury evaporation, is taken into consideration while calculating capillarity. The following equation is derived for easy calculation of capillarity,

$P_{c}=P_{o i l}-\left(\rho_{H g}\left(\Delta h_{H g}\right)-\rho_{w}\left(h_{1}-h_{w}\right)\right)$.

Here,

$P_{\text {oil }}=$ pressure in the oil phase (transducer reading), psi

$\rho_{H g}=$ density of mercury, $l b / i^{3}$

$\Delta h_{H g}=$ difference between the mercury height, in

$\rho_{w}=$ density of water, $l b / \mathrm{in}^{3}$

$h_{1}=$ height of water column below the initial oil-water contact, in

$h_{w}=$ dead water head in the left manometer leg, in

\subsubsection{Results and Discussion}

High viscosity of the original oil limits the application of the conventional approach of capillary pressure measurement. Experiments are conducted focusing mainly on the lower level of viscosity to generate a trend. With this idea in mind, the original oil is diluted by kerosene at two different weight percentages to generate two separate oil samples having different viscosities. Properties of samples 1 and 2 are presented in Table 3.2. It can be noted that higher oil percentage results in an oil sample having higher viscosity and density. Figure 3.6 and 3.7 represent the capillary pressure curves for 


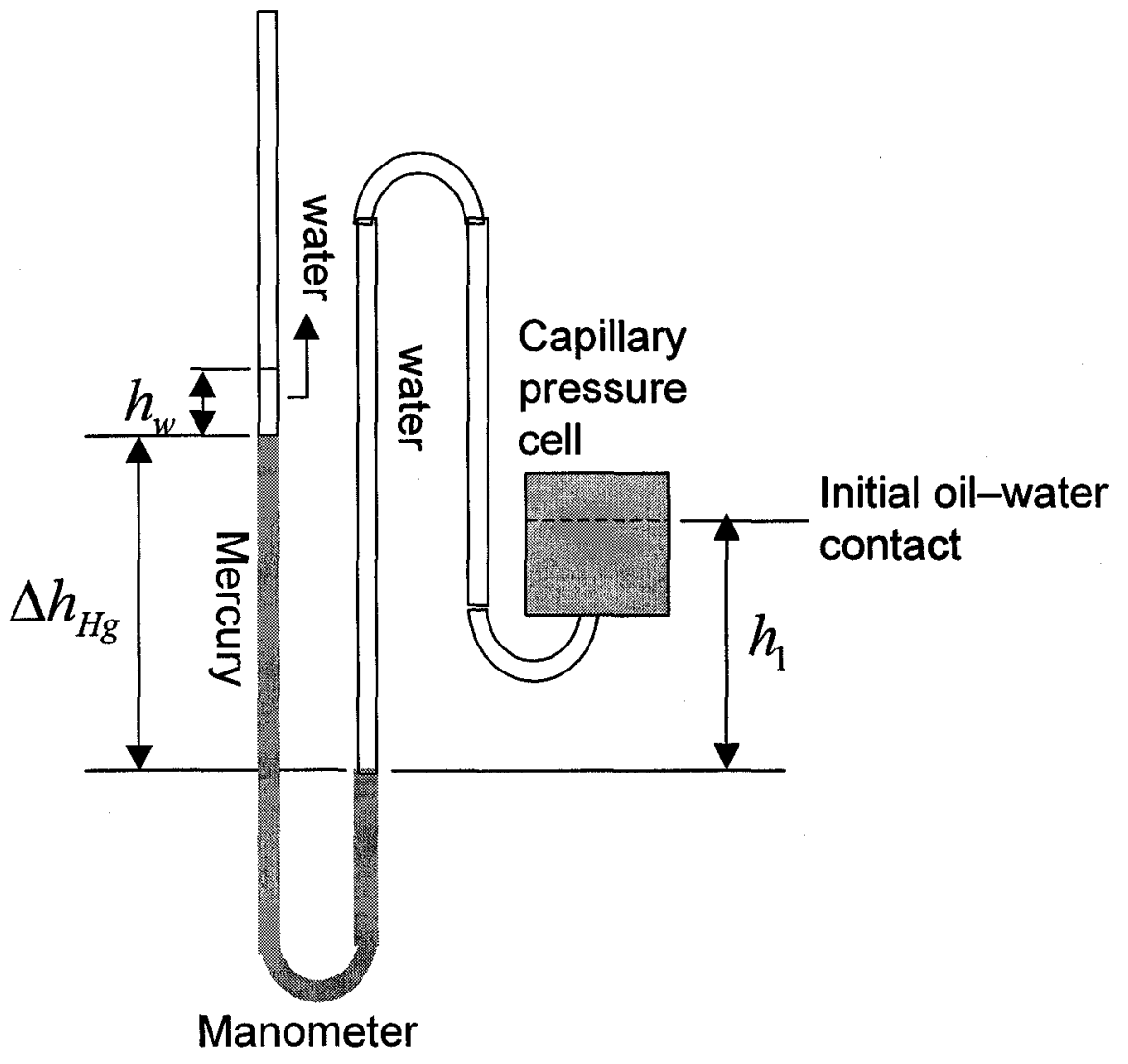

Figure 3.5. Capillary pressure calculation - equation development 
Table 3. 2. Properties of sample $1 \& 2$ (at $22^{\circ} \mathrm{C}$ )

\begin{tabular}{|c|c|c|c|}
\hline Sample \# & Oil Weight \% & Viscosity $(c p)$ & Threshold $\mathrm{P}_{\mathrm{C}}$ (psi) \\
\hline 1 & 30 & 6 & 0.665 \\
\hline 2 & 40 & 14 & 0.80 \\
\hline
\end{tabular}

Table 3. 3. Viscous oil samples and their properties (at $22.5^{\circ} \mathrm{C}$ )

\begin{tabular}{|c|c|c|c|c|}
\hline Sample \# & Oil Weight \% & $\begin{array}{c}\text { Viscosity } \\
(\mathrm{cp})\end{array}$ & $\begin{array}{c}\text { Density } \\
(\mathrm{g} / \mathrm{cc})\end{array}$ & $\begin{array}{c}\text { Connate } \mathrm{S}_{\mathrm{W}} \\
(\%)\end{array}$ \\
\hline 3 & 90 & 5800 & 963 & 14.32 \\
\hline 4 & 95 & 14400 & 985 & 8.69 \\
\hline
\end{tabular}




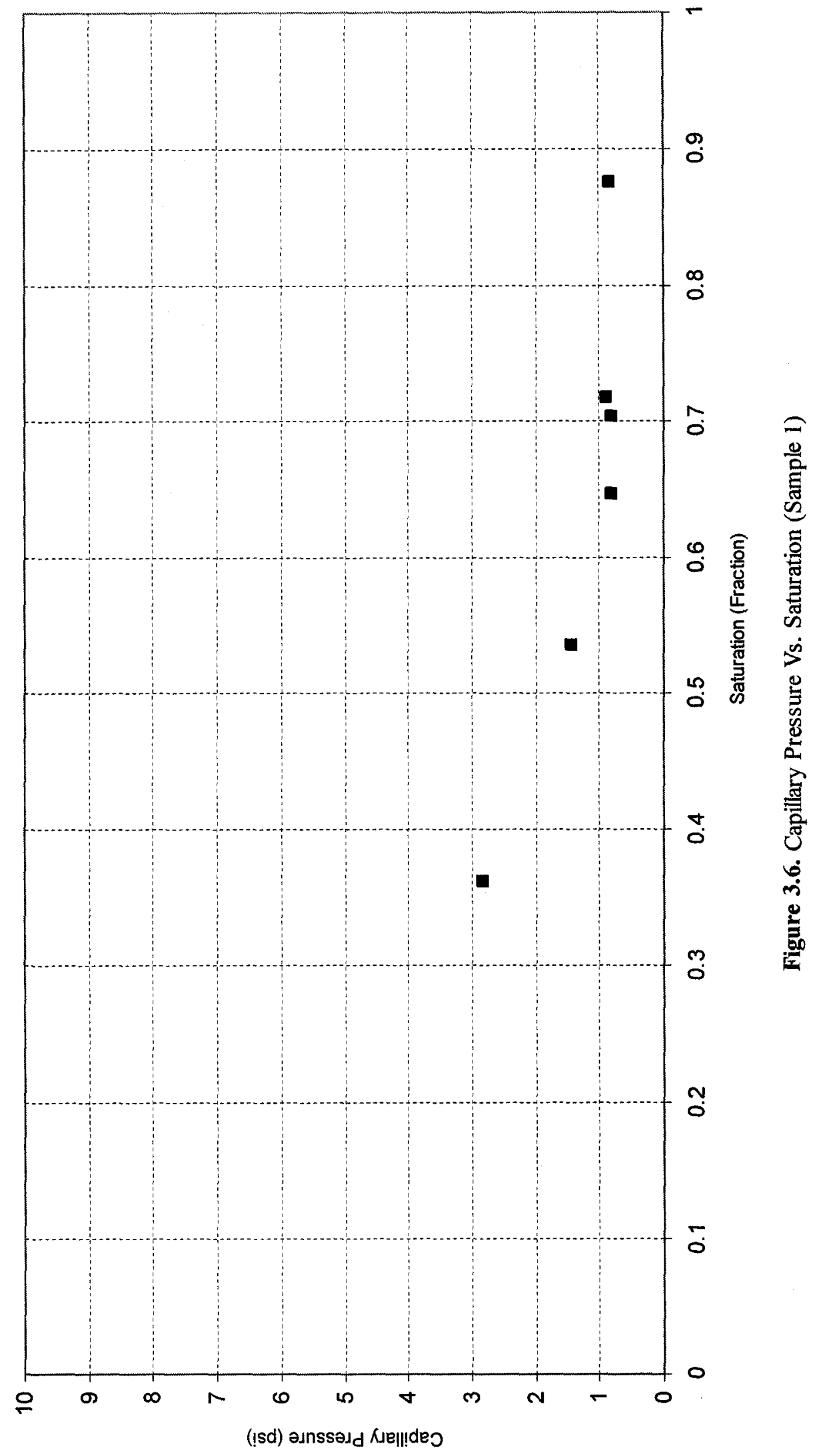

53 


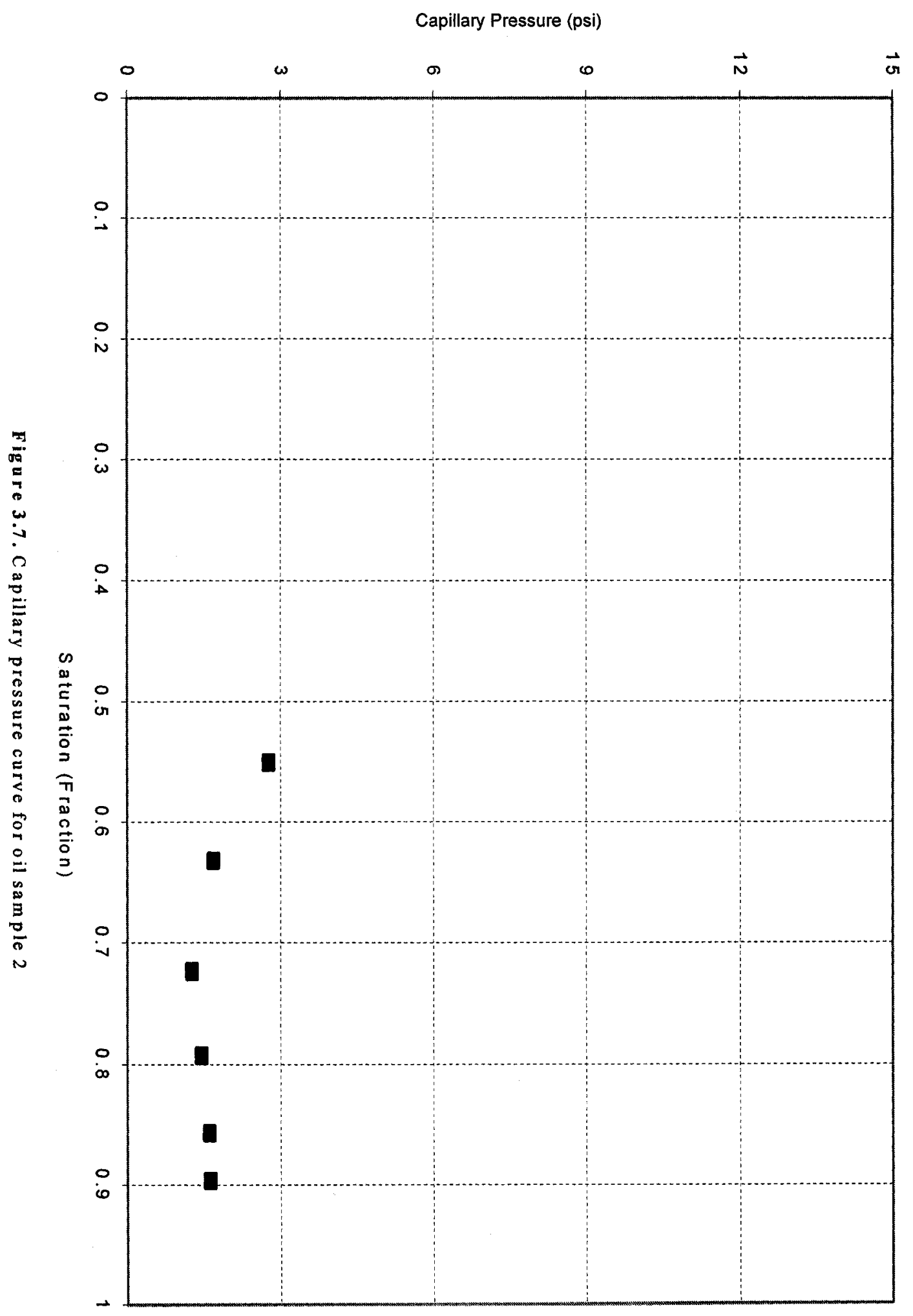


samples 1 and 2 respectively. Ten percent oil weight difference resulted in a viscosity difference of approximately $8 \mathrm{cp}$. Threshold capillary pressure for sample 2 is higher than that for sample 1. Similarity in the shape of the capillary pressure curves demonstrates that capillarity is indeed a property of porous media. Only by observing the flat middle portion of the capillary pressure curve, can it be deduce that the homogeneous porous medium has uniform pore size distribution. Considering the area under the capillary pressure curve, it can be said that a great deal of work is necessary for the oil to displace water, which also depicts a strongly water-wet porous medium (Anderson, 1987).

\subsubsection{Capillary Pressure Utilized for Simulation}

Constructing the capillary pressure curves for the heavy oil samples (Samples 3 and 4) is not possible within the limited scope of the laboratory facilities. High injection pressure makes the employed capillary pressure cell inapplicable for heavy oils. On the other hand, existing impurities within heavy oil undermines the accuracy of the interfacial tension measurement and, hence, eliminates the possibility of applying any capillary pressure correlation techniques (Brooks and Corey, (1964, 1966), Skjaeveland et al., 2000). To overcome this problem, the already derived capillary pressure curves will be fitted into the GEM simulator to identify how two different capillary pressure curves can affect the VAPEX process.

In VAPEX, lighter solvent components diffuse into the oil to continue the dynamic leaching process. Within and surrounding the vapour chamber, the liquid density, viscosity and composition continuously change, and so does the capillary pressure. In 
order to fully understand the effect of capillary pressure on the VAPEX process, the experimentally obtained capillary pressure curves will be utilized, along with all other laboratory data, for each of the oil samples and final results will be analyzed to derive a conclusion. 


\subsection{Vapour Extraction Process (VAPEX)}

In all the VAPEX experiments conducted in this study, butane is used as a solvent because of its low Dew Point pressure, which eventually lowers the actual operating pressure and permits the use of a low pressure, scaled physical model. The process is observed in real time through a transparent cell wall. The low-pressure characteristic of the process can also be utilized in field applications to extract bitumen from very shallow deposits where the cap seal is adequate to hold the pressure (Das, 1995).

\subsubsection{Experimental Set - up}

A low-pressure laboratory model is designed to simulate the VAPEX process in the lab as close as possible to the original reservoir scenario. The interior of the physical model to contain the porous medium has the dimension of 12 in $\times 12$ in $\times 1 / 2$ in. Figure 3.8 shows the components of the model. The two sides available for visualization are made of 1 in thick transparent Acrylic plates. There are holes on both of these plates for horizontal well installation, and, with axial grooves and o-rings on the wells, the holes are prevented from any unwanted leakage. The spacer is placed in between the transparent plates to create the chamber for the porous medium. The spacer has two ports for packing and three holes on each of the remaining two sides for flooding experiments. Available locations for the installation of injector and producer are shown in Figure 3.9. In this configuration, the injection and production wells are located at the center near the bottom edge of the packing, the injector being vertically $31 / 4$ in above the producer. The wells are uniquely designed and are representative of the horizontal well 


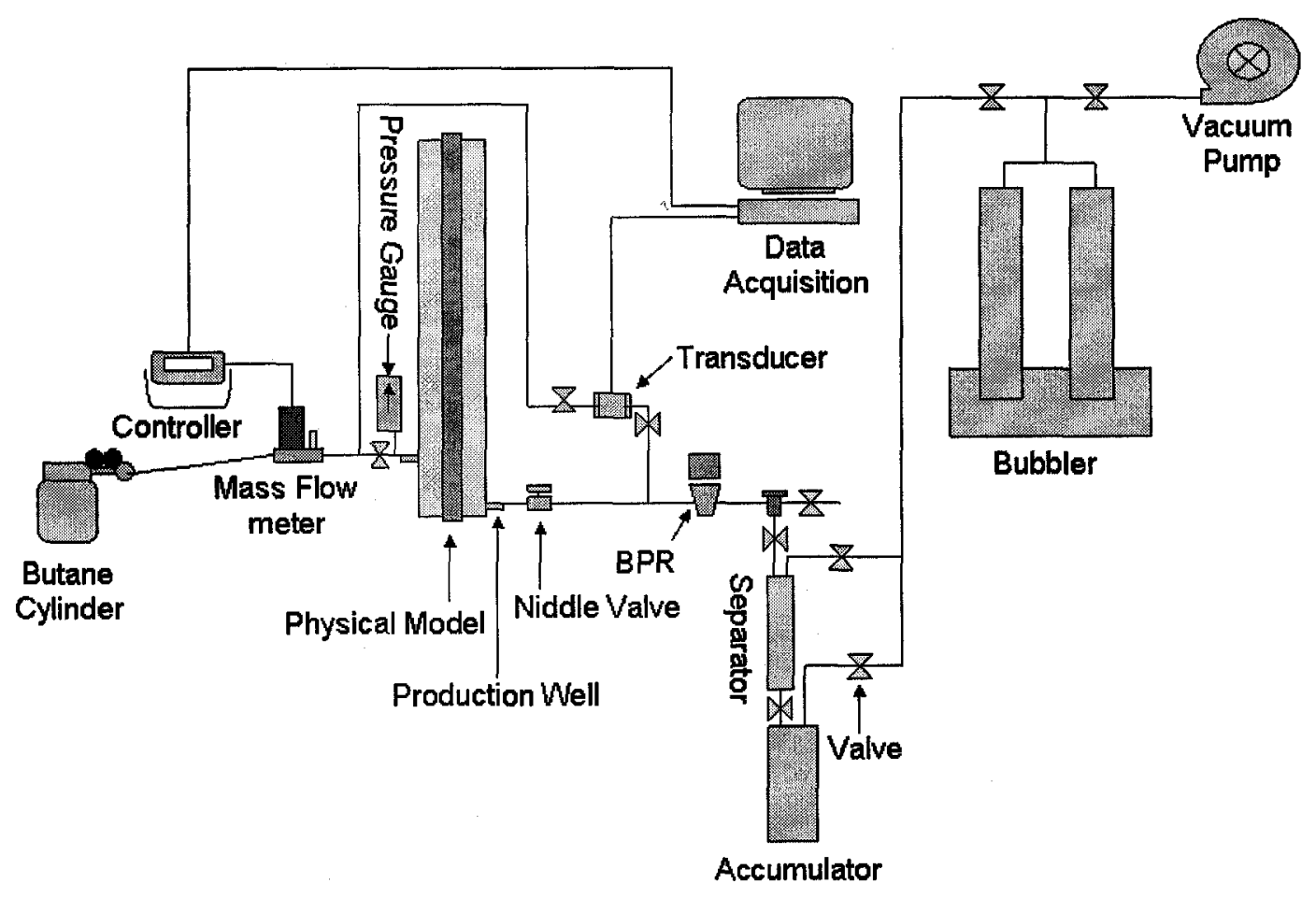

Figure 3.8. Components of the experimental model 


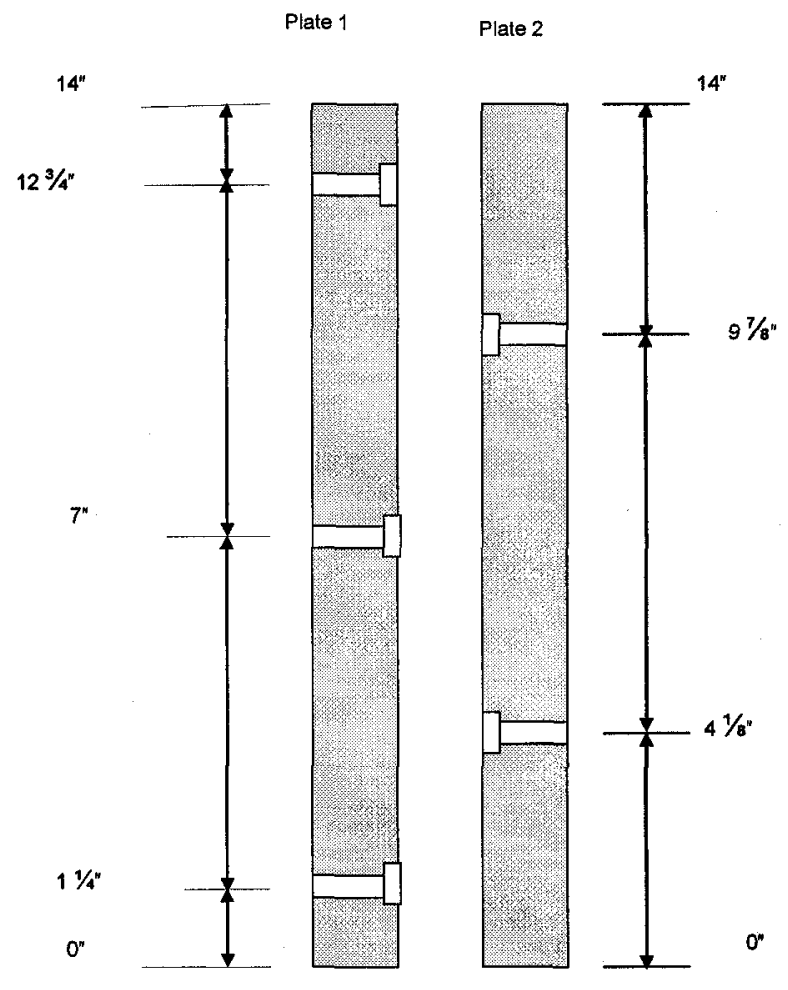

Figure 3.9. Locations of the wells on the glass plates 
concept. This unique characteristic places the experimental model employed in this study a step beyond the previous and contemporary studies. Care was taken to design the wells so that the spherical extensions in the wells sit perfectly in the groove on the Acrylic plates and do not create any barriers in the flow path of the diluted oil. The wells are perforated, and with the help of 200 mesh size screen, are prevented from blockage caused by the sand grains. When installed, the wells are on the same vertical plain, and the ends of the wells are only 1/64 in away from the opposite Acrylic plate. This is done with a view to assume that the wells cover the whole thickness of the reservoir. External clamps are used to force the sheets and spacer together. External supports (Figure 3.10) are also provided on the visual area to prevent any deflection at relatively higher operating pressure. To develop early communication between the injector and producer and also to keep the swept area atop the injector at the maximum, only the bottom two ports are used for well installation.

80-120 US mesh size sands are used as packing in the bed. The cell represents a vertical cross section of the reservoir, and the wells, perpendicular to the vertical section of the reservoir, represent a thin section of original reservoir wells. Butane is supplied from a cylinder suspended in water. The ambient temperature in the laboratory is controlled in the range of $21 \pm 1^{\circ} \mathrm{C}$; butane has a vapour pressure of 31.61 psia at $22^{\circ} \mathrm{C}$. Hence, the operating pressures are well within the range of allowable pressure.

An ALBOG flowmeter (Model No. AFC 26) with controller and totalizer, was attached to the injection line. To simulate ideal VAPEX, which is mainly guided by gravity 


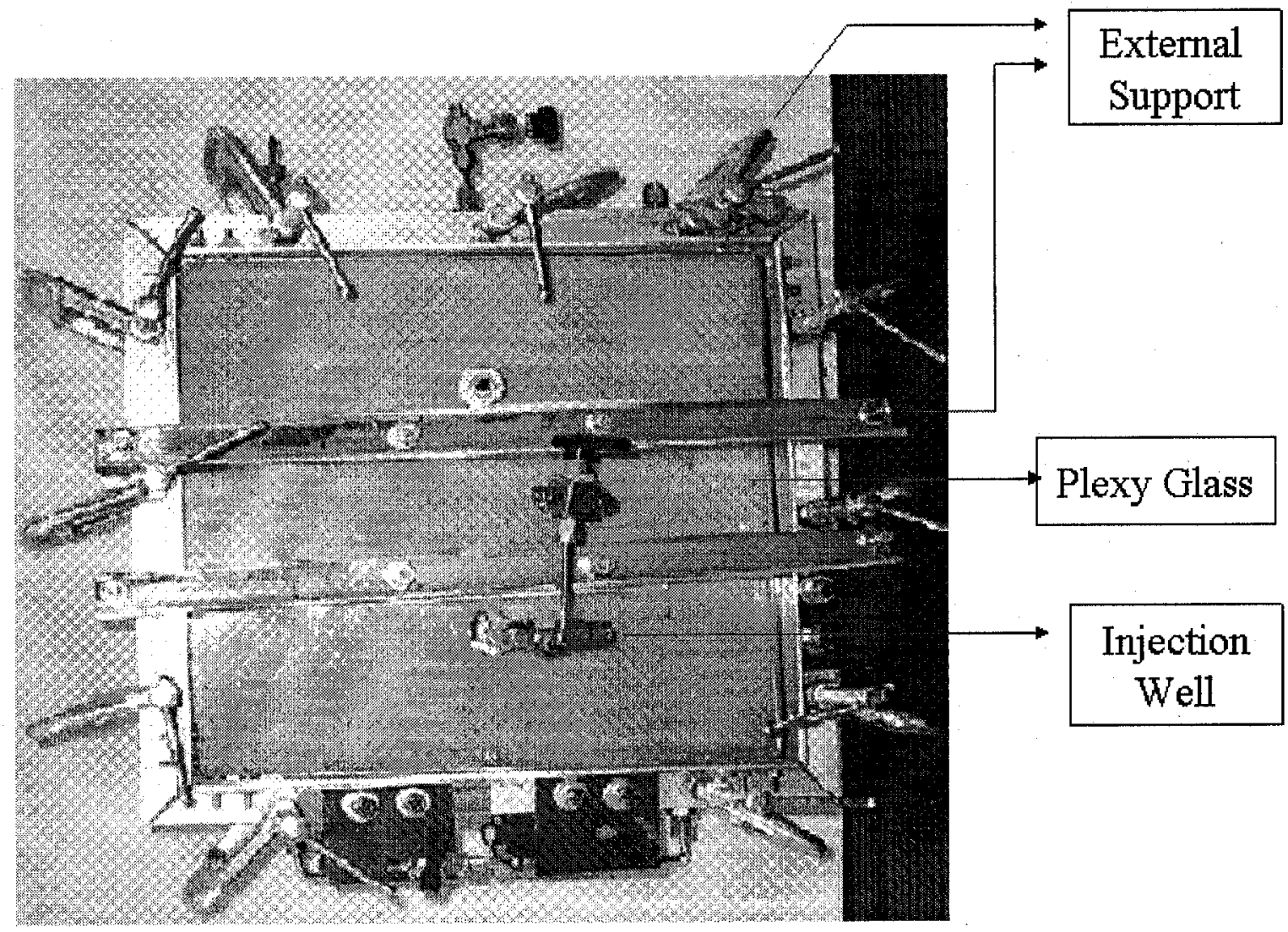

Figure 3.10. Visual cell with the wells and external components installed 
drainage, a Swagelok backpressure regulator (BPR) is attached to the production line. With the help of this back pressure regulator and Validyne pressure transducer (Pressure range: $0-12.5 \mathrm{psi}$ ), both ends of which are connected to the injection and production line, a differential pressure within the range of $0.1-0.25$ psi is allowed in order to help maintain the oil flow rate. The additional components attached to the BPR on the production end are the separator and accumulator. The separator is connected to the BPR, which, with the help of a three-way valve, also allows an option of connecting a Gasometer online with the production string to periodically measure the producing GOR. The accumulator, which is the last physical component in the system, basically contains the produced oil long enough time to get rid of the solution gas. Both the separator and accumulator are connected to the bubblers for trapping the produced gas.

\subsubsection{Experimental Procedure}

To prepare the model for an experimental run, the acrylic plates and spacer are attached together after the installation of horizontal wells at proper locations. Then, the empty cell is clamped with a vibrator and is vibro-packed with the desired size of sand. Water is then introduced at a very slow rate from the bottom of the physical model. Once $100 \%$ water saturation is achieved, the model is dried overnight by allowing air to flow from the top and by producing water from the bottom. Once fully dried, a void chamber atop the porous medium is created for additional sand intake. Then, the newly created void space is vibropacked with the same sand grain, vacuum is applied, and water is introduced from a burette to the porous medium. When water imbibition stops, $100 \%$ water saturation is recorded from the burette. Three pore volumes of water are injected to expel residual air 
bubbles from the sand pack. The physical model is then left for two days in each of the experimental runs for creating the same saturation history. The next stage begins with the injection of oil sample at a rate as low as $0.5 \mathrm{ml} / \mathrm{min}$ from the top and producing water from the bottom. Produced water is collected in graduated cylinders, which later on makes it possible for calculating initial oil saturation within the porous medium. For reaching the accurate irreducible water saturation $\left(S_{\text {wirr }}\right)$, 3-pore volume of oil sample is injected.

Pure n-butane is introduced at its cylinder pressure and at room temperature through the injection well into the system for initial pressurization. At each 1-hour interval, a valve attached to the production line is opened to check the diluted oil movement in the production line. A trace of oil in the production line indicates the initiation of the VAPEX process. Any decrease in pressure due to consumption in the packed model is compensated by the supply of fresh vapour from the supply cylinder. Volumetric oil and gas production at intervals of every two to three hours are recorded from the separator and bubblers, respectively. Oil collected during the GOR calculation is also considered in recovery calculation.

The weight of the butane cylinder is recorded each time the production is collected and is double checked with the totalizer value displayed by the flow meter controller on the computer monitor. The weight of the oil sample emptied from the separator is considered as the live oil production. After the successful run of the each experiment, the lid of the accumulator is kept loose to vent dissolved butane until the weight becomes almost constant. The final weight, considered as being the weight of produced oil (dead oil) 
is recorded. Unless mentioned otherwise, the weight of the dead oil is reported.

Viscosity and density of the original oil sample and corresponding produced oil for each experiment are measured. Oil sample having viscosities of $5800 \mathrm{cp}$ (sample 3), $14400 \mathrm{cp}$ (sample 4) are used as the targeted oil for the two experimental runs.

\subsubsection{Results of the Visual Cell Experiments}

The experimental conditions for Samples 3 and 4 are summarized in Table 3.4. In the well configuration employed in these experiments, after a short period of pressure displacement, the vapour chamber rises and spreads sideways as the extraction continues. After the chamber reaches the top of the reservoir, it spreads sideways until the reservoir boundary is reached. Figure 3.11 represents the snap shot of the VAPEX experiment when the vapour chamber is visible from outside. Within the swept zone, residual oil saturation is almost negligible, as can be seen from the color of the porous medium.

The oil production rates and GORs are plotted with respect to time for both of the oil samples, given in Figure 3.12 and 3.13, respectively. The initial higher drainage rates and GORs are due to the displacement process occurring, because of the pressure gradient between the injection and production wells, until the solvent breakthrough occurs and pressure at the production end becomes almost equal with the injection pressure. After gas breakthrough, the only driving mechanism is gravity drainage, and the production rates become more or less stabilized. 
Table 3.4. Initial Experimental Conditions

\begin{tabular}{|l|c|c|}
\hline & VAPEX I & VAPEX II \\
\hline Oil Sample \# & 3 & 4 \\
\hline Oil Sample & Oil by $90 \%$ weight & Oil by $95 \%$ weight \\
\hline Viscosity of sample $(c p)$ & 5800 & 14400 \\
\hline Temperature $\left({ }^{\circ} \mathrm{C}\right)$ & 21 & 21 \\
\hline Pressure $(p s i a)$ & 31 & 31 \\
\hline Irreducible Water Saturation $(\%)$ & 14.32 & 8.69 \\
\hline
\end{tabular}




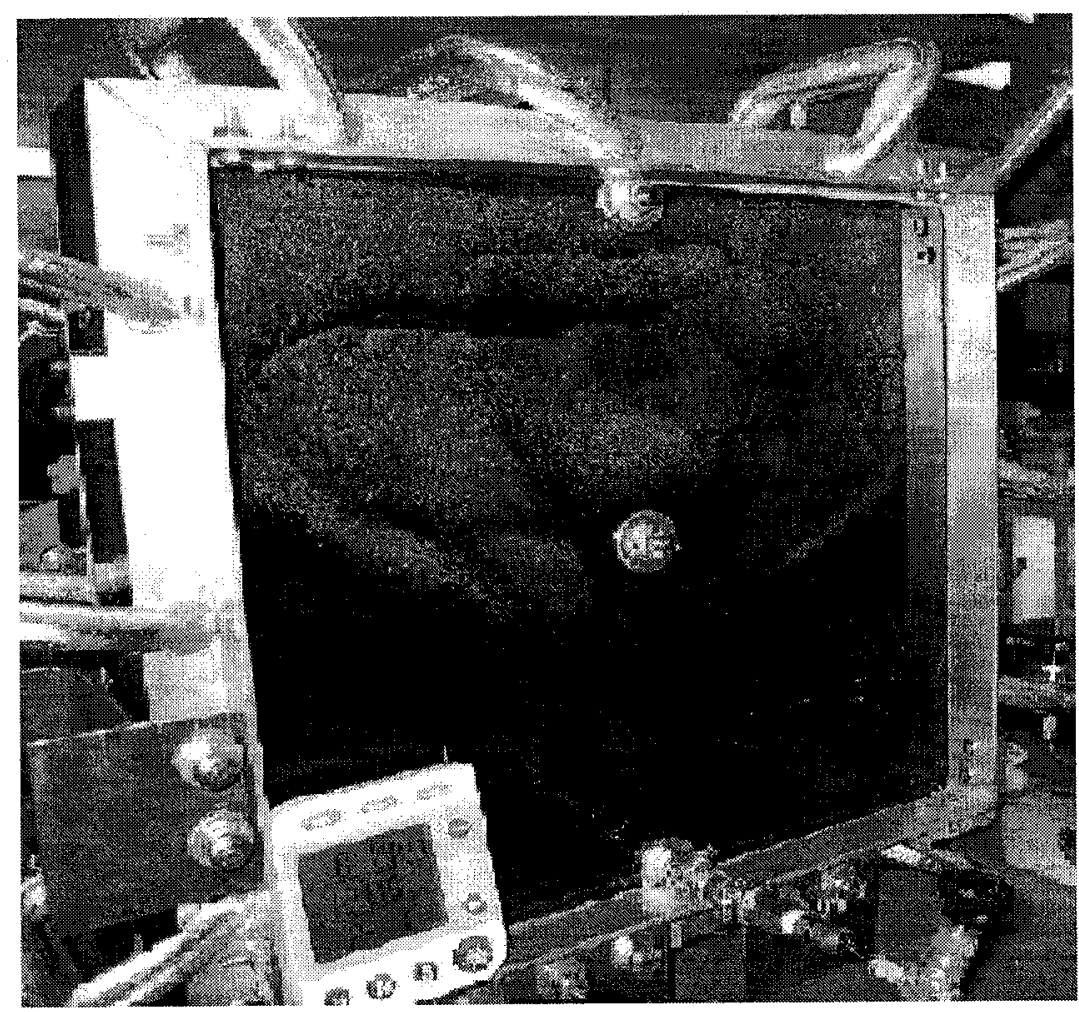

Figure 3.11. Growth of the vapour chamber 


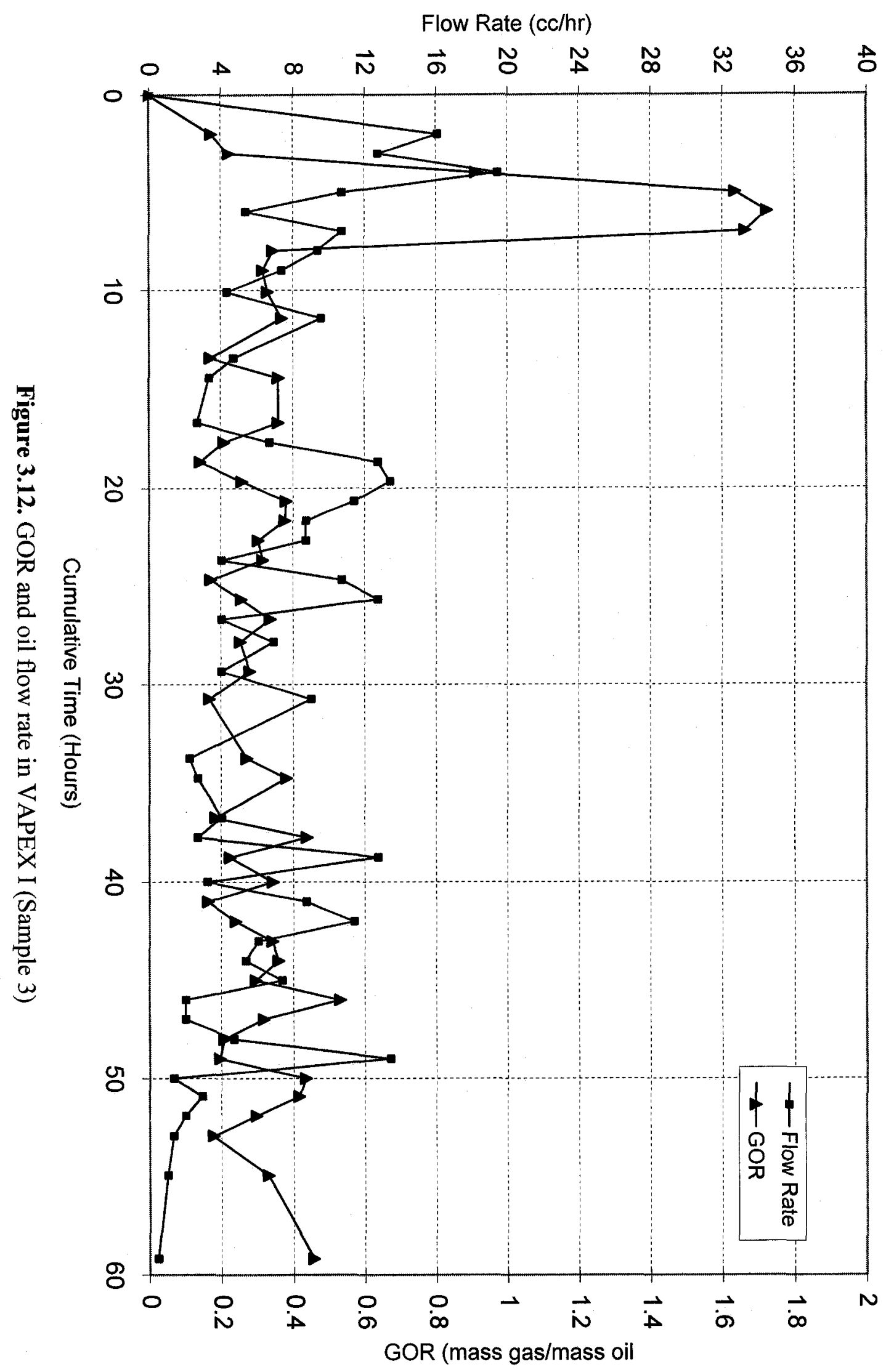




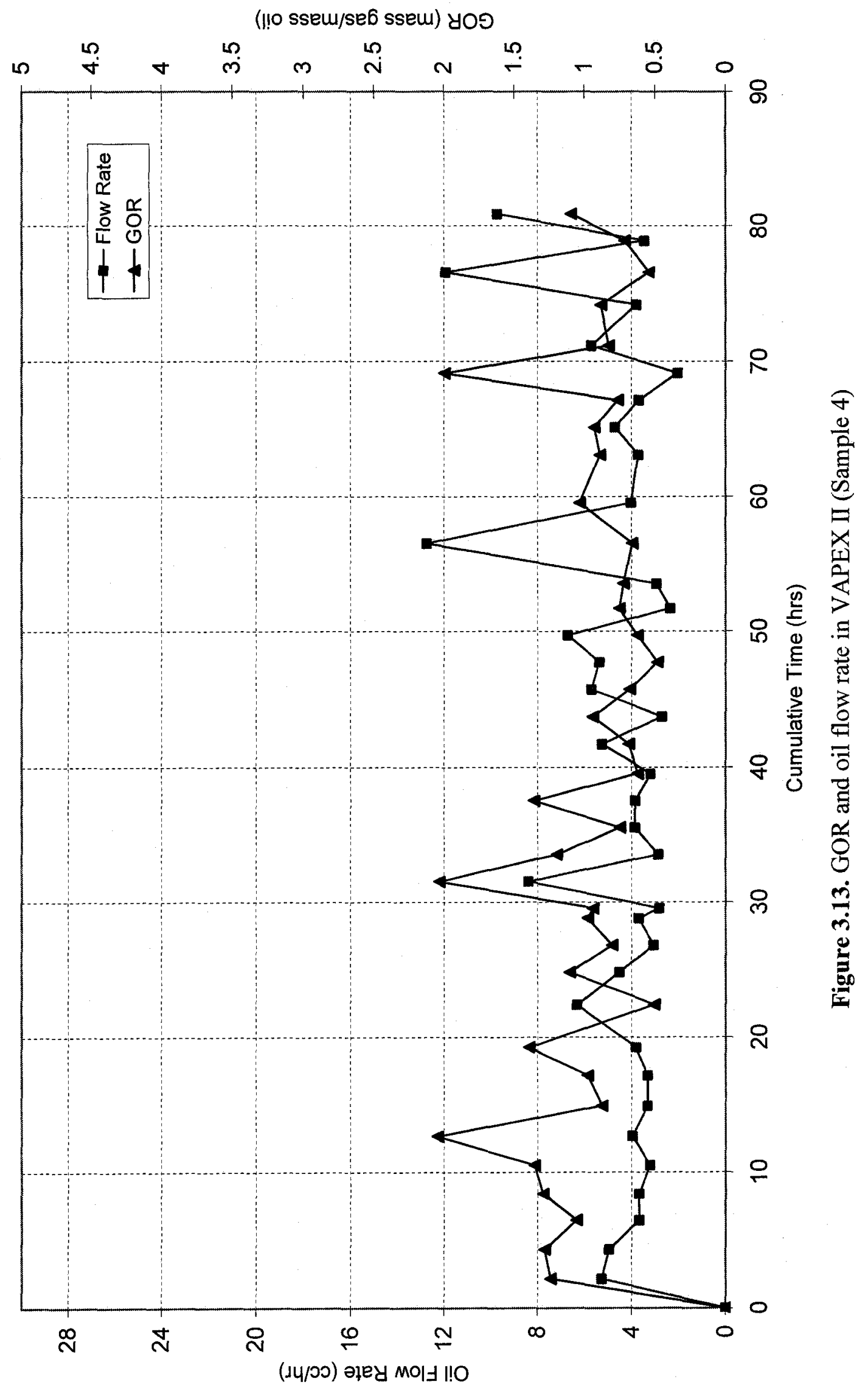


This concept is more predominant in the case with the lower viscosity oil sample. Fluctuations within the stabilized flow rates are due to the difficulties in temperature control, which in turn cause some viscosity variation. Also, asphaltene precipitation can be another factor causing the rate fluctuation that was observed in the experiments, especially when the whole set-up is dismantled after the termination of the experiments. The maximum amount of asphaltene precipitation occurs around the production well, which also causes the oil flow rate to drop drastically and GOR to reach its maximum. Whenever this situation is encountered, the niddle valve attached to the production string is turned off to let the diluted oil accumulate around the production well. Care has been taken to keep the shut-in time equal to the preceding production time. When the experiment resumes, an increase in oil flow rate and decrease in the GOR is observed. The second VAPEX experiment with sample 4 was terminated after 80 hours, with the assumption that sufficient data points have been collected to generate a trend to match the simulation results.

Average drainage rate within the stabilized production interval is higher in the low viscosity oil sample. This is logical, as oil drainage rate, previously defined by Butler, in 1991, and later modified by Maini, in 2004, is proportional to diffusivity, which in turn is inversely proportional to oil viscosity (Butler and Das, 1996; Mehrotra and Upreti, 2002). Approximately $425 \mathrm{~g}$ of butane is needed to produce $70 \%$ of the OOIP for sample 4 , whereas only $290 \mathrm{~g}$ butane is injected to gain the same recovery in the case with sample 3. The experimental run with the heavier oil sample is conducted for 20 additional hours to reach the same recovery as the run with the lighter oil sample. Table 3.5 lists the 
injection-production scheme of the solvent and oil for each of the VAPEX experiments. Viscosity and density of the produced oil are lower than the original oil sample and are listed in Table 3.6. Cumulative live oil productions with respect to time are plotted in Figure 3.14. 
Table 3.5. Injection - production scheme for the Experiments

\begin{tabular}{|l|c|c|}
\hline & VAPEX I & VAPEX II \\
\hline Total live oil produced $(g)$ & 358.50 & 371.67 \\
\hline Total dead oil produced $(g)$ & 289.85 & 313.95 \\
\hline Butane Injected $(g)$ & 291.44 & 424.55 \\
\hline Butane produced as free gas $(g)$ & 178.00 & 350.82 \\
\hline Solvent to Oil Ratio (mass/mass) & $1: 1$ & $1.3: 1$ \\
\hline
\end{tabular}

Table 3.6. Density viscosity information

\begin{tabular}{|l|c|c|}
\hline & VAPEX I & VAPEX II \\
\hline Original Oil Viscosity $(c p)$ & 5800 & 14400 \\
\hline Original Oil Density $(g / c c)$ & 0.963 & 0.985 \\
\hline Produced Oil Viscosity $(c p)$ & 2194 & 6334 \\
\hline Produced Oil Density $(g / c c)$ & 0.960 & 0.974 \\
\hline
\end{tabular}




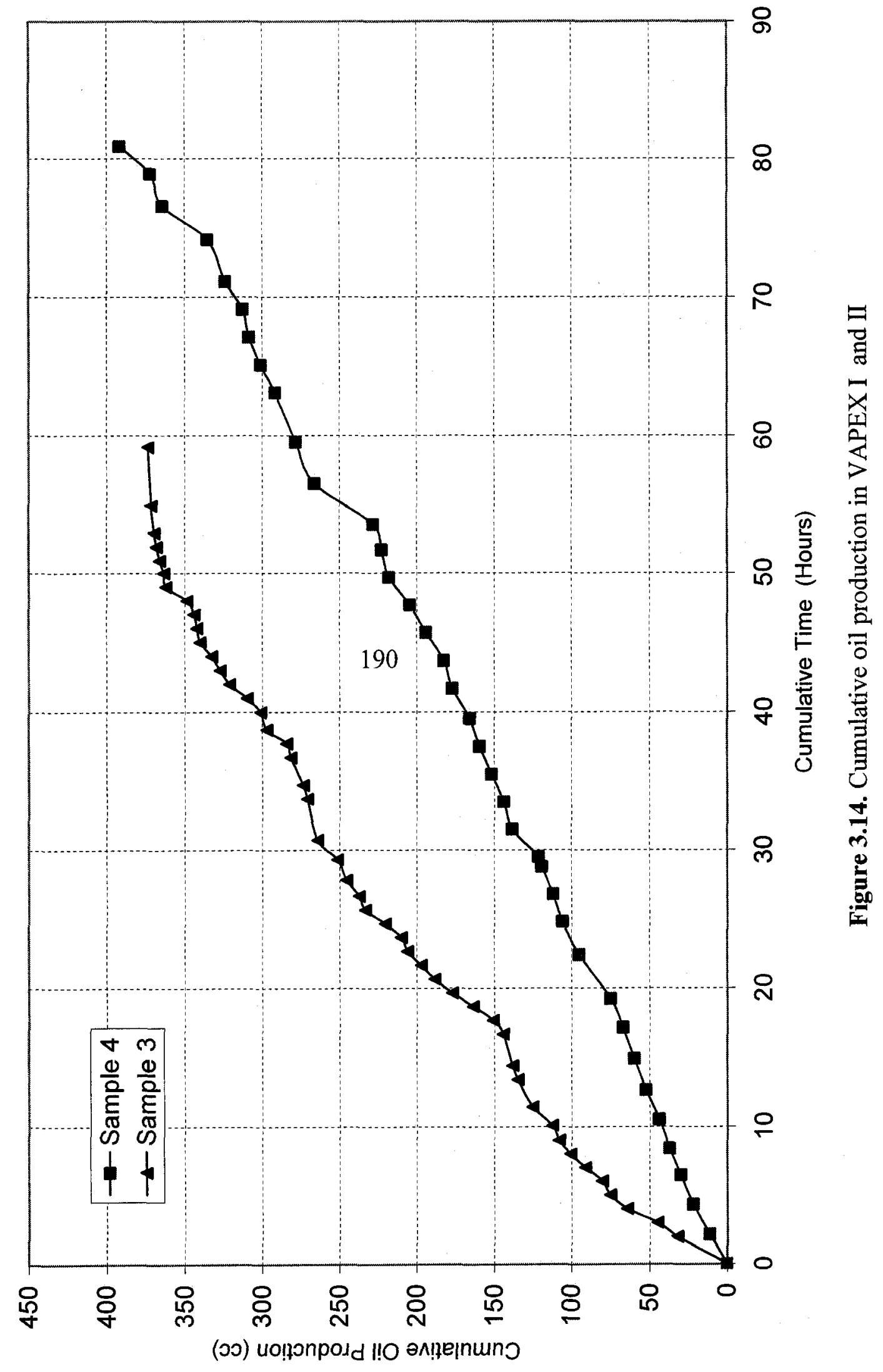




\subsection{Relative Permeability}

Water and oil relative permeabilities are calculated using data obtained through flooding experiments from a sand-pack model by applying the JBN method described earlier.

\subsubsection{Experimental Set - up}

The experimental set-up can be best described with the help of Figure 3.15. Two ends of the sand-pack are connected to the two sides of the Validyne Pressure Transducer for automated differential pressure data acquisition. The outlet end of the sand-pack is connected to a Fraction Collector, able to collect a maximum of 1.5 litres of affluent at a pre-programmed time interval. The injection end, on the other hand, is connected conjugately, with the help of a 3-way valve, to two cylinders, one containing the oil sample and the other containing injection water. The core holder (Table 3.7) contains the desired porous medium (80-120 mesh Ottawa sand) for the linear flooding experiment.

\subsubsection{Experimental Procedure}

The core-holder is initially vibro-packed with 80-120 mesh size Ottawa sand and, after vacuum is applied, is saturated with water. Considering the dead-end volumes and volumetric amount of injected water, the $100 \%$ water saturation (also pore volume) is calculated. The saturated sand-pack is left for two days to create the same saturation history as the VAPEX and Capillary experiments. The sand-pack is then positioned horizontally, and after completing the experimental set-up described in Figure 3.15, oil is injected slowly into the system and water is collected in the fraction collector. To reach 


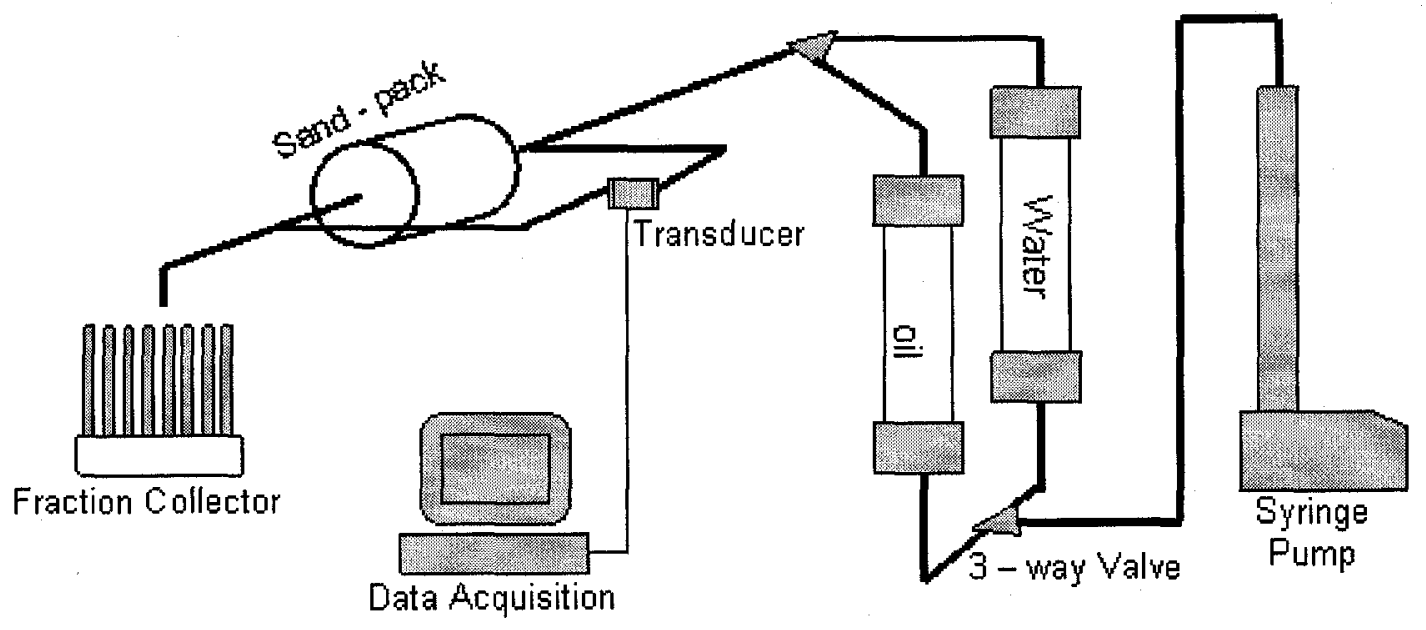

Figure 3.15. Schematic of the relative permeability experiment 
Table 3.7. Dimension of the Core - holder

\begin{tabular}{|c|c|c|c|}
\hline Length $($ in $)$ & Diameter $($ in $)$ & X-area $\left(i n^{2}\right)$ & Dead end vol. $(c c)$ \\
\hline 5.65 & 1.675 & 2.204 & 4 \\
\hline
\end{tabular}


the irreducible water saturation, 3-pore volume of oil is injected to displace water. Table 3.8 lists the initial flooding and saturation data for both of the experiments.

Once irreducible water saturation level is achieved, water is injected to displace oil and pressure data are recorded with the computer. Initial affluent collection time intervals are shorter than the latter. This is done with an intention to locate the time of water breakthrough. Water and oil flow rates at the outlet are calculated by visibly inspecting the affluent collected in the Fraction Collector.

Adverse mobility ratio undermines the flooding experiment and results in much higher residual oil saturation $\left(S_{o r}\right)$ than anticipated for both of the experiments. Wang et al., in 2006 , stated that, theoretically, thousands of pore volumes of water are required to reach the precise residual oil saturation, which cannot be achieved in flooding experiments. This error is overcome in GEM by extrapolating the relative permeability curves to the desired $S_{o r}$, and those extrapolated values are used in the simulation of VAPEX.

\subsubsection{Experimental Results}

Two floods were run on the sand-pack model at oil-water viscosity ratios of 5800:1 (Sample 3) and 14400:1 (Sample 4). First, affluent collected in the fraction collector is utilized to plot the $f_{W}$ vs. $S_{W}$ data points and the best line to fit the data points is plotted to derive the fractional flow curve (Figure 3.16 and 3.17). Points lying on the fractional flow curve are used for further manipulation. Cumulative water injected at each step is converted to equivalent pore volume $\left(W_{i}\right)$. By making use of the pressure data and 
Table 3.8. Initial Saturation Information

\begin{tabular}{|l|c|c|}
\hline & Experiment 1 & Experiment 2 \\
\hline Oil Viscosity $(c p)$ & 5800 & 14400 \\
\hline $100 \% S_{W}(c c)$ & 78.6 & 78.6 \\
\hline$S_{W C}(\%)$ & 14.78 & 8.97 \\
\hline Oil Injection Rate $(c c /$ min $)$ & 0.5 & 0.4 \\
\hline
\end{tabular}




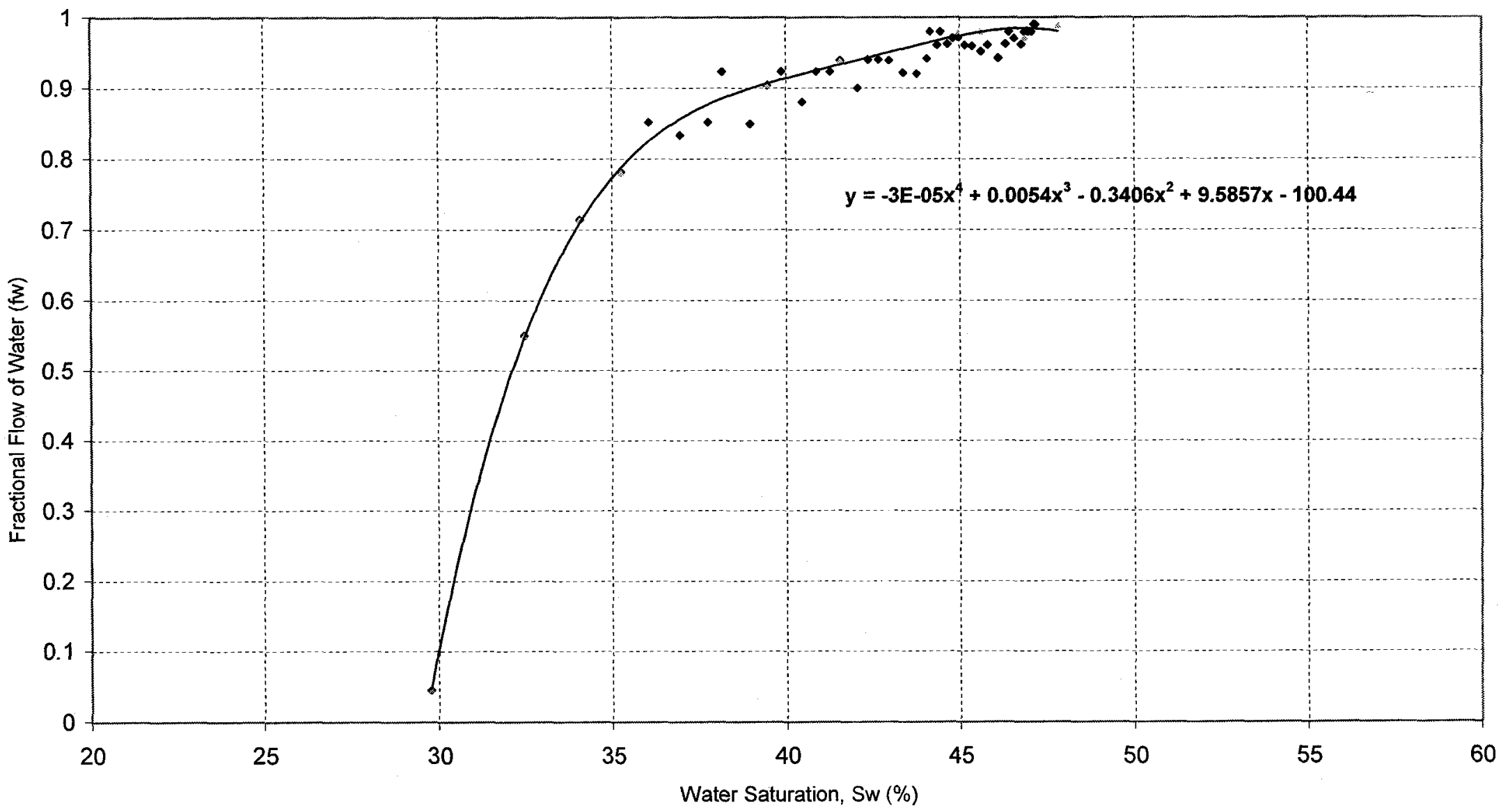

Figure 3.16. Fractional flow curve for sample 3 (90\% Oil) 


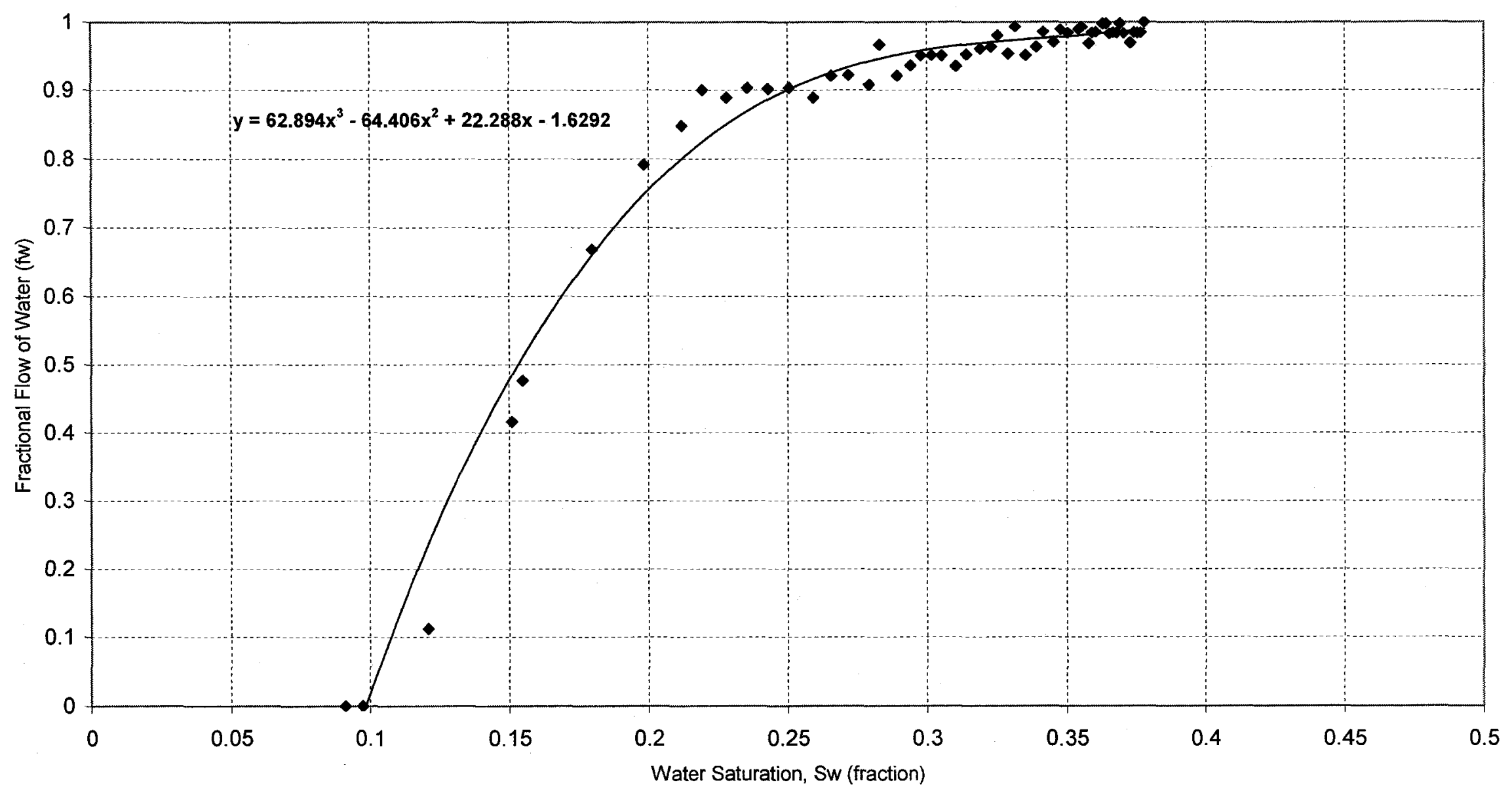

Figure 3.17. Fractional flow curve for sample 4 (95\% Oil) 
dimension of the sand-pack, relative injectivity at each saturation level is calculated. $1 /\left(I_{r} x W_{i}\right)$ vs. $1 / W_{i}$ is plotted (Figure 3.18 and 3.19 ), and from the equation of the bestfitted line, $d\left(1 / I_{r} W_{i}\right) / d\left(1 / W_{i}\right)$ at each saturation level is easily calculated. Obtained values are plugged into Eqn. (3.3.1.11) to calculate corresponding $k_{r o}$, and, thereafter, by inserting the values in Eqn. (3.3.1.12), corresponding $k_{r w}$ values are calculated. Data thus obtained are plotted against saturation to derive the complete relative permeability curve (Figure 3.20 and 3.21 ) for both of the experiments. Because flooding behavior is dependent on viscosity ratio, the calculated relative permeability curves covered a different range in saturation for each of the floods.

The theoretical investigation by Kevin $\mathrm{Li}$, in 1988, showing that the effect of oil/water viscosity ratio on relative permeabilities of non-wetting phase is large is rightly proved by the relative permeability experiments conducted using two different ratios of fluidfluid system. For instance, at instantaneous wetting phase saturation of $40 \%$, the nonwetting phase relative permeabilities are found to be 0.7 and 0.2 , for Sample 3 and Sample 4 , respectively, whereas, the wetting phase relative permeabilities coincided at 0.0008. Experimental data shows a trend of higher non-wetting phase relative permeability for the lower oil/water viscosity ratio than the higher one. Very low wetting phase relative permeability values make the phase immobile in the simulation run and viably supports the assumption of only oil production during the original VAPEX experiment. 


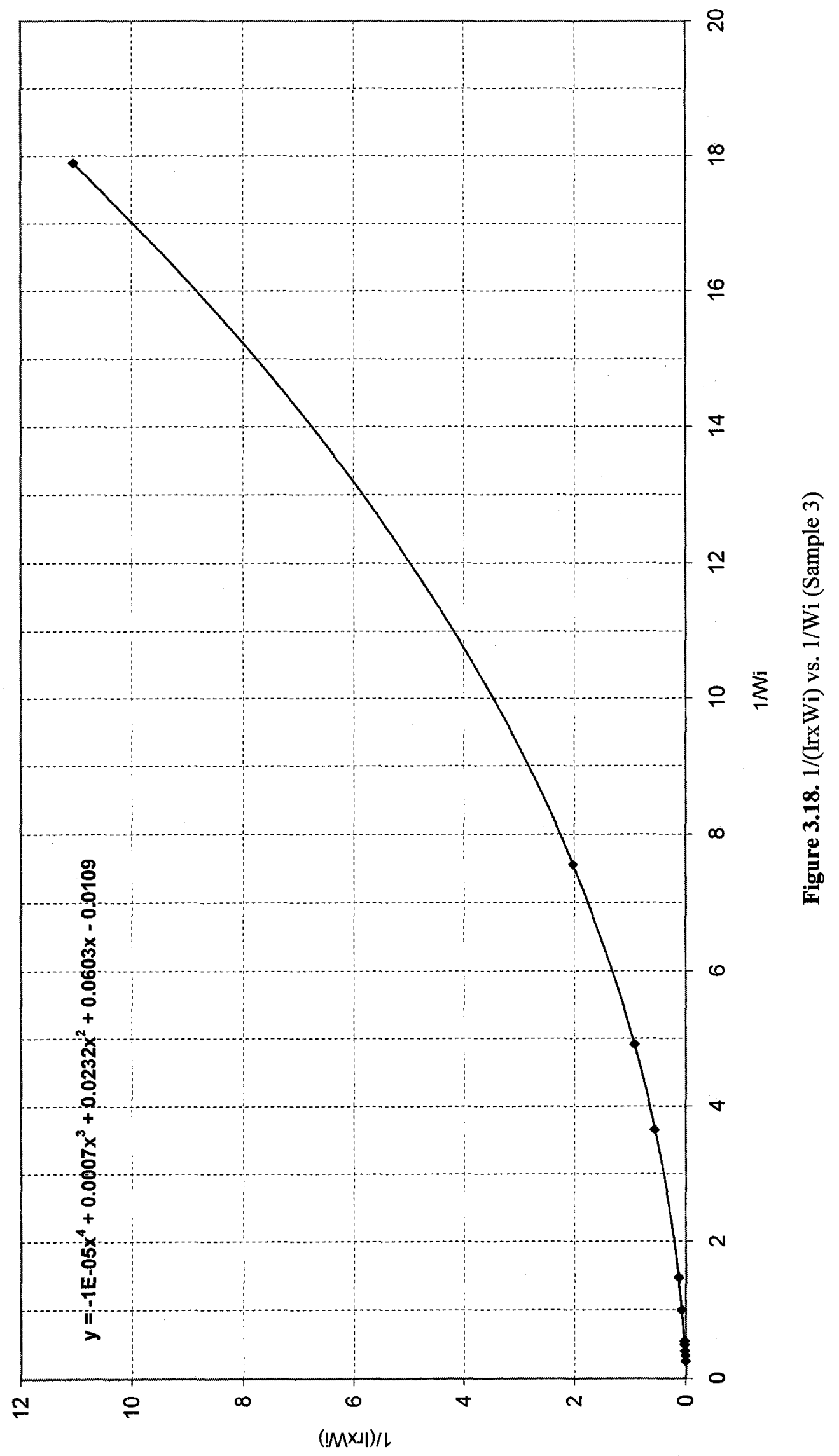




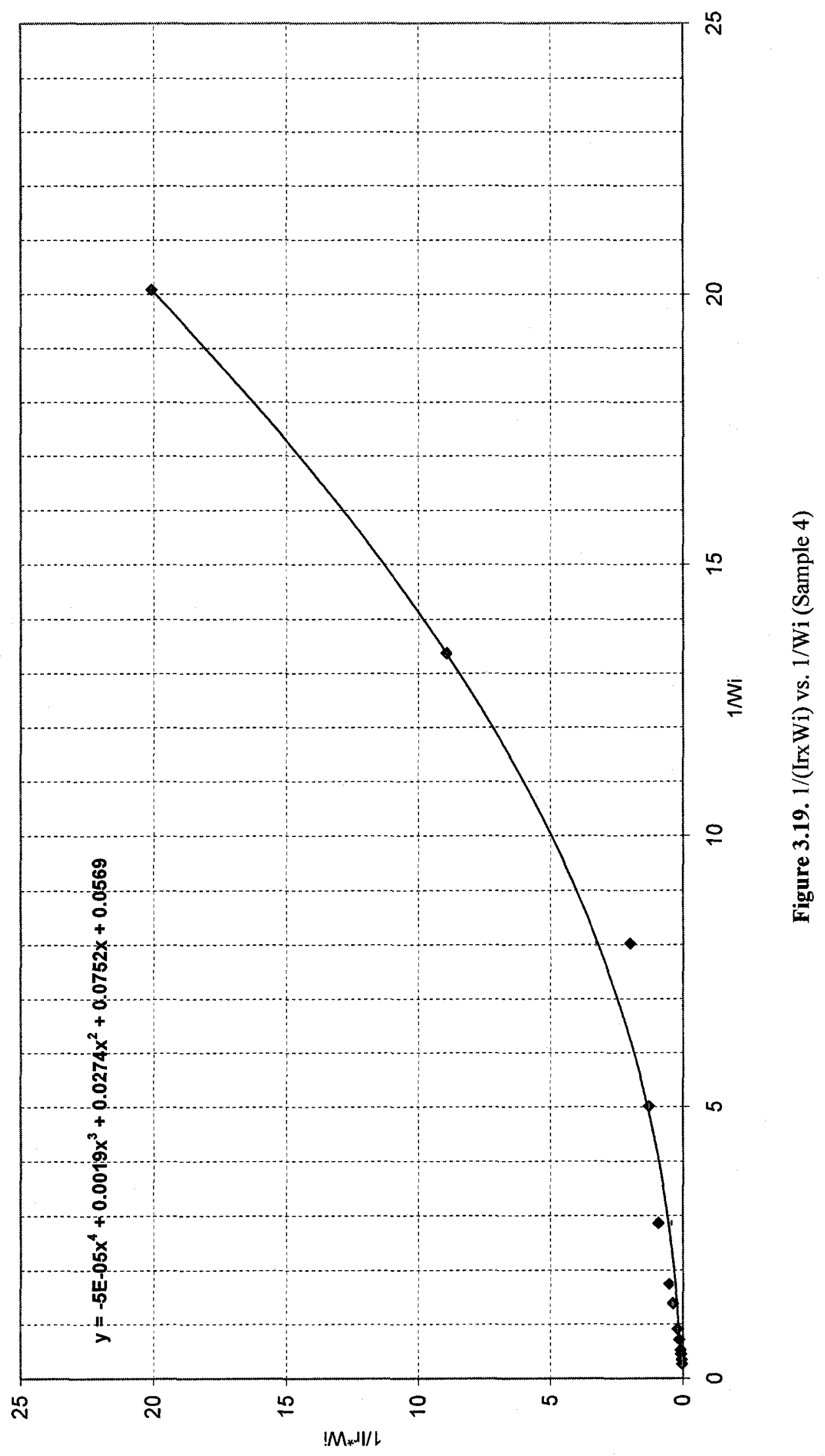




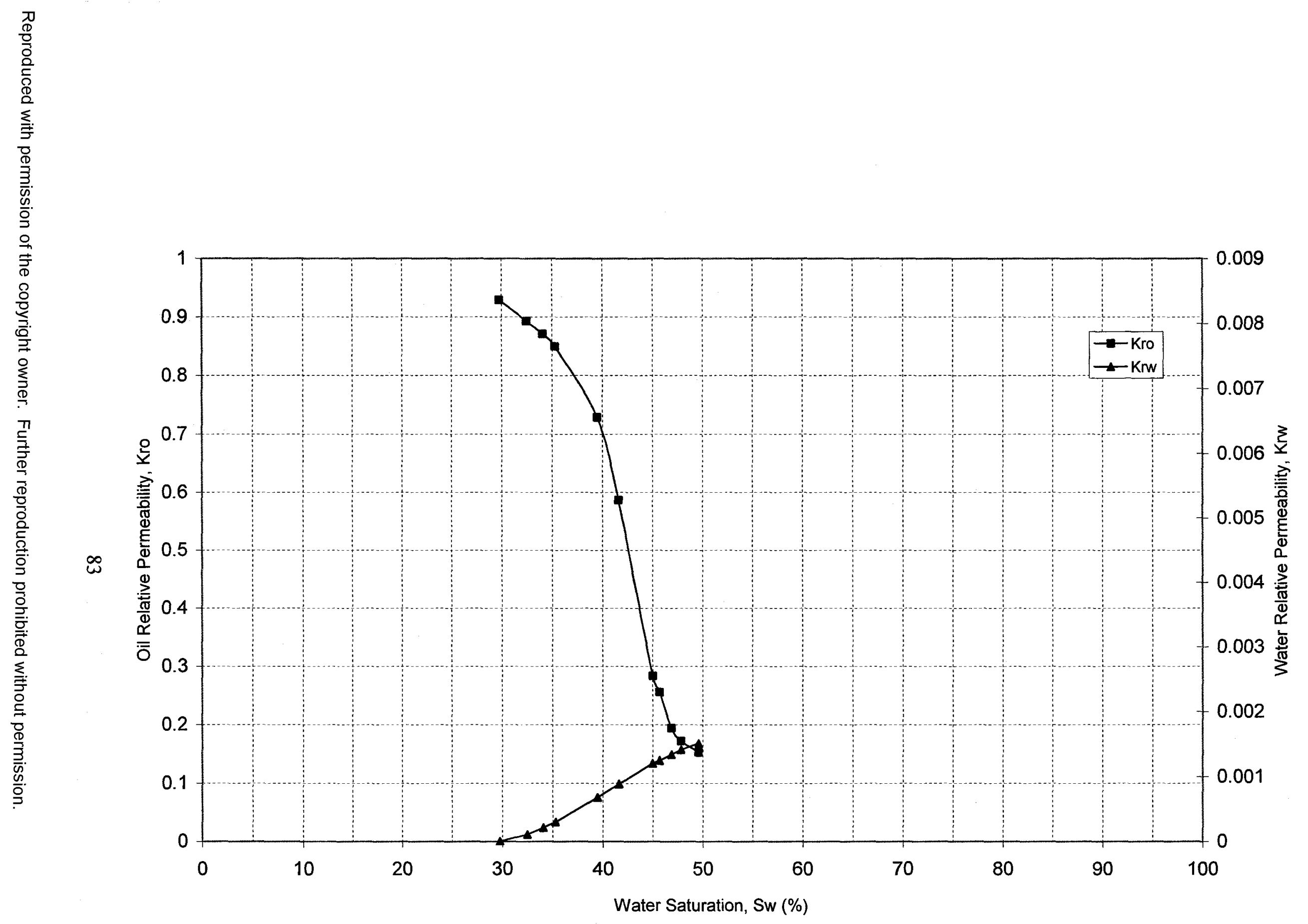

Figure 3.20. Relative permeability for sample 3 


\section{SIMULATION IN GEM}

\subsection{Introduction}

Effect(s) of Capillary Pressure on VAPEX can not be determined by experimental studies alone due to the complexities therein and absence of direct relationships among the derived data. Numerical simulation can be the only means of linking the experimental data to reach a conclusion. In view of this, GEM was employed as a means to study the experimental data because it was developed to simulate compositional effects of reservoir fluid during primary and enhanced oil recovery processes. Compositional simulation allows the composition of the liquid or gas phases to vary in adiabatic condition and, hence, calculates different properties for each of the phases as the composition changes, usually as a result of pressure changes in different parts of the reservoir.

\subsection{Builder}

Builder is a MS-Windows based softwere tool, wused to create simulation input files (datasets) for GEM. Builder covers all areas of data input, including creating and importing grids and grid properties, locating wells, importing well production data, and importing or creating fluid models, rock-fluid properties, and initial conditions. Builder contains a number of tools for data manipulation, including creating tables from correlations and data checking. It also allows visualizing and checking of data before the running of a simulation. 


\subsubsection{Reservoir}

The first section in the Builder named as 'Reservoir Description', describes in detail how to create and modify a simulation grid and also to how specify and assign properties to each grid block. To simulate the physical model used for experimental studies, a Cartesian griding system is chosen. Along $i, j$, and $k$ axes 15,1 , and 15 grids are assigned, respectively. The thickness of each grid block along $i, j$, and $k$ axes are $0.0667,0.0417$, and $0.0667 \mathrm{ft}$ respectively. Each grid block, excluding the blocks that are the housings for the horizontal injector and producer, is again divided into 3 more blocks along the $i$ and $k$ axes with the help of the 'Refine Griding System'. Keeping only one block along the $j$ axis makes the physical model 2-dimensional. Initial reservoir conditions (Pressure and Temperature) and reservoir properties (Absolute Permeability and Porosity) are defined in this section. Compressibility of the porous medium is obtained from the study conducted by Jerry et al., in 1997, and is presented in Figure 4.1.

\subsubsection{Components}

This section of the simulator discusses creating and editing fluid models, PVT, and components used by GEM. The available component properties data exported to Winprop for editing can be saved and re-imported into Builder. All hydrocarbon phase properties are calculated using an equation of state (EOS). The basic properties needed for EOS calculations are the critical properties of each component and the interaction coefficient $\left(D_{i j}\right)$ of each component pair. The critical properties $\left(P_{c}\right.$ and $\left.T_{c}\right)$ are generally not known for User Defined Components. They may be estimated internally in GEM by using built in correlations based on other properties such as $S_{g}, T_{b}$, and $M W$. Unavailability of 


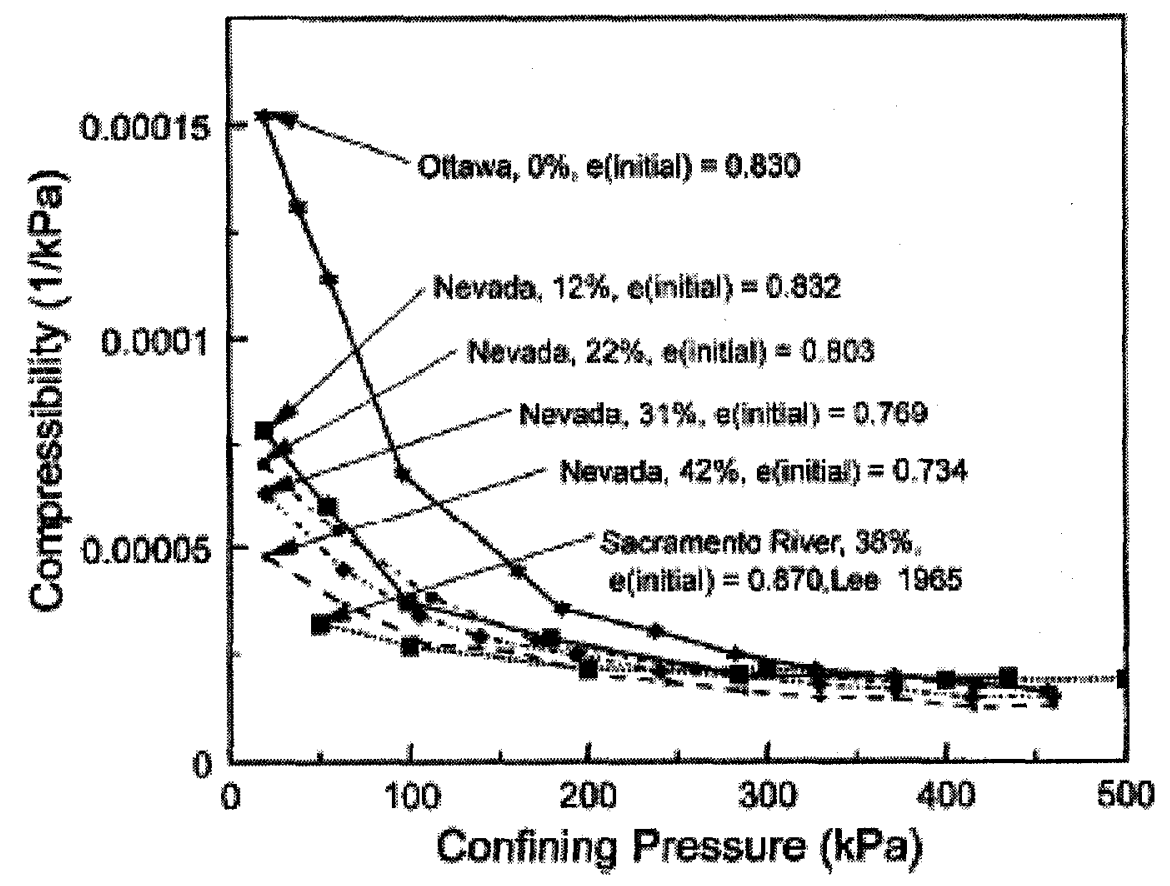

Figure 4.1. Isotropic compression tests on different sands 
compositional analysis of oil samples 3 and 4 leads to the assumption that similar viscosities and densities of oil will have nearly identical complete sets of capillary pressure curves and similar time dependent oil flow rates in VAPEX, where the latter assumption was previously supported by Maini in 2004 .

\subsubsection{Oil Sample Generation in Winprop}

Based on the original oil composition found in a paper written by Luo et al in 2005, two different oil samples were simulated, and viscosities and densities were kept as close as possible to the original samples. To achieve this, the composition of the extracted sample presented in Table 4.1 is fed in Winprop, and single-phase fluid properties are calculated under the same temperature and pressure $\left(1\right.$ atmosphere and $\left.23.9^{\circ} \mathrm{C}\right) . \mathrm{C}_{45^{+}}$is user defined based on $\mathrm{S}_{\mathrm{g}}, \mathrm{T}_{\mathrm{b}}$, and MW. Initially, $\mathrm{S}_{\mathrm{g}}, \mathrm{T}_{\mathrm{b}}$, and $\mathrm{MW}$ values are assumed as $0.988,1100^{\circ} \mathrm{F}$ and 650 respectively. These assumed values resulted in much higher viscosity and much lower density (150,000 $\mathrm{cp}$ and $49.84 \mathrm{lb} / \mathrm{ft}^{3}$, respectively) than the original ones (Table 4.2). The Regression feature of Winprop is used to "tune" the equation of state to match experimental measurements. Winprop uses the Regression procedure of Agarwal et al. From the specified list of parameters, the procedure orders the parameters such that the most sensitive parameters are used first. Regression is carried out by selecting the Pedersen Corresponding States Model and by using correlation coefficients and the component critical properties as regression parameters. In between the Regression Start and End tab, the available laboratory data are entered in the Single Phase Calculation form. The CMG GEM EOS Model option is used to print component properties before 
Table 4.1. Composition of the sample extracted from literature

\begin{tabular}{|c|c|}
\hline Components & Mole Fraction (\%) \\
\hline $\mathrm{C}_{12}$ & 0.86 \\
\hline $\mathrm{C}_{13}$ & 1.15 \\
\hline $\mathrm{C}_{14}$ & 1.34 \\
\hline $\mathrm{C}_{15}$ & 1.75 \\
\hline$\overline{\mathrm{C}_{16}}$ & 1.77 \\
\hline $\mathrm{C}_{17}$ & 2.01 \\
\hline$\overline{\mathrm{C}_{18}}$ & 2.08 \\
\hline $\mathrm{C}_{19}$ & 2.14 \\
\hline $\mathrm{C}_{20}$ & 1.88 \\
\hline$\overline{C_{21}}$ & 2.29 \\
\hline $\mathrm{C}_{22}$ & 1.50 \\
\hline $\mathrm{C}_{23}$ & 2.24 \\
\hline $\mathrm{C}_{24}$ & 2.10 \\
\hline $\mathrm{C}_{25}$ & 1.66 \\
\hline $\mathrm{C}_{26}$ & 1.56 \\
\hline $\mathrm{C}_{27}$ & 1.80 \\
\hline $\mathrm{C}_{28}$ & 1.85 \\
\hline$\overline{\mathrm{C}_{29}}$ & 1.56 \\
\hline $\mathrm{C}_{30}$ & 1.5 \\
\hline $\mathrm{C}_{31}$ & 1.92 \\
\hline $\mathrm{C}_{32}$ & 1.80 \\
\hline$\overline{C_{33}}$ & 1.05 \\
\hline $\mathrm{C}_{34}$ & 1.05 \\
\hline $\mathrm{C}_{35}$ & 1.48 \\
\hline $\mathrm{C}_{36}$ & 1.48 \\
\hline $\mathrm{C}_{37}$ & 0.90 \\
\hline $\mathrm{C}_{38}$ & 0.85 \\
\hline$\overline{C_{39}}$ & 1.35 \\
\hline $\mathrm{C}_{40}$ & 1.25 \\
\hline $\mathrm{C}_{41}$ & 0.62 \\
\hline $\mathrm{C}_{42}$ & 0.62 \\
\hline $\mathrm{C}_{43}$ & 1.10 \\
\hline$\overline{\mathrm{C}_{44}}$ & 0.80 \\
\hline $\mathrm{C}_{45}$ & 0.80 \\
\hline $\mathrm{C}_{45+}$ & 49.89 \\
\hline
\end{tabular}


Table 4.2. Densities and viscosities of the standard and simulated sample at 1 atmosphere and $75.02^{\circ} \mathrm{F}$

\begin{tabular}{|l|c|c|}
\hline \multicolumn{1}{|c|}{ Sample } & Density $\left(\boldsymbol{l b} / f^{3}\right)$ & Viscosity $(\boldsymbol{c} \boldsymbol{p})$ \\
\hline Original & 61.678 & 200267 \\
\hline Initial Simulation & 49.842 & 150,000 \\
\hline After Regression & 60.683 & 200460 \\
\hline
\end{tabular}


and after the regression in Table 4.3, and matched final density and viscosity values are documented in Table 4.2. Components properties are updated after the successful Regression run. Using the updated component properties, sample viscosity and density are calculated as $28137.71 \mathrm{cp}$ and $52.713 \mathrm{lb} / \mathrm{ft}^{3}$, respectively, at $21.9^{\circ} \mathrm{C}$.

The compositional analysis obtained with modified $\mathrm{C}_{45+}$ components properties is assumed as 'Standard' and afterwards is utilized to create imaginary compositional analysis for sample 3 and sample 4 simply by reducing the mole fraction in the heavier ends and adding to the mole fraction at the lighter ends. Although the 'Standard' sample does not have any Butane $\left(\mathrm{nC}_{4}\right)$, a small amount of Butane $(0.01 \%)$ is added while creating Samples 3 and 4, which allows the simulator to increase the gas saturation from an initial value. Initially, much effort is employed to match the viscosity and density. When the 36 components ( $\mathrm{C}_{45+}$ inclusive) are lumped into 6 groups to be compatible with GEM, critical properties are regressed to match the desired density and viscosity. Table 4.4 and 4.5 lists the simulated compositional analysis for Samples 3 and 4 respectively. Whereas, Table 4.6 to 4.9 list the component properties for Samples 3 and 4 before and after regression, when the components are lumped. Finally, matched viscosity and density of Samples 3 and 4, after lumping and regression are presented in Table 4.10.

\subsubsection{Rock fluid properties}

This section discusses the creation and editing of rock-fluid properties. Experimentally achieved capillary pressure (Chapter 3), and relative permeability (Chapter 3) data are entered in this section. Utilizing the 'Tool' tab, curves are smoothed and end points for 
Table 4.3. Summary of Regression Variables

\begin{tabular}{|l|l|l|l|}
\hline Components & Variable & Before Regression & After Regression \\
\hline $\mathrm{C}_{45+}$ & $\mathrm{P}_{\mathrm{c}}(\mathrm{atm})$ & 9.026 & 9.0565 \\
\hline $\mathrm{C}_{45+}$ & $\mathrm{V}_{\mathrm{c}}(\mathrm{lt} / \mathrm{mol})$ & 1.6855 & 1.6855 \\
\hline $\mathrm{C}_{45+}$ & $\mathrm{T}_{\mathrm{c}}\left({ }^{\circ} \mathrm{F}\right)$ & 1025.8 & 9936.1 \\
\hline $\mathrm{C}_{45+}$ & $\mathrm{MW}$ & 650 & 563 \\
\hline $\mathrm{C}_{45+}$ & Vol. Shift, $\mathrm{S}_{\mathrm{H}}$ & 0 & 0.2071 \\
\hline
\end{tabular}


Table 4.4. Composition model of the Sample 3

\begin{tabular}{|c|c|}
\hline Components & Mole Fraction (\%) \\
\hline $\mathrm{nC}_{4}$ & 0.01 \\
\hline $\mathrm{C}_{12}$ & 0.86 \\
\hline $\mathrm{C}_{13}$ & 1.15 \\
\hline $\mathrm{C}_{14}$ & 3.34 \\
\hline $\mathrm{C}_{15}$ & 3.75 \\
\hline $\mathrm{C}_{16}$ & 3.75 \\
\hline $\mathrm{C}_{17}$ & 3.50 \\
\hline $\mathrm{C}_{18}$ & 3.90 \\
\hline $\mathrm{C}_{19}$ & 2.56 \\
\hline $\mathrm{C}_{20}$ & 3.29 \\
\hline $\mathrm{C}_{21}$ & 3.30 \\
\hline $\mathrm{C}_{22}$ & 1.51 \\
\hline $\mathrm{C}_{23}$ & 2.25 \\
\hline $\mathrm{C}_{24}$ & 2.26 \\
\hline $\mathrm{C}_{25}$ & 1.67 \\
\hline $\mathrm{C}_{26}$ & 1.57 \\
\hline $\mathrm{C}_{27}$ & 1.80 \\
\hline $\mathrm{C}_{28}$ & 1.85 \\
\hline $\mathrm{C}_{29}$ & 1.56 \\
\hline $\mathrm{C}_{30}$ & 3.42 \\
\hline $\mathrm{C}_{31}$ & 1.03 \\
\hline $\mathrm{C}_{32}$ & 1.50 \\
\hline $\mathrm{C}_{33}$ & 1.00 \\
\hline $\mathrm{C}_{34}$ & 1.05 \\
\hline $\mathrm{C}_{35}$ & 1.45 \\
\hline $\mathrm{C}_{36}$ & 1.45 \\
\hline $\mathrm{C}_{37}$ & 0.87 \\
\hline $\mathrm{C}_{38}$ & 0.75 \\
\hline $\mathrm{C}_{39}$ & 1.25 \\
\hline $\mathrm{C}_{40}$ & 1.20 \\
\hline $\mathrm{C}_{41}$ & 0.55 \\
\hline $\mathrm{C}_{42}$ & 0.55 \\
\hline $\mathrm{C}_{43}$ & 0.05 \\
\hline $\mathrm{C}_{44}$ & 0.10 \\
\hline $\mathrm{C}_{45}$ & 0.10 \\
\hline $\mathrm{C}_{45+}$ & 39.80 \\
\hline
\end{tabular}


Table 4.5. Composition model of the Sample 4

\begin{tabular}{|c|c|}
\hline Components & Mole Fraction (\%) \\
\hline $\mathrm{nC}_{4}$ & 0.01 \\
\hline$\overline{C_{12}}$ & 0.81 \\
\hline $\mathrm{C}_{13}$ & 1.15 \\
\hline $\mathrm{C}_{14}$ & 1.34 \\
\hline $\mathrm{C}_{15}$ & 1.75 \\
\hline $\mathrm{C}_{16}$ & 1.77 \\
\hline $\mathrm{C}_{17}$ & 2.01 \\
\hline $\mathrm{C}_{18}$ & 2.10 \\
\hline $\mathrm{C}_{19}$ & 2.14 \\
\hline $\mathrm{C}_{20}$ & 1.88 \\
\hline $\mathrm{C}_{21}$ & 1.11 \\
\hline $\mathrm{C}_{22}$ & 2.60 \\
\hline $\mathrm{C}_{23}$ & 2.20 \\
\hline $\mathrm{C}_{24}$ & 3.52 \\
\hline$\overline{\mathrm{C}_{25}}$ & 3.30 \\
\hline $\mathrm{C}_{26}$ & 2.90 \\
\hline $\mathrm{C}_{27}$ & 1.80 \\
\hline $\mathrm{C}_{28}$ & 1.85 \\
\hline $\mathrm{C}_{29}$ & 1.56 \\
\hline $\mathrm{C}_{30}$ & 1.51 \\
\hline $\mathrm{C}_{31}$ & 1.92 \\
\hline $\mathrm{C}_{32}$ & 1.80 \\
\hline $\mathrm{C}_{33}$ & 2.30 \\
\hline $\mathrm{C}_{34}$ & 1.15 \\
\hline $\mathrm{C}_{35}$ & 1.65 \\
\hline $\mathrm{C}_{36}$ & 1.60 \\
\hline $\mathrm{C}_{37}$ & 1.78 \\
\hline $\mathrm{C}_{38}$ & 0.85 \\
\hline $\mathrm{C}_{39}$ & 1.35 \\
\hline $\mathrm{C}_{40}$ & 1.25 \\
\hline $\mathrm{C}_{41}$ & 0.62 \\
\hline $\mathrm{C}_{42}$ & 0.62 \\
\hline $\mathrm{C}_{43}$ & 1.10 \\
\hline $\mathrm{C}_{44}$ & 0.80 \\
\hline $\mathrm{C}_{45}$ & 0.90 \\
\hline $\mathrm{C}_{45+}$ & 43.0 \\
\hline
\end{tabular}


Table 4.6. Compositional analysis and properties of the lumped components for Sample 3 (Before Regression)

\begin{tabular}{|c|c|c|c|c|c|c|}
\hline Properties & $\mathrm{nC}_{4}$ & $\mathrm{C}_{12}$ to $\mathrm{C}_{21}$ & $\mathrm{C}_{22}$ to $\mathrm{C}_{31}$ & $\mathrm{C}_{32}$ to $\mathrm{C}_{38}$ & $\mathrm{C}_{39}$ to $\mathrm{C}_{45}$ & $\mathrm{C}_{45+}$ \\
\hline Mole & 0.01 & 29.40 & 18.92 & 8.07 & 3.80 & 39.80 \\
\hline$S_{g}$ & 0.584 & 0.85018 & 0.89422 & 0.91923 & 0.93161 & 0.988 \\
\hline$T_{b}\left({ }^{\circ} \mathrm{K}\right)$ & 272.70 & 616.603 & 686.136 & 758.2900 & 797.471 & 866.483 \\
\hline$P_{c}(a t m)$ & 37.50 & 24.9301 & 11.1245 & 9.0061 & 7.8671 & 9.0565 \\
\hline$T_{c}\left({ }^{\circ} \mathrm{K}\right)$ & 425.200 & 733.112 & 845.005 & 876.254 & 910.255 & 993.615 \\
\hline$V_{c}$ & 0.25500 & 0.93525 & 1.26894 & 1.58070 & 1.62548 & 1.72546 \\
$\left(m^{3} / k m o l\right)$ & & & & & & \\
\hline$M W$ & 58.124 & 235.580 & 353.789 & 442.841 & 497.303 & 563.718 \\
\hline
\end{tabular}


Table 4.7. Compositional analysis and properties of the lumped components for Sample 3 (After Regression)

\begin{tabular}{|c|c|c|c|c|c|c|}
\hline & $\mathrm{nC}_{4}$ & $\mathrm{C}_{12}$ to $\mathrm{C}_{21}$ & $\mathrm{C}_{22}$ to $\mathrm{C}_{31}$ & $\mathrm{C}_{32}$ to $\mathrm{C}_{38}$ & $\mathrm{C}_{39}$ to $\mathrm{C}_{45}$ & $\mathrm{C}_{45+}$ \\
\hline Mole & 0.01 & 29.40 & 18.92 & 8.07 & 3.80 & 39.80 \\
\hline$S_{g}$ & 0.584 & 0.85018 & 0.89422 & 0.91923 & 0.93161 & 0.988 \\
\hline$T_{b}\left({ }^{\circ} \mathrm{K}\right)$ & 272.70 & 616.603 & 686.136 & 758.2900 & 797.471 & 866.483 \\
\hline$P_{c}(\mathrm{~atm})$ & 37.50 & 24.9301 & 16.1879 & 9.0061 & 7.8671 & 9.0565 \\
\hline$T_{c}\left({ }^{\circ} \mathrm{K}\right)$ & 425.200 & 756.724 & 792.003 & 876.254 & 910.255 & 993.615 \\
\hline$V_{c}$ & 0.25500 & 0.93525 & 1.26894 & 1.58070 & 1.62548 & 1.72546 \\
$\left(m^{3} / k m o l\right)$ & & & & & & \\
\hline$M W$ & 58.124 & 235.580 & 353.789 & 442.841 & 497.303 & 563.718 \\
\hline
\end{tabular}


Table 4.8. Compositional analysis and properties of the lumped components for Sample 4 (Before Regression)

\begin{tabular}{|c|c|c|c|c|c|c|}
\hline & $\mathrm{nC}_{4}$ & $\mathrm{C}_{12}$ to $\mathrm{C}_{21}$ & $\mathrm{C}_{22}$ to $\mathrm{C}_{31}$ & $\mathrm{C}_{32}$ to $\mathrm{C}_{38}$ & $\mathrm{C}_{39}$ to $\mathrm{C}_{45}$ & $\mathrm{C}_{45+}$ \\
\hline $\begin{array}{c}\text { Mole } \\
\text { fraction (\%) }\end{array}$ & 0.01 & 16.06 & 23.16 & 11.13 & 6.64 & 43.00 \\
\hline$S_{g}$ & 0.584 & 0.84909 & 0.89212 & 0.91917 & 0.93408 & 0.988 \\
\hline$T_{b}\left({ }^{\circ} \mathrm{K}\right)$ & 272.700 & 570.502 & 680.167 & 757.876 & 806.006 & 866.483 \\
\hline$P_{c}(\mathrm{~atm})$ & 37.500 & 16.6002 & 11.5731 & 8.9757 & 7.6436 & 9.0565 \\
\hline$T_{c}\left({ }^{\circ} \mathrm{K}\right)$ & 425.200 & 744.731 & 840.058 & 904.076 & 942.161 & 993.615 \\
\hline$V_{c}$ & 0.255 & 0.86992 & 1.24487 & 1.57824 & 1.83629 & 1.68550 \\
$\left(m^{3} / \mathrm{kmol}\right)$ & & & & & & \\
\hline$M W$ & 58.124 & 233.250 & 346.883 & 442.306 & 509.613 & 563.718 \\
\hline
\end{tabular}


Table 4. 9. Compositional analysis and properties of the lumped components for Sample 4 (After Regression)

\begin{tabular}{|c|c|c|c|c|c|c|}
\hline & $\mathrm{nC}_{4}$ & $\mathrm{C}_{12}$ to $\mathrm{C}_{21}$ & $\mathrm{C}_{22}$ to $\mathrm{C}_{31}$ & $\mathrm{C}_{32}$ to $\mathrm{C}_{38}$ & $\mathrm{C}_{39}$ to $\mathrm{C}_{45}$ & $\mathrm{C}_{45+}$ \\
\hline $\begin{array}{c}\text { Mole } \\
\text { fraction (\%) }\end{array}$ & 0.01 & 16.06 & 23.16 & 11.13 & 6.64 & 43.00 \\
\hline$S_{g}$ & 0.584 & 0.84909 & 0.89212 & 0.91917 & 0.93408 & 0.988 \\
\hline$T_{b}\left({ }^{\circ} \mathrm{K}\right)$ & 272.700 & 570.502 & 680.167 & 757.876 & 806.006 & 866.483 \\
\hline$P_{c}(\mathrm{~atm})$ & 37.500 & 26.5522 & 13.9670 & 9.0142 & 8.2780 & 10.2549 \\
\hline$T_{c}\left({ }^{\circ} \mathrm{K}\right)$ & 425.200 & 790.125 & 870.543 & 873.752 & 926.618 & 969.242 \\
\hline$V_{c}$ & 0.255 & 0.86992 & 1.24487 & 1.57824 & 1.83629 & 1.68550 \\
$\left(m^{3} / \mathrm{kmol}\right)$ & & & & & & \\
\hline$M W$ & 58.124 & 233.250 & 346.883 & 442.306 & 509.613 & 563.718 \\
\hline
\end{tabular}


Table 4.10. Matched viscosity and density of Sample 3 and 4 after lumping and regression

\begin{tabular}{|l|c|c|c|c|}
\hline \multirow{2}{*}{} & \multicolumn{2}{|c|}{ Sample 3 } & \multicolumn{2}{c|}{ Sample 4 } \\
\cline { 2 - 5 } & Original & Simulated & Original & Simulated \\
\hline Density, $l b / f t^{3}$ & 60.12 & 59.70 & 61.49 & 60.86 \\
\hline Viscosity, $c p$ & 5800 & 5799.94 & 14400 & 14394 \\
\hline
\end{tabular}


$S_{o r}$ in the relative permeability table are extrapolated following the trend of the smoothed curves. Extrapolated $S_{o r}$ values were $15 \%$ and $20 \%$ for Samples 3 and 4 respectively. The liquid-gas relative permeability table was generated using the built in correlation.

Experimentally derived capillary pressure data were extrapolated to the desired $S_{w c}$ and $S_{o r}$ values in this section and were introduced to play a role in the mechanism of the VAPEX process for both oil samples. The original and extrapolated capillary pressure curves are shown in Figures 4.2 and 4.3 for sample 3. Capillary pressure itself is a dynamic process. Viscosity, density, and composition alterations of the heavy oil during the VAPEX process evolve changes in the trend of the capillary pressure curve. Depending on the vapour concentration, different capillary pressure values act in different sections of the vapour-liquid interface and within the chamber. Unfortunately, these dynamic changes in capillary pressure cannot be incorporated in the simulation with GEM. Setting Capillary pressure values higher than the reservoir pressure during simulation will simply plug the pores and produce no outcome. This is the main reason for using previously generated $P_{c}$ data for lighter oil samples in the simulation of oil samples 3 and 4 .

\subsubsection{Initialization}

In this section of Builder, the initial reservoir condition was set. User specified reservoir pressure, water saturation, and global fluid composition at each grid block were specified at the 'Reservoir Array Property' section. Injector's standard pressure and temperature are also set in the 'Initialization' section. 


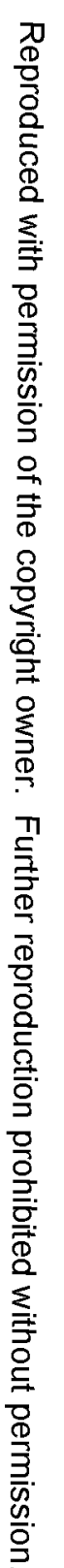

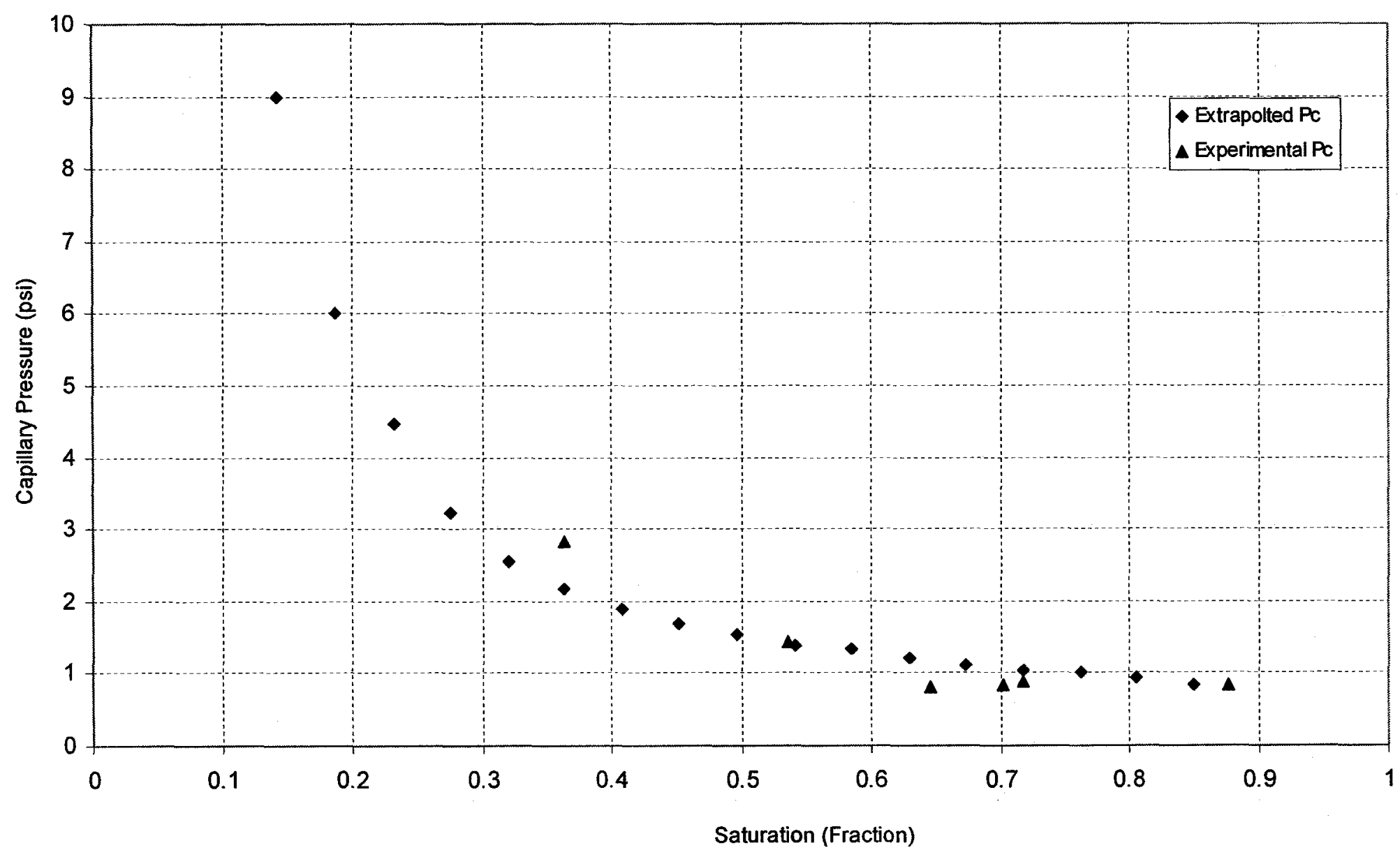

Figure 4.2. Original and extrapolated capillary pressure curves 1 for sample 3 


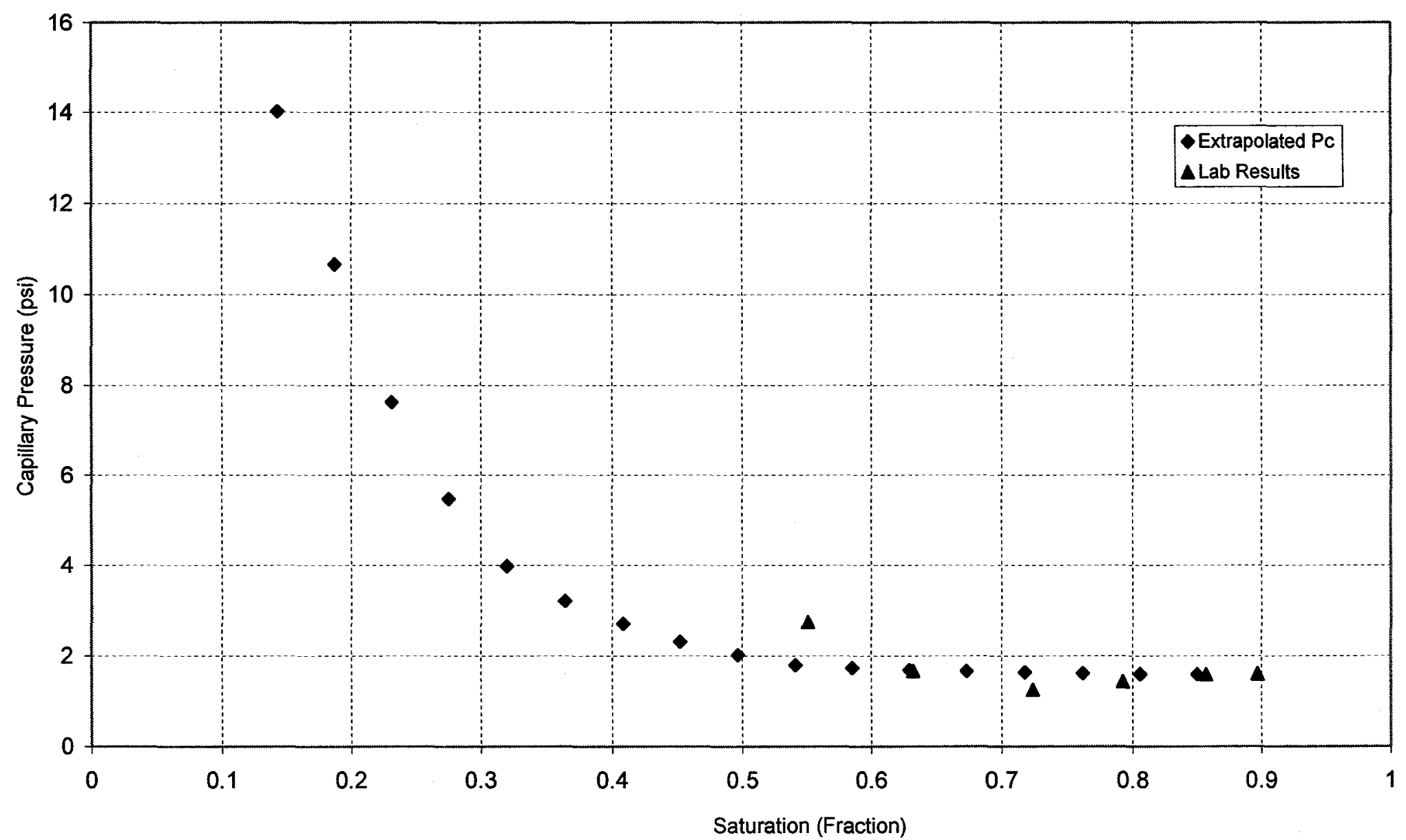

Figure 4.3. Original and extrapolated capillary pressure curves 2 for sample 3 


\subsubsection{Wells and Recurrent Data}

Wells are placed at proper locations and constraints are defined in this section. Locations and dimensions of the wells are listed in Table 4.11. Injection fluid from the injection well is pure butane, injected at a mole fraction of 1 . The primary constraint for both of these wells is the pressure constraint. The injector is set to operate at a maximum pressure of 31.386 psia, which is also the vapour pressure of pure butane at the operating temperature of $71.42^{\circ} \mathrm{F}$. The producer, on the other hand, is set to operate at $31.1 \mathrm{psia}$ to allow very low differential pressure so that gravity plays the major role in the production operation. Maximum GOR values encountered in the experiments are used as the 'Monitoring Constraint,' by defining the producer as 'Autowell,' so that it automatically shuts of to lower the GOR values. This secondary constraint for both of the oil samples is listed in Table 4.12. After gas breakthrough, it was very difficult to control the simulation, as composition varies too much along a finite element (grid). Another primary constraint was set at the injector to control the gas injection, which is also listed in Table 4.12.

\subsubsection{Executing the Simulator}

Once a data file is created and constraints have been set, the file is run in GEM and production data is checked from the output file and compared to the experimental data. Unless similar trends have been observed, the gas-oil relative permeability curve is manipulated, the simulator is re-run and the outputs are compared. 
Table 4.11. Locations and properties of the wells

\begin{tabular}{|l|c|c|c|c|}
\hline & Direction & Depth $(f t)$ & Radius $(f t)$ & Length $(f t)$ \\
\hline Injector & $j$-axis & 0.739 & 0.01 & 0.04 \\
\hline Producer & $j$-axis & 0.979 & 0.01 & 0.04 \\
\hline
\end{tabular}

Table 4.12. Constraints for Sample 3 and Sample 4

\begin{tabular}{|l|c|c|c|c|}
\hline \multirow{2}{*}{ Constraints } & \multicolumn{2}{|c|}{ VAPEX I (Sample 3) } & \multicolumn{2}{c|}{ VAPEX II (Sample 4) } \\
\cline { 2 - 5 } & Injector & Producer & Injector & Producer \\
\hline Pressure (psia) & 31.386 & 31.1 & 31.386 & 31.1 \\
\hline GOR $\left(f t^{3} / b b l\right)$ & ---- & 4693.54 & ----- & 2253.53 \\
\hline Gas Injection (max. $f t^{3} /$ day) & 1.695 & ----- & 2.118 & $-\cdots$ \\
\hline
\end{tabular}




\section{RESULTS AND DISCUSSION}

Effects of capillary pressure on VAPEX can be discussed based on visible inspection, as well as by production data observation. During VAPEX experiments, the communication between the two wells is established by external intervention (increase in differential pressure), which cannot be achieved in the GEM simulator, where, the displacement is partly influenced by an immiscible gas displacement process until the occurrence of gas breakthrough. After the gas breakthrough, the drainage process is mainly influenced by gravitational force and somewhat stabilizes the oil drainage rate. Data points after breakthrough are taken into consideration in order to compare them with experimental results. GEM's inability to change the capillary pressure curve in accordance with the oil dilution process, as well as stabilized production justify that data obtained $20-25$ hours following the gas breakthrough can be compared to the experimental results to predict the performance of the complete recovery process. A quick review of Table 5.1, which provides the time to gas breakthrough and corresponding cumulative oil productions for each scenario, reveals that the existence of capillary pressure in simulation prolongs the solvent breakthrough.

\subsection{Growth of the Vapour Chamber}

Capillary pressure plays an important role in creating the ideal mushroom-shaped vapour chamber. Figure 5.1 shows the growth of vapour chamber from simulation run at equal time interval with and without the capillary pressure data. Capillary pressure retards the upward movement of the butane vapour at the initial stage. Moreover, existence of very 
small differential pressure allows the vapour molecules to diffuse into the surrounding oils. 
Table 5.1. Cumulative oil production and time to gas breakthrough

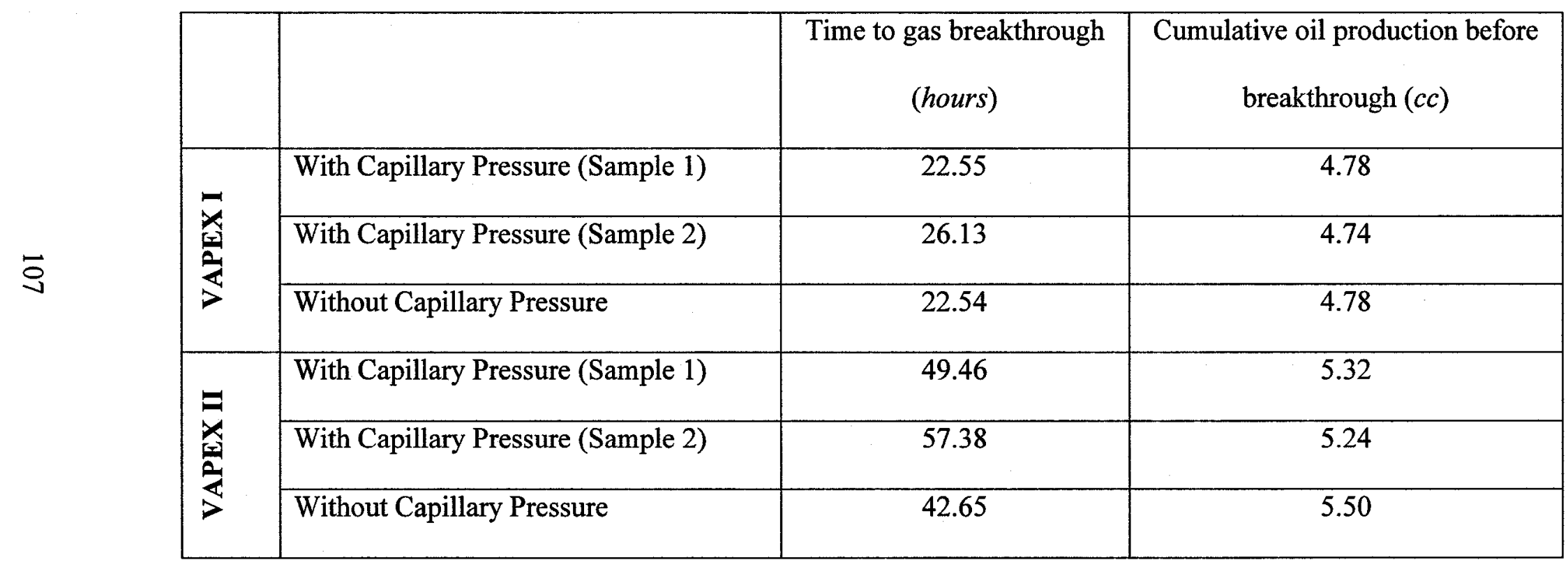




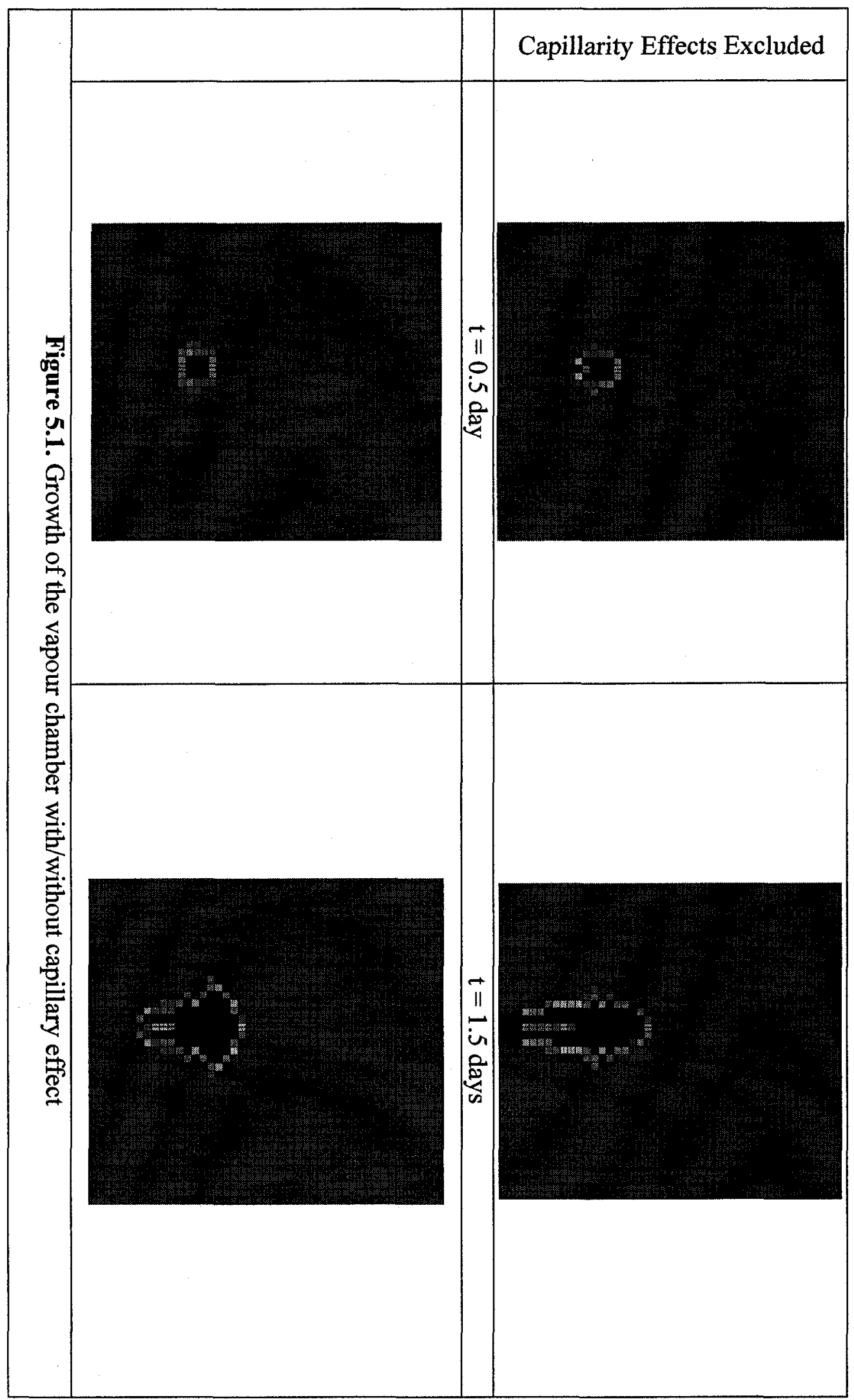


As a result, the chamber experiences vertical as well as lateral growth. But once solvent breakthrough occurs and flow rates stabilize, diluted oil from the top starts flowing along the vapour-liquid interface, chamber reaches the top boundary, and then grows sideways to sweep the model boundary.

\subsection{Effects on Drainage Rate and Gas Production}

Gravity, capillarity, and viscous forces are the major forces controlling the VAPEX process. Evolution of the transition zone between the vapour chamber and virgin oil is attributed to capillary retention. It is assumed that the solvent gas will bypass the smaller pores and preferentially will access the larger pores in the displacement process. Due to large capillary entry pressure, oil in the smaller pores is left behind.

The oil drainage rates, cumulative productions, and gas rates for VAPEX I and II, featuring all three scenarios (capillarity 1, capillarity 2, and without capillarity), are plotted in Figures 5.2 to 5.5. Simulation results are in good agreement with experimental results and represent similar trends.

Based on Poisseuille's law, Green (1998) pointed out that reduction of the oil viscosity would improve flow rate. Comparing the plotted data, it can be concluded that a lower viscosity oil sample delivers higher flow rate within the same simulation conditions. Higher capillary pressure affected the production data positively for the lower viscosity oil sample (Figure 5.2 and 5.3). It maximized the effective area (Figure 5.6) for molecular 


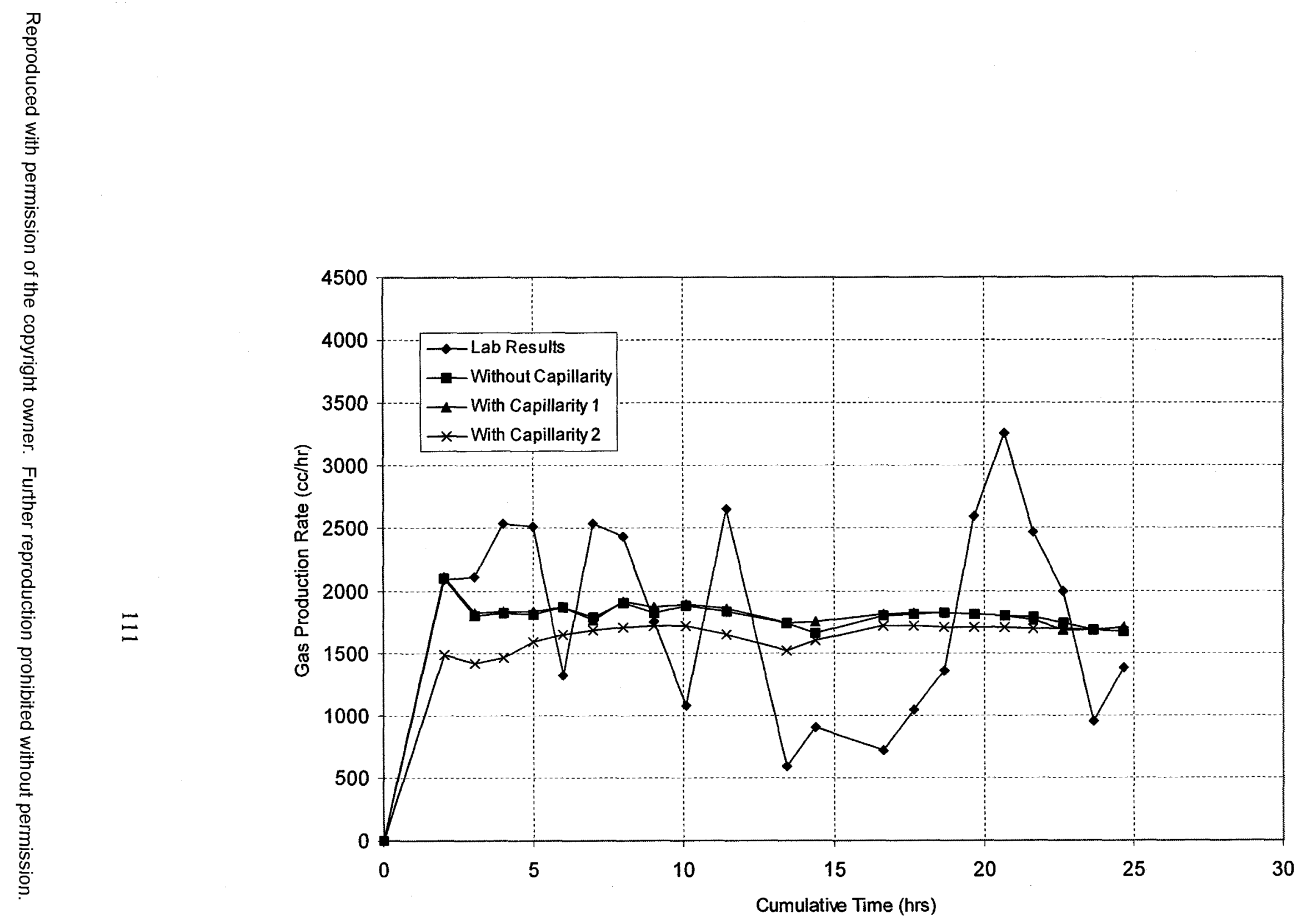

Figure 5. 3. Gas rate with/without capillary pressure (sample 3) 


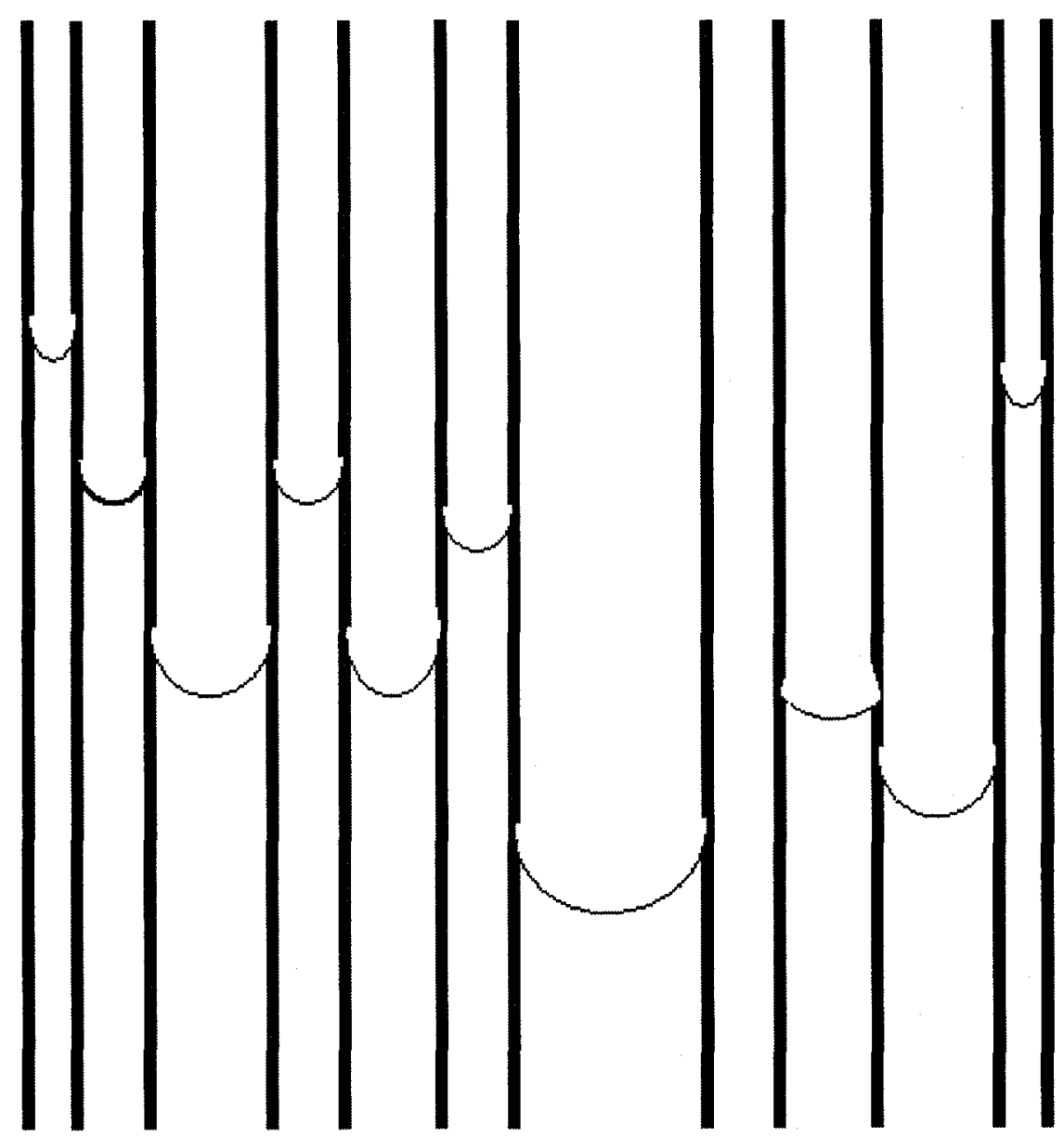

Figure 5.6. Enhanced diffusion area because of capillary pressure 
diffusion and increased the flow rate to produce more oil than the other two cases. Lower capillary pressure and absence of capillary pressure produced identical outcomes. This implies that, for this particular oil sample, there exists a minimal capillarity value below which, no effect(s) on VAPEX can be observed.

The second set of production data (Figures $5.4 \& 5.5$ ) creates more insight into the capillary pressure effects. Fitting in lower capillary data produces a maximum amount of oil and minimum amount of gas. Both sets of VAPEX simulation runs indicate that capillarity does not favour gas production, which is ideal for saving solvent gas.

All the experimental plots are plagued with fluctuations. This can be attributed to the pressure control surges, ambient temperature, and heterogeneity of the porous medium. Importance of differential pressure on flow rate can be easily understood from Darcy's law. Temperature is another factor, which fluctuated within the range of $19-21^{\circ} \mathrm{C}$ during the flooding experiments and, thus, caused the viscosity of the untouched reservoir liquid to change drastically. Heterogeneity, which arises while vibro-packing the physical model affects the permeability and pore-size to influence the recovery data. 


\section{CONCLUSIONS AND RECOMMENDATIONS}

Experimental investigations and simulation studies have been combined to determine the effects of capillary pressure on the VAPEX process in this research. In view of this, capillary pressure curves have been derived focusing mainly on light oil samples, relative permeability curves have been generated based on unsteady-state method, and, finally, VAPEX experiments were conducted in a uniquely built lab model. Thereafter, the GEM simulator was employed to match the lab data by fitting in two sets of capillary pressure curves and no capillary pressure curves at all. Simulation outputs were compared to each other, as well as with experimental results. Based on this research, the following conclusions can be drawn:

- Capillary pressure creates the similar vapour chamber observed in the experimental study. Absence of capillary pressure allows the vapour to achieve maximum vertical propagation with lowest amount of sideways leaching.

- The gas breakthrough time is highly enhanced in the presence of capillarity.

- Due to capillarity, solvent vapour advances to the larger pore and, thus, bypasses the oil in the smaller pores. In short, capillary pressure controls the oil drainage and relative positioning of oil-gas in the porous medium.

- Capillary pressure tends to retard gas production without affecting the overall recovery.

- Drainage rate is higher in low viscous oils, irrespective of the simulation and experimental conditions. 
- High viscosity oil tends to have a pertinent capillary pressure curve, which allows the production data to reach their peak values.

- With fine sand grains, maximum amount of asphaltene precipitation occurs around the injection well. This contributed adversely to the oil drainage rate.

This work is a preliminary investigation of the effect of capillarity on the VAPEX process. The dynamic behavior of the capillary phenomenon, because of the solvent concentration change, could not be studied due to the limitations of the simulator. Both the experimental and simulation studies suggest an urgent need of additional research involving multiphase flow systems that will also consider the weak capillary force between the solvent and oil.

The conclusion drawn in this study is solely applicable for the porous medium with which the experiments were conducted. The work is too preliminary to conclude that capillary pressure will increase production in all homogeneous medium. Apart from that, gravitational forces will be more predominant in field cases, which emphasizes the urgency of including capillary pressure in VAPEX field case simulation.

Economic considerations currently undermine the widespread application of the VAPEX process in the field. Research at a larger scale, however, is indispensable to pinpointing its performance through pilot test. As early communication between the wells is a priority to commencement of field production, fractures could be created to uplift the production. VAPEX could also be coupled with SAGD to test its performance in oil recovery. 


\section{REFERENCES}

1. Adamson, A. W., Physical Chemistry of Surfaces, $4^{\text {th }}$ Edition, John Wiley and Sons, New York City (1982).

2. Alikhan, A. A., Farouq Ali, S. M., "Heavy Oil Recovery by Steam - Driven Hydrocarbon Slugs from Linear Porous Medium", SPE 5109 presented at the 1974 SPE Annual Meeting, Huston, Oct. 6-9.

3. Anderson, W. G., "Wettability Literature Survey - Part 4: Effects of Wettability on Capillary Pressure", Journal of Petroleum Technology, October 1987.

4. Anli, J., and Bentsen, R. G., "Using Parameter Estimation Techniques to Convert Centrifuge Data into a Capillary Pressure Curve", SPEJ (February 1977) 17, 57, Trans. AIME, 263.

5. Boberg, T., Pujol, L., "Scaling Accuracy of Laboratory Steam Flooding Models", SPE 4191, California Regional Meeting of the SPE, Bakersfield, November 8-10, 1972.

6. Brooks, R. H., and Corey, A. T., "Hydraulic Properties of Porous Medium", Hydraulic Paper No. 3, Colorado State U., 1964.

7. Brooks, R. H., and Corey, A. T., "Properties of Porous Medium Affecting Fluid Flow", J. Irrigation Drainage Div. Proc. ASCE (1966) 92, No. IR2, 61.

8. Butler R. M., Mokrys I. J., "In-Situ upgrading of Heavy Oils and Bitumen by Propane Deasphalting: the VAPEX Process", SPE 25452 presented at the Production Operations Symposium, Oklahoma City, OK, USA, March 21-23, 1993. 
9. Butler, R. M., "Horizontal Wells for the Recovery of Oil, Gas and Bitumen", the Petroleum Society of CIM, monograph No. 2, 1994.

10. Butler, R. M., and Das, S. K, "Extraction of Heavy Oil and Bitumen Using Solvents at Reservoir Pressure", CIM Paper No. 95-112, $6^{\text {th }}$ Petroleum Conference of the South Saskatchewan Section, The Petroleum Society of CIM, Regina, October 16-18, 1995.

11. Butler, R. M., and Das, S. K., "Enhancement of Extraction Rate in the VAPEX process by Water Injection", The Petroleum Society, Paper $96-28$, presented at the $47^{\text {th }}$ Annual Technical Meeting of the Petroleum Society, Calgary, Alberta, June 10-12, 1996.

12. Butler, R. M., and Das, S. K., "Countercurrent Extraction of Heavy Oil and Bitumen", SPE 37094, Prepared for presentation at 1996 SPE International Conference on Horizontal Well Technology, Calgary, Canada, 18-20 Nov., 1996.

13. Butler, R. M., and Das, S. K., "Diffusion Coefficients of Propane and Butane in Peace River Bitumen", The Canadian Journal of Chemical Engineering, vol. 74, December 1996.

14. Butler, R. M., and Das, S. K., "Mechanism of the vapour extraction process for heavy oil and bitumen", Journal of Petroleum Science and Engineering, Nov 13, 1997.

15. Butler, R. M., and Das, S. K., "Mechanism of the Vapour Extraction Process for Heavy Oil and Bitumen", Journal of Petroleum Science and Engineering, vol. 21, 1998. 
16. Butler, R. M., and Jiang, Q., "Improved VAPEX performance using widely spaced horizontal injectors and producers", SPE 97174, Presented at the $7^{\text {th }}$ Petroleum Conference of the South Saskatchewan Section, The Petroleum Society of CIM, Regina, October 19-22, 1997.

17. Butler, R. M., and Jiang, Q., "Selection of well configuration in VAPEX process", SPE 37145. Presented at the 1996 International Conference on Horizontal Well Technology, Calgary, Canada, November 15-20, 1996.

18. Butler, R. M., Mokrys, I. J., "Solvent analog model of steam-assisted gravity drainage", AOSTRA Journal of Research. Vol 5, pp. 17-32, 1989.

19. Butler, R. M., Mokrys, I. J., “A New Process (VAPEX) for Recovering Heavy Oils Using Hot Water and Hydrocarbons Vapour", Journal of Canadian Petroleum Technology, vol. 30, no. 1, 1991.

20. Butler, R. M., and Mokryrs, I. J., "Recovery of Heavy Oils Using Vapourized Hydrocarbons Solvents: Further Development of the VAPEX Process", Journal of Canadian Petroleum Technology, Vol. 32, No. 6, pp 56-62, June 1993.

21. Butler, R. M., Das, S. K., Mokrys, I. J., "Solvent Requirements for VAPEX Recovery", SPE 30293 presented at the Heavy Oil Symposium, Calgary, AB, Canada, June 19-21, 1995.

22. Butler, R. M., Mokrys, I. J., "Closed - loop Extraction Method for the Recovery of Heavy Oils and Bitumens Underlain by Aquifers: the VAPEX Process", JCPT, Volume 37, No. 4, April 1998. 
23. Chatzis, I., Lohi, A., Oduntan, A. R., Smith, J., "Heavy Oil Recovery Using the VAPEX Process: Scale-up Issues", presented at the Canadian international Petroleum Conference, Calgary, Alberta, 2001.

24. Das, S. K., "In Situ Recovery of Heavy Oil and Bitumen Using Vapourized Hydrocarbon Solvents", PhD Dissertation, March 1995, University of Calgary, Alberta.

25. Das, S. K., "VAPEX: An Efficient Process for the Recovery of Heavy Oil and Bitumen", SPE 37826, presented at the 1997 SPE International Thermal Operations Symposium, Bakersfield, California, February 10-12, 1997.

26. Das, S. K., Ito, Y., Kasraie, M., Leggitt, S. M., Singhal, A. K., "Screening of Reservoirs for Exploitation by Application of Steam Assisted Gravity Drainage/VAPEX Processes", SPE 37144, International Conference on Horizontal Well Technology, 18-20 Nov., Calgary, Alberta, 1996.

27. Dullien, F. A. L., Porous Medium: Fluid Transport and Pore Structure, Academic Press, New York City (1979)

28. Farouq Ali, S. M., and Snyder, S. G., "Miscible Thermal Methods Applied to a 2D Vertical Tar Sand Pack, with Restricted Fluid Entry", J. Cdn. Pet. Tech., (Oct.Dec. 1973) pp. 20-26.

29. Frauenfeld, T., Jossy, C., Kissel, G., Rispler, K., "Evaluation of the bottom water drive reservoir VAPEX process", Presented at Petroleum Society's $5^{\text {th }}$ Canadian International Petroleum Conference, Calgary, Alberta, June 8-10, 2004.

30. Gu, Y., Luo, P., Tharanivasan, A. K., Yang, C., "In Situ Upgrading of Heavy Oil in a Solvent-Based Heavy Oil Recovery Process", Paper 2005-098, 
Presented at the Petroleum Society's $6^{\text {th }}$ Canadian International Petroleum Conference, Calgary, Canada, June 7-9, 2005.

31. Harman, K. J., and Shu, W. R., "Effect of Solvent on Steam Recovery of Heavy Oil", SPE 14223, SPE Reservoir Engineering, May 1988.

32. Huang, D. D., Honarpour, M. M., and Al-Hussainy, R., “An Improved Model for Relative Permeability and Capillary Pressure Incorporating Wettability", paper presented at the 1997 Society of Core Analysis International Symposium, Calgary, 7-10 Sept.

33. Karmaker, K., and Maini, B., "Applicability of Vapour Extraction Process to Problematic Viscous Reservoirs", SPE 84034, Presented at the SPE Annual Technical Conference and Exhibition, Denver, Colorado, USA, October 5-8, 2003.

34. Karmaker, K., and Maini, B., "Experimental Investigation of Oil Drainage Rates in the VAPEX Process for Heavy Oil and Bitumen Reservoirs", SPE 84199, Presented at the SPE Annual Technical Conference and Exhibition, Denver, Colorado, USA, October 5-8, 2003

35. Li, K., "Theoretical Study of Calculating Oil-Water Relative Permeability by Use of Effective Medium Theory (EMT)", Journal of Jianghan Petroleum Institute, 10, $3,55-65,1988$.

36. Maini, B. B., and Yazdani, A., "Effect of drainage height and grain size on the convective dispersion in the VAPEX process: Experimental Study", Presented at the $14^{\text {th }}$ Symposium on Improved Oil Recovery, Tulsa, Oklahoma, USA, 17-21 April, 2004. 
37. Maini, B., and Talbi, K., "Evaluation of $\mathrm{CO}_{2}$ based VAPEX process for the recovery of Bitumen from tar sand reservoirs", SPE 84868, Presented at the SPE International Improved Oil Recovery Conference in Asia Pacific, Kuala Lumpur, Malaysia, October 20-21, 2003.

38. Maini, B., and Talbi, K., "Further Investigation of $\mathrm{CO}_{2}$ based VAPEX for the Recovery of Heavy Oils and Bitumen", presented at the $5^{\text {th }}$ Canadian International Petroleum Conference, Calgary, Alberta, June 8 -10, 2004.

39. Mehrotra, A. K., and Upreti, S. R., "Diffusivity of $\mathrm{CO}_{2}, \mathrm{CH}_{4}, \mathrm{C}_{2} \mathrm{H}_{6}$ and $\mathrm{N}_{2}$ in Athabasca Bitumen", The Canadian Journal of Chemical Engineering, vol. 80, February 1996.

40. Parker J. C., and Lenhard, R. J., "A model for Hysteretic Constitutive Relations Governing Multiphase Flow, 1. Saturation - Pressure Relations", Water Resource Research (1987) 23, No. 12, 2187.

41. Rapoport, L. A., and Leas, W. J., "Properties of Linear Waterfloods", Trans. AIME (1953), 198, 139.

42. Rapport, L. A., and Leas, W. J., "Properties of Linear Waterfloods", Trans. AIME (1953), 198, 139.

43. Redford, D. A., McKay, A. S., "Hydrocarbon Steam Process for Recovery of Bitumen from Oil Sands", SPE 8823 presented at the 1980 SPE/DOE Enhanced Oil Recovery Symposium, Tulsa, OK, April 20-23.

44. Skjaeveland, S. M., Siqveland, L. M., Kjosavic, A., Hammervold, W. L., and Virnovsky, G. A., "Capillary Pressure Correlation for Mixed-Wet Reservoirs", SPE Reservoir Eval. \& Eng. 3 (1), February 2000. 
45. Speight, J. G., "Chemistry and Technology of Petroleum", Marcel Decker Inc., ( $2^{\text {nd }}$ Edition), 1991, pp.316-25.

46. Standing, M. B., "Notes on Relative Permeability Relationships", Proc., U of Throndheim, NTH, Norway (1975).

47. Welge, H. J., "Simplified Method for Computing Oil Recovery by Gas or Water Drive", Trans. AIME (1952), 195, 91. 


\section{APPENDIX: Glossary}

SOR: Ratio of the amount of the injected steam measured in terms of equivalent water volume to the volume of produced oil

\section{Mobility Ratio:}

When a waterflood is assumed to be piston-like, oil flows at interstitial water saturation ahead of the sharp front, while water flows at residual oil saturation behind the front. The mobility for a very sharp front displacement is given by:

$M=\frac{\lambda_{D}}{\lambda_{d}}$

where $\lambda_{D}$ is the mobility of the displacing phase behind the front and $\lambda_{d}$ is the mobility of the displaced phase ahead of the front. For waterflood under piston-like displacement, $\lambda_{D}=\lambda_{w}=\left(\frac{k_{w}}{\mu_{w}}\right)_{S_{o r}}$ and $\lambda_{d}=\lambda_{o}=\left(\frac{k_{o}}{\mu_{o}}\right)_{S_{i w}}$, and the mobility ratio is given by: $M=\frac{\left(\frac{k_{w}}{\mu_{w}}\right)_{S_{o r}}}{\left(\frac{k_{o}}{\mu_{o}}\right)_{S_{i w}}}=\frac{\left(\frac{k_{r w}}{\mu_{w}}\right)_{S_{o r}}}{\left(\frac{k_{r o}}{\mu_{o}}\right)_{S_{i w}}}$

Stabilized Displacement: The frontal advance solution applies to a stabilized displacement process. When a stabilized zone forms, the breakthrough saturation and the recovery at the PV-injected curve (after breakthrough) should be independent of the length of the core and the rate of injection. Rate and length effects were observed in many laboratory studies. Interpretation of displacement data was complicated by the 
presence of capillary end effects in some systems. Displacement behavior became independent of injection rate and length for systems with long lengths and high injection rates.

\section{Pujol and Boberg scaling:}

Pujol and Boberg studied the adequacy of scaling methods used for steam-flooding studies in laboratory models of reservoirs containing viscous oil. Scaling requirements for the thermal models can be generalized as follows:

- Field and model must be the same width-to-length ratio, height-to-length ratio, dip angle, and reservoir heterogeneities.

- The values of several parameters containing fluid and rock properties, as well as terms related to the transport of heat and mass, must be equal in the field and in the model.

- Field and model must have the same initial and boundary conditions.

The following table gives the scaling ratios that would apply to an example case in which the model-to-field length ratio is $1 / 100$. The case assumes that the field and model fluids are the same; therefore, no fluid property groups are considered. Also, initial saturation, pressure and temperature conditions are assumed to be equal. 
Table A-1. Scaling Ratios (Source: Pujol and Boberg (1972))

\begin{tabular}{|l|c|c|}
\hline Property & Scaling Parameters & Ratio (model/field) \\
\hline Lengths & $R_{L}$ (set) & $1 / 100$ \\
\hline Dip Angle & Same & 1 \\
\hline Porosity & Same & 1 \\
\hline Permeability & $\frac{k_{m}}{k_{f}}=\frac{L_{f}}{L_{m}}=\frac{1}{R_{L}}$ & 100 \\
\hline Injection Rate & $\frac{q_{m}}{q_{L}}=\frac{v_{m}}{v_{f}}=\frac{A_{m}}{A_{f}}=\frac{L_{m}}{L_{f}}=R_{L}$ & $1 / 100$ \\
\hline Pressure Drop & $\frac{\Delta p_{m}}{\Delta p_{f}}=\frac{v_{m}}{v_{f}} \frac{L_{m}}{L_{f}} \frac{k_{f}}{k_{m}}=\frac{L_{m}}{L_{f}}=R_{L}$ & $1 / 100$ \\
\hline Time & $\frac{t_{m}}{t_{f}}=\frac{v_{f}}{v_{m}} \frac{L_{m}}{L_{f}}=\left(\frac{L_{m}}{L_{f}}\right)=R_{L}^{2}$ & $1 / 1000$ \\
\hline
\end{tabular}

